Universidade de São Paulo Faculdade de Arquitetura e Urbanismo

Curso de Pós-Graduação

LEED-NC como sistema de avaliação da sustentabilidade: uma perspectiva nacional?

Arq. Thiago Zaldini Hernandes 
Universidade de São Paulo

Faculdade de Arquitetura e Urbanismo

Curso de Pós-Graduação

\title{
LEED-NC como sistema de avaliação da sustentabilidade: uma perspectiva nacional?
}

\author{
Arq. Thiago Zaldini Hernandes
}

\section{Dissertação de Mestrado}
Dissertação de Mestrado a ser apresentada à Faculdade de Arquitetura e Urbanismo da Universidade de São Paulo, Curso de Pós Graduação para a obtenção do título de MESTRE em arquitetura e urbanismo.

Área de Concentração Tecnologia da Arquitetura

Orientadora: Profa. Dra. Denise Helena Duarte. 


\section{AUTORIZAÇÃO DE USO:}

Autorizo a reprodução e divulgação total ou parcial deste Trabalho, por qualquer meio convencional ou eletrônico, para fins de estudo e pesquisa, desde que citada a fonte.

Ass.:

e-mail: thiagohernandes@gmail.com

HERNANDES, Thiago Zaldini

H557L

LEED-NC como sistema de avaliação da sustentabilidade: uma perspectiva nacional?/ Thiago Zaldini Hernandes. — São Paulo, 2006. 134p. : il. FAUUSP.

Dissertação (Mestrado — Área de Concentração: Tecnologia da Arquitetura) —

Orientadora: Denise Helena Duarte

1.Avaliação de desempenho - Arquitetura 2.Edifícios sustentáveis 3.Edifícios Avaliação 4.Edifícios - Desempenho 5. Conforto ambiental 6. Edifícios - Sustentabilidade I.Título 


\section{Dedicatória}

Às pessoas que eu já amava, por terem ao longo desse trabalho, inventado ainda mais motivos para que eu os ame. 


\section{Agradecimentos}

À minha admirada e eterna MESTRA Denise Helena (desculpe tinha que colocar por extenso) Duarte. Obrigado por me ensinar incansavelmente todos os dias a melhor definição das palavras: professora, orientadora, pesquisadora e líder.

À minha admirada e eterna MESTRA Joana Carla (desculpe Jô, não ia perder essa oportunidade também) Soares "Gonzales" Gonçalves por ter me ensinado a sonhar com o melhor, sempre.

À nossa admirada e eterna "chefa" Márcia Alucci pela eficiente e energética motivação cosmológica.

À equipe de excelência do LABAUT pela satisfação e orgulho que todos vocês me proporcionam por poder dizer que de alguma forma eu fiz parte desse "algo" notável que vocês são.

À memória do meu querido Professor Philip Gunn por ter me ensinado, entre tantas coisas maravilhosas, a conhecer 0

Brasil. Tenho muito orgulho de ser seu aluno e de poder dizer que o lado de cima ficou um pouco mais brasileiro.

Obrigado.

À FAU, essa entidade indefinível que ironicamente define muitos metros quadrados de tudo o que eu sou. Por ter me seduzido com o que você faz de melhor: DESCONSTRUIR.

Aos profissionais, mestres, colegas e professores que contribuíram para esse trabalho. Em especial: Prof. Dr. Roberto

Lamberts da UFSC, Profa. Dra. Sheila W. Ornstein, Prof. Dr. Fulvio Vittorino, Sr. Saulo Rozendo, Dr. Artur Eduardo R. Bastos. Por terem oferecido tão generosamente suas experiências e seu tempo para amadurecerem alguns dos conceitos centrais desse trabalho.

Ao Professor Marcelo Romero pelo carinho e generosidade com que, nesses anos todos, tem se dedicado a iluminar naturalmente minhas idéias com alta eficiência energética.

Aos meus Pais por tão desprendidamente comprometerem as suas vidas para realizarem as nossas. Nada do que eu faça poderá retribuir essa doação.

À você, Sá, por me iluminar como o Sol da Minha Vida principalmente durante as piores tempestades.

Ao meu Irmão, que esse trabalho seja uma homenagem ao apoio, inspiração, orientação e socorro que me proporcionou nesses anos. Não teria chegado tão longe sem aproveitar o caminho que você desbravou como pioneiro.

Aos meus "pais" e "auditores" Soninha e Marcão, que a conclusão desse trabalho ilustre com um objeto singelo os incontáveis milagres que vocês operam pelas cabeças e mãos daqueles que vocês iluminam.

Aos irmãos de longe, de perto, de ontem, de hoje e de sempre: Caisinho, Marquito, Branco, Ortoba, Sig, Leo, M\&M, Mau, Marcão. Vocês terão sempre uma mansão de veraneio no meu coração.

Ao amigo Humberto pela paciência, motivação e inspiração. Obrigado por fazer ser tão fácil gostar e admirar você.

Aos amigos que tão generosamente completam tudo o que eu sou.

Mas principalmente,,$\ldots$

...à todas as boas luzes que aqui ou do outro lado iluminam o meu caminho, hoje e sempre. 


\section{Resumo}

A partir da constatação da introdução do uso do sistema LEED — Leardership in Energy and Environmental Design - no Brasil este trabalho foca sua análise, como um sistema de avaliação da sustentabilidade ambiental para o espaço construído, a partir de uma perspectiva nacional. Reunindo um panorama de críticas; uma análise do seu potencial de influência; um quadro da evolução histórica da certificação LEED de mais de 250 projetos nos EUA (entre 2000 e 2005) e um quadro com comentários pormenorizados de itens específicos do sistema, este trabalho embasa a análise crítica do sistema e da sua introdução no país identificando aspectos positivos e negativos, perspectivas para seu uso e as lições mais significativas aprendidas com sua experiência. 


\section{Abstract}

Taking the introduction in Brazil of the use of the LEED system as a starting point this work focus on it, as a construction sustainability assessment method, from a brazilian point of view. Gathering a review framework; an analysis of its influence potential; an historical evolution of its use as a certification program for over 250 projects in the USA (between 2000 and 2005) and a individualized comment of its credits, this work stands as a basis for its review and introduction in Brazil, identifying positives and negatives aspects, prospects of its use and the lessons learned with its experience. 


\section{Lista de Figuras}

Figura 1 - Pegada Ecológica mundial X a Biocapacidade do planeta (GLOBAL FOOTPRINT NETWORK, 2006)............15

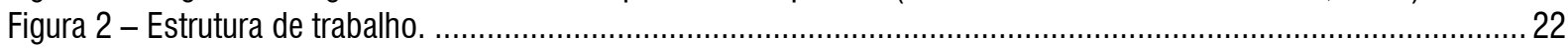

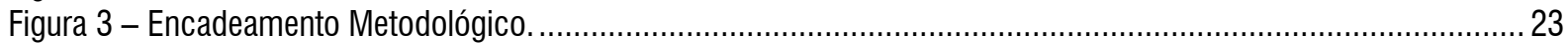

Figura 4 - Freedom Tower em Nova lorque (disponível em: <http://www.renewnyc.com/>) ............................... 39

Figura 5 - Sede do Índia Green Building Council certificado com o LEED-NC v2.0 nível Platinum (disponível em

$<$ http://greenbusinesscentre.com/Documents/Cll-Godrej+GBC.pdf >) ......................................................... 40

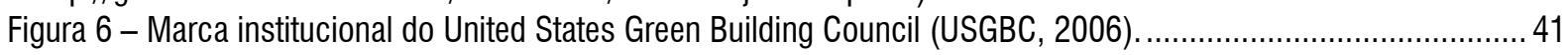

Figura 7 - Marca institucional do World Green Building Council (WGBC, 2006a). ................................................. 41

Figura 8 - Marcas institucionais dos Conselhos de Construção "Verde" nacionais (WGBC, 2006a). ......................... 41

Figura 9 - Modelo eletrônico do Edifício Ventura Corporate. Empreendimento da Tishman Speyer no centro do Rio de

Janeiro (EMPORIS BUILDING, disponível em: <http://www.emporis.com> acesso em: 02 de dezembro de 2006)... 43

Figura 10 - Modelo eletrônico do Edifício Ventura Corporate e entorno. Empreendimento da Tishman Speyer no centro do Rio de Janeiro (EMPORIS BUILDING, disponível em: <http://www.emporis.com> acesso em: 02 de dezembro de 2006).

Figura 11 - Modelo Eletrônico do Edifício Rochaverá. Empreendimento da Tishman Speyer em São Paulo (EMPORIS

BUILDING, disponível em: <http://www.emporis.com> acesso em: 02 de dezembro de 2006)............................. 44

Figura 12 - Centro de Pesquisas da Petrobrás — CENPES II — na ilha do Fundão, Rio de Janeiro (LABAUT, 2006) . . 45

Figura 13 - Edifício Primavera Office Green em Florianópolis, SC. (LAMBERTS, 2006) ........................................... 46

Figura 14 - Edifício Eldorado Business Tower em São Paulo, SP. (disponível em: <http://www.cbrichardellis.com.br>

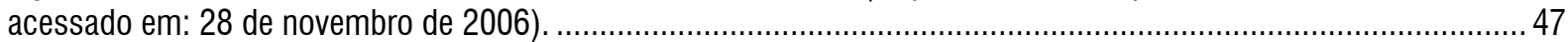

Figura 15 - Marca institucional do UK Green Building Council (disponível em: <http://www.ukgbc.org/> acessado em:

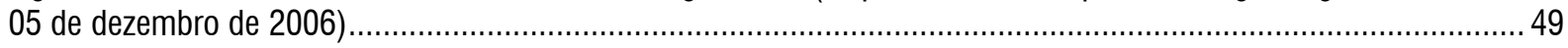

Figura 16 - Proposta do LEED para alcançar 25\% do mercado americano de construção (USGBC, 2004). ................60

Figura 17 - Divisão de Custos e Benefícios (reproduzido e traduzido de JOHNSON, 2000). ....................................... 67

Figura 18 -Blair Town. (disponível em: <http://leedcasestudies.usgbc.org> acesso em: 02 de dezembro de 2006) 75

Figura 19 - IBM Tivoli System. (disponível em: < http://leedcasestudies.usgbc.org > acesso em: 02 de dezembro de

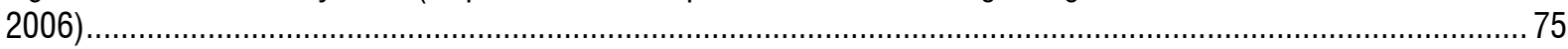

Figura 20 - Bachelors Enlisted Quarters. (disponível em: <http://leedcasestudies.usgbc.org > acesso em: 02 de

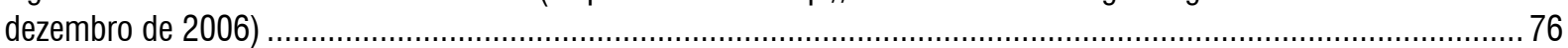

Figura 21 - Centro Internacional de Negócios - CIN. (disponível em: <http://www.tilt-up.org/awards/2003/cin.htm>

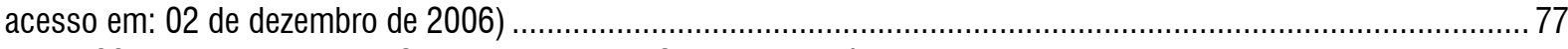

Figura 22 - William Jefferson Clinton Presidential Center (disponível em: <http://www.clintonfoundation.org > acesso

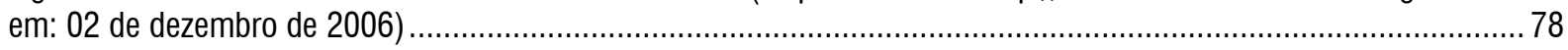

Figura 23 - One and Two Potomac Yard (disponível em: <http://leedcasestudies.usgbc.org > acesso em: 02 de

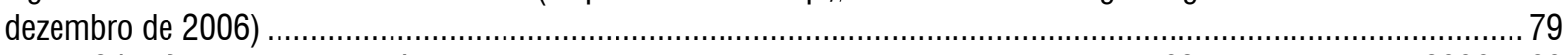

Figura 24 - Seminar II (disponível em: < http://leedcasestudies.usgbc.org > acesso em: 02 de dezembro de 2006) .. 80

Figura 25 - Colorado Court Affordable Housing (disponível em: < http://leedcasestudies.usgbc.org > acesso em: 02 de dezembro de 2006).

Figura 26 - Technopolis (disponível em: <http://leedcasestudies.usgbc.org> acesso em: 02 de dezembro de 2006)82 Figura 27 - Grundfos Pumps (disponível em: <http://www.grundfos.com> acesso em: 02 de dezembro de 2006)... 82 Figura 28 - Inland Empire Utilities Agency Headquarters Buildings (disponível em: <http://leedcasestudies.usgbc.org>

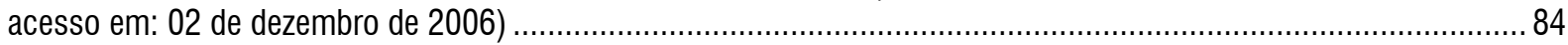
Figura 29 - Audubon Center at Debs Park (disponível em: <http://leedcasestudies.usgbc.org > acesso em: 02 de

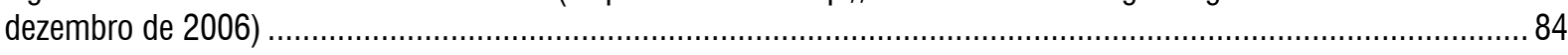
Figura 30 - Gurgaon Development Centre (disponível em: < http://leedcasestudies.usgbc.org > acesso em: 02 de

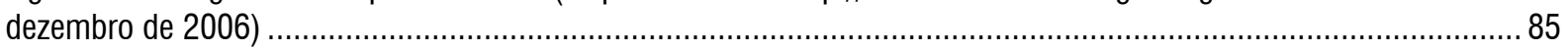
Figura 31 - Genzyme Center (disponível em: <http://leedcasestudies.usgbc.org > acesso em: 02 de dezembro de 2006)...

Figura 32 - Exemplo de Perfil de Certificação de um empreendimento (USGBC, 2006) ........................................ 88 Figura 33 - Parte do Banco de Dados tabulado a partir do perfil de certificação de 263 projetos diferentes entre 2000 e 2005 pelo LEED-NC.

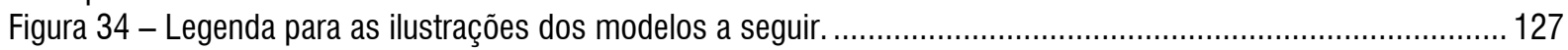

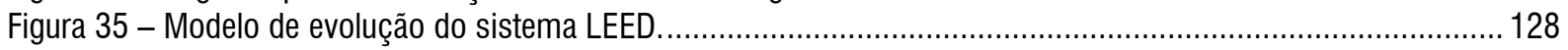
Figura 36 - Modelo proposto para um sistema nacional. ............................................................................ 128 


\section{Lista de Tabelas}

Tabela 1 - Quadro Comparativo entre Agenda Verde e Agenda Marrom (fonte: CIB, 2002) ….................................. 32

Tabela 2 - Lista pública de Projetos Registrados no USGBC para certificação (USGBC, 2006c)................................ 47

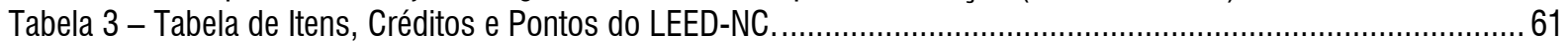




\section{Lista de Gráficos}

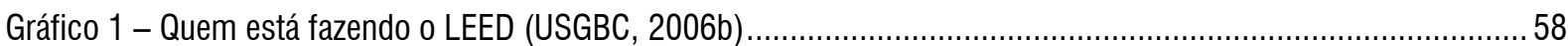

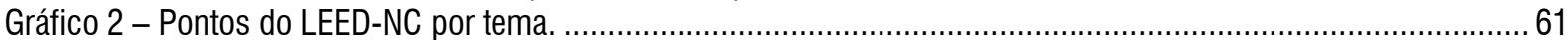

Gráfico 3 - Faixa de Notas (Categorias) do LEED-NC X Quantidade de Créditos..................................................... 63

Gráfico 4 - Pesos Obtidos em Consulta Pública sobre Sustentabilidade do Espaço Construído (reproduzido do trabalho

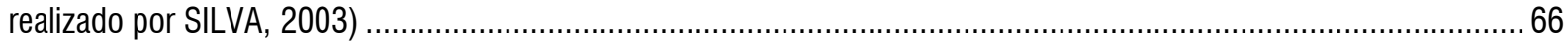

Gráfico 5 - Número de Créditos para cada camada de benefício para o sistema LEED como um todo (segundo divisão

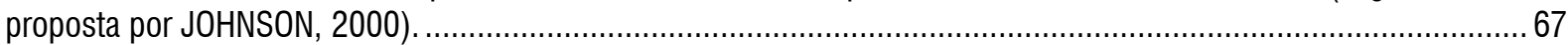

Gráfico 6 - Quantidade de itens do LEED-NC que exigem adequação a alguma norma específica. ............................70

Gráfico 7 - Mudanças na atualização do LEED-NC v2.1 para v2.2 (USGBC, 2006c) ............................................ 71

Gráfico 8 - Nível de Desafio dos itens para serem alcançados com um projeto nacional hipotético.............................72

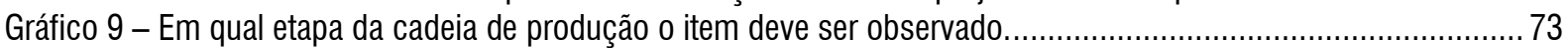

Gráfico 10 - Qual agente da cadeia de produção influencia de maneira mais determinante cada item...........................73

Gráfico 11 - Qual tipo de solução técnica tem maior relação com 0 item. ........................................................... 74

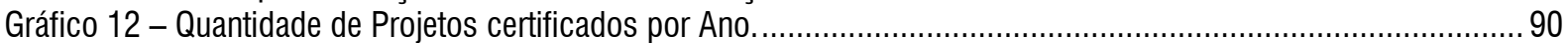

Gráfico 13 - Notas Médias e Notas Máximas dos projetos certificados por Ano ......................................................90

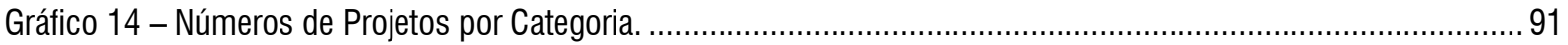

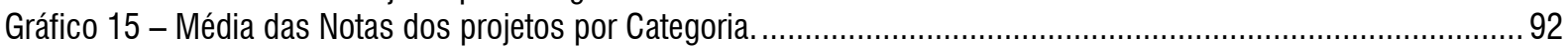

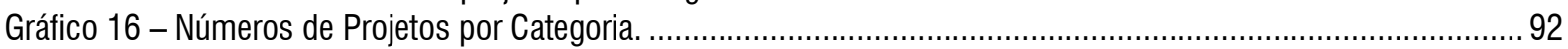

Gráfico 17 - Média dos Créditos por Categoria para cada crédito do sistema......................................................93

Gráfico 18 - Número de pontos alcançados pelos projetos em cada crédito do sistema........................................94

Gráfico 19 - Número de pontos alcançados pelos projetos em cada crédito do sistema, em ordem decrescente. ...... 95

Gráfico 20 - "MAPA" de Créditos do LEED-NC para cada Categoria.................................................................97

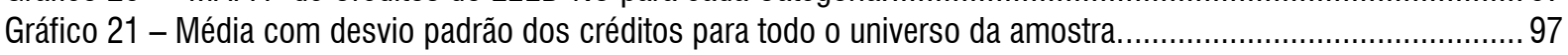

Gráfico 22 - 0s temas presentes nos 16 itens MAIS conseguidos (25\% mais altos). ...........................................98

Gráfico 23 - 0s temas presentes nos nos 32 itens MAIS conseguidos (50\% mais altos) ....................................... 98

Gráfico 24 - 0s temas mais presentes nos 16 itens MENOS conseguidos (25\% mais baixos).................................99

Gráfico 25 - Número de Créditos X Camada de Benefício dos 16 itens MAIS conseguidos. .....................................99

Gráfico 26 - Número de Créditos X Camada de Benefício dos 16 itens MENOS conseguidos................................... 100 


\section{Sumário}

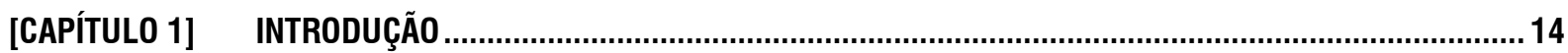

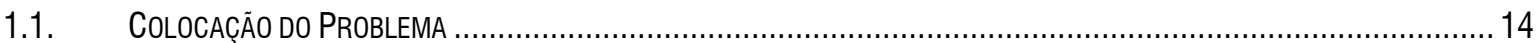

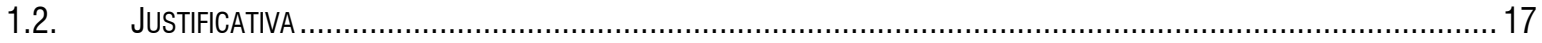

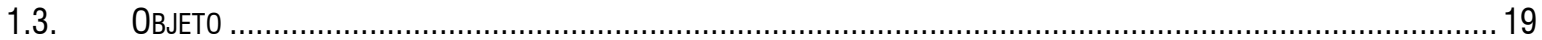

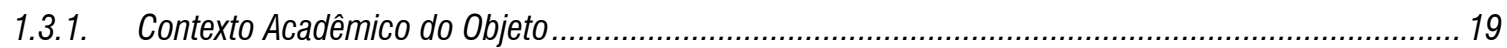

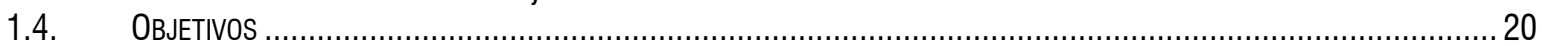

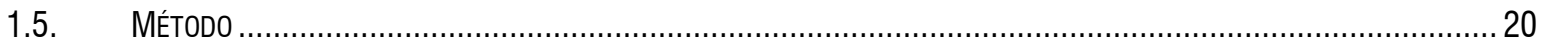

1.5.1. Impacto Ambiental do Ambiente Construído ……................................................................. 20

1.5.2. Sustentabilidade e Desenvolvimento Sustentável.................................................................... 20

1.5.3. Sistemas de Avaliação da Sustentabilidade Ambiental ................................................................ 21

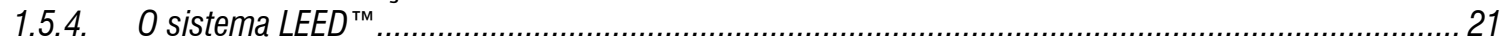

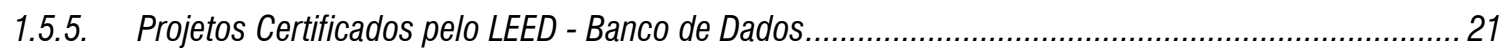

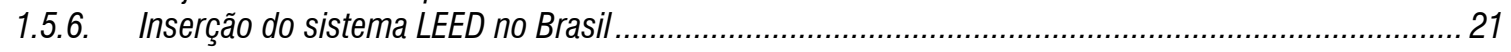

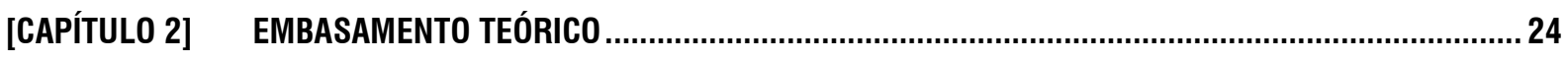

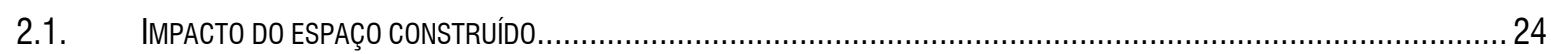

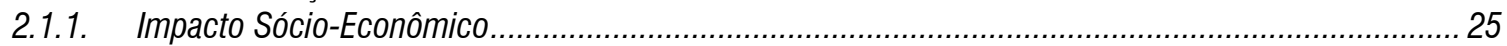

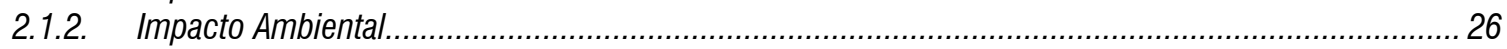

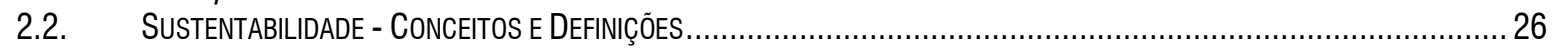

2.2.1. Sustentabilidade e Desenvolvimento Sustentável....................................................................... 27

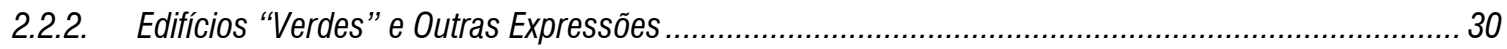

2.2.3. Arquitetura de Baixo Impacto Humano e Ambiental............................................................................ 31

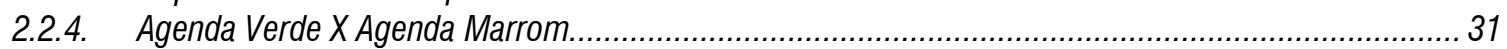

2.2.5. Sustentabilidade e Desenvolvimento Sustentável.......................................................................... 32

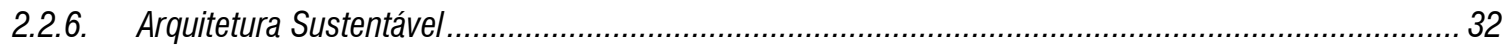

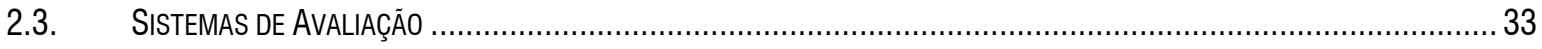

2.3.1. BREEAM - Building Research Establishment Environmental Assessment Method, Reino Unido.......... 35

2.3.2. BEPAC - Building Environmental Performance Assessment Criteria, Canada .......................................35

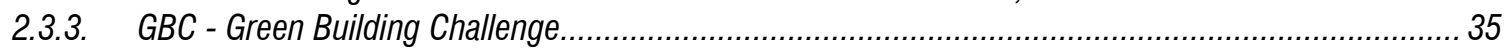

2.3.4. LEED - Leadership in Energy and Environmental Design, Estados Unidos ...................................... 36

2.3.5. CASBEE - Comprehensive Assessment System for Building Environmental Efficiency, JapÃo ............ 37

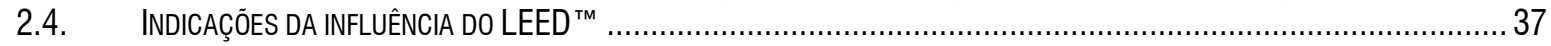

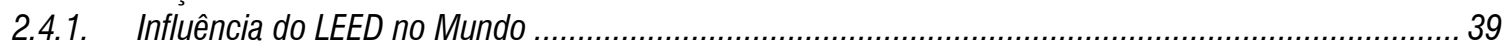

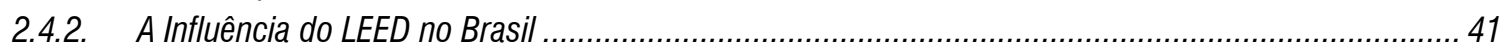

2.4.3. Fatores para o aparente sucesso do LEED ${ }^{\mathrm{TM}}$

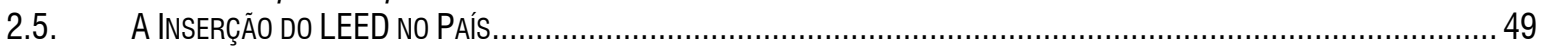

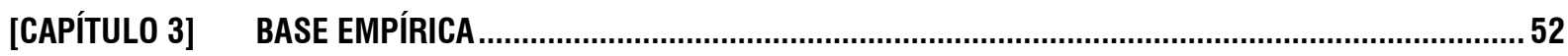

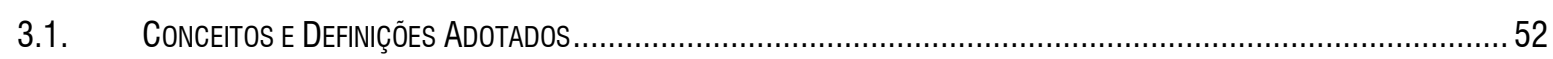

3.2. 0 SISTEMA LEED ${ }^{\text {TM }}$

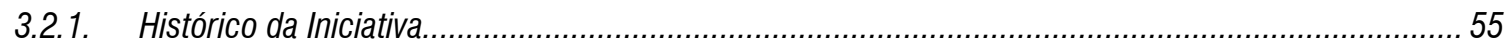

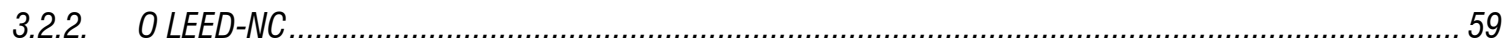

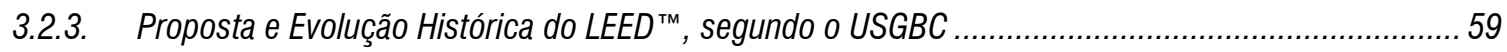

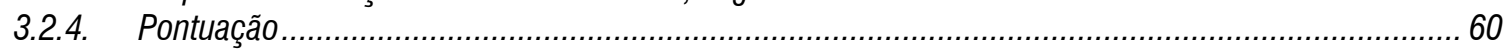

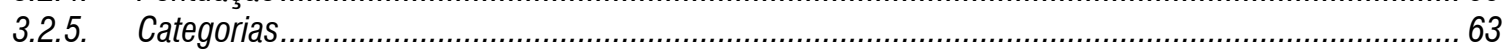

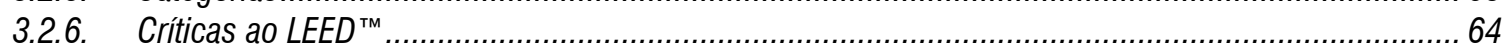

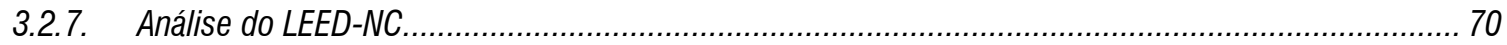

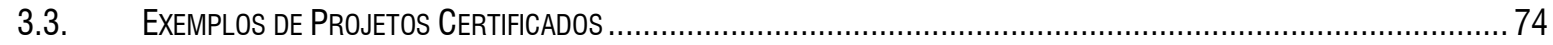

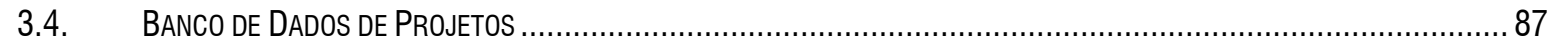

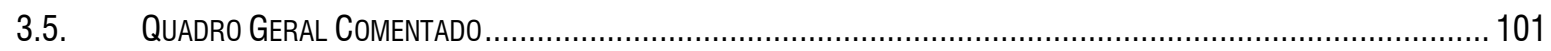

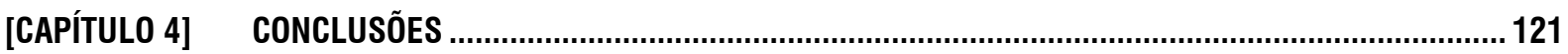

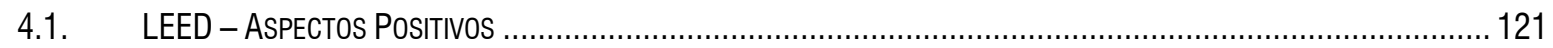




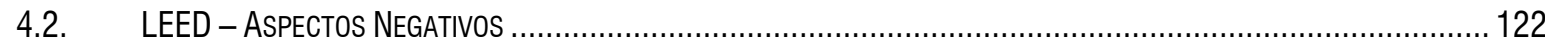

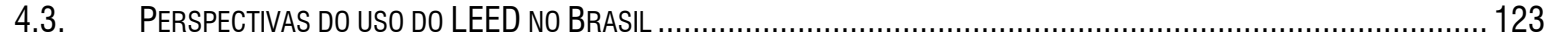

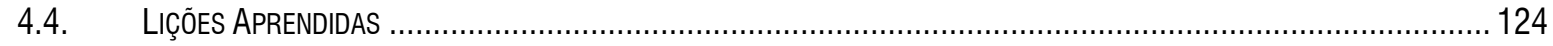

4.5. INSUMOS PARA UM SISTEMA DE AVALIAÇÃO DA SUSTENTABILIDADE DO ESPAÇO CONSTRUÍDO NO BRASIL: PROPOSTA DE PARTIDO 125

4.5.1. Contexto 126

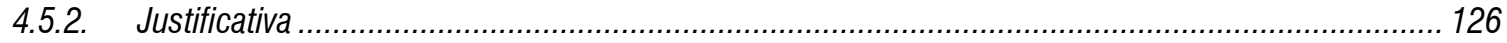

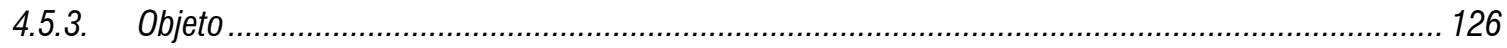

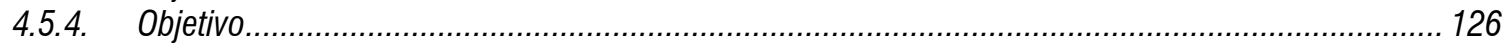

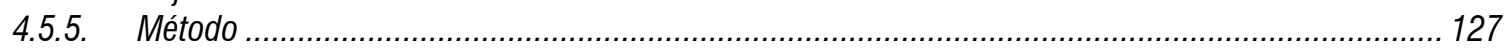

[CAPÍTULO 5] REFERÊNCIAS BIBLIOGRÁFICAS ............................................................................ 129 
"Earth provides enough to satisfy every man's need, but not every man's greed." Mohandas Karamchand "Mahatma" Gandhi no livro "Small Is Beautiful" de E. F. Schumacher.

"I want to make it clear, if there is ever a conflict (between environmental quality and economic growth), I will go for beauty, clean air, water, and landscape." Jimmy Carter, citado no "the New York Times", 19 de setembro, 1976.

"This is the first age that's ever paid much attention to the future, which is a little ironic since we may not have one." Arthur C. Clarke, escritor de "2001: Uma Odisséia no Espaço".

"It's all about bucks, kid. The rest is conversation." Gordon Gekko, personagem de Michael Douglas no filme "Wall Street "(1987). 


\section{[CAPÍTUL0 1] INTRODUÇÃO}

\subsection{COLOCAÇÃo do PROBlema}

A construção da experiência humana no planeta demanda recursos do meio natural em um ritmo que não permite que esses mesmos recursos sejam renovados pelos processos naturais.

Recurso natural não diz respeito apenas aos elementos materiais específicos, tais como minério de ferro ou toras de madeira. Considerando-se que a biosfera global desempenha um papel determinante regulando o clima do planeta e esta capacidade é limitada pode-se entender esta mesma capacidade como um recurso natural a ser preservado por meio dos princípios da sustentabilidade: usar menos e aumentar o "estoque".

Como exemplo basta entender que uma porção de mata tropical preservada não é apenas um estoque de toras de madeira esperando para serem usadas na construção civil. Essa mesma mata desempenha outras funções na biosfera, sendo que uma delas é contribuir para a regulação do clima no planeta. Pode-se usar menos esse recurso otimizando a demanda e pode-se aumentar esse "estoque" aumentando a quantidade e a qualidade de áreas preservadas.

Pensando de maneira abrangente a expressão RECURSO NATURAL pode ser aplicada a muito mais elementos do que usualmente se considera: a regulagem do clima pelas matas e oceanos é recurso 
natural, ventilação com alta umidade e baixo índice de contaminantes nas áreas urbanas é recurso natural, disponibilidade de céu em áreas urbanas é recurso natural, áreas permeáveis com vegetação nas áreas urbanas é recurso natural, etc.

Acredita-se que hoje o impacto ambiental ${ }^{1}$ negativo da civilização humana no planeta seja algo próximo de 23\% além do que ele é capaz de se regenerar (GLOBAL FOOTPRINT NETWORK, 2006). O planeta está longe do ponto de inflexão dessa curva.

\section{Footprint and Biocapacity}

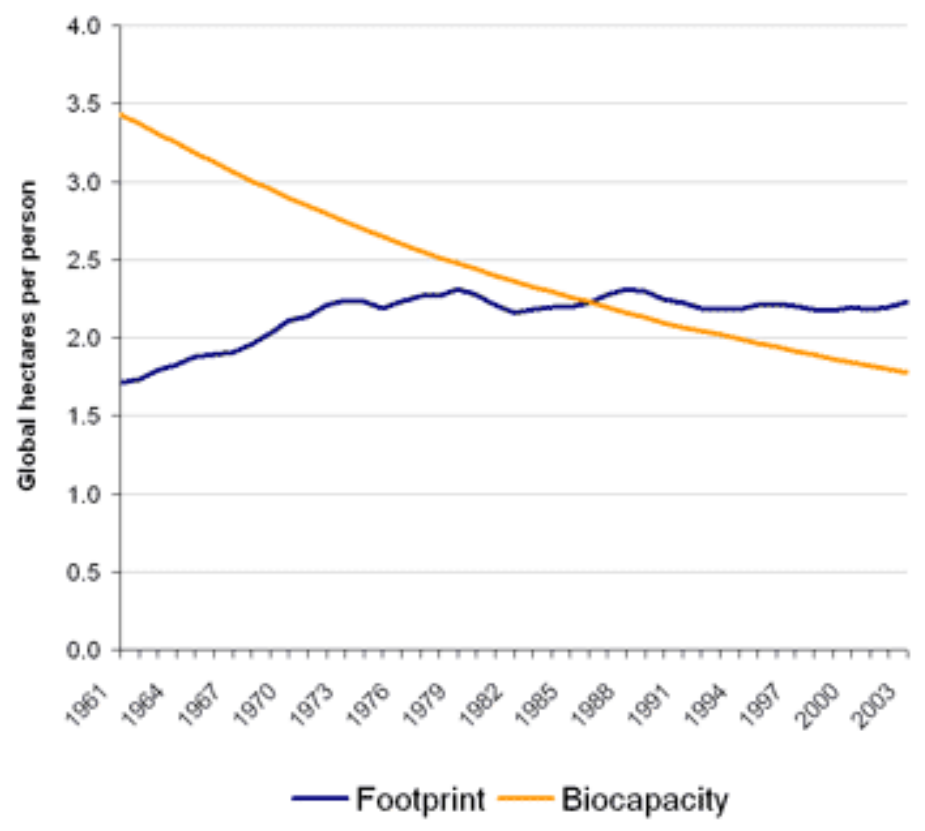

Figura 1 - Pegada Ecológica mundial X a Biocapacidade do planeta (GLOBAL FOOTPRINT NETWORK, 2006).

Vive-se e reproduz-se para as gerações futuras um modelo de desenvolvimento tão finito quanto, por exemplo, a estimativa atual de vida das reservas de petróleo e gás natural no planeta. Esse é o desafio da civilização atual.

Em diversas partes do mundo estão sendo construídos hoje os edifícios que representarão o padrão do estoque construído em 2030 ou 2040. Caso as perspectivas se confirmem serão esses os edifícios que estarão em uso quando os efeitos das mudanças climáticas e da crise energética se tornarem mais agudos do que já são hoje.

A sustentabilidade é uma necessidade frente a essa constatação e tem por objetivo garantir a perpetuação da civilização humana sem, no entanto, sacrificar todos os recursos naturais do planeta. Sustentabilidade é durabilidade, permanência, perpetuação. Já Desenvolvimento Sustentável é um modelo de

\footnotetext{
${ }^{1}$ No âmbito desse trabalho será feito uso da definição da ISO 14.000 que define impacto ambiental como qualquer modificação do meio ambiente, adversa ou benéfica, que resulte, no todo ou em parte, das atividades, produtos ou serviços de uma organização (ABNT, 1996).
} 
desenvolvimento capaz de garantir uma evolução que dure, que se sustente através dos tempos e com a sucessão de gerações.

Em uma de suas definições mais aceitas, desenvolvimento sustentável seria:

"Desenvolvimento econômico e social que atenda as necessidades da geração atual sem comprometer a habilidade das gerações futuras atenderem as suas próprias necessidades" (BRUNDTLAND, 1987).

Observa-se, no entanto, que o termo "necessidades" da expressão se refere não somente às questões ambientais. A evolução humana tem "necessidades" tanto ambientais como sociais ou econômicas. Sustentabilidade no sentido amplo não diz respeito, então, somente ao meio ambiente, mas, sim, à economia e à situação social também. Esse é o conceito de sustentabilidade tripolar ou triple bottom line of sustainability, como se conhece.

Vale observar que mesmo o conceito sendo um consenso internacional, não se pode perder de perspectiva o fato de que, por representar um equilíbrio dinâmico, a Sustentabilidade e o Desenvolvimento Sustentável não são os mesmos em contextos diferentes.

A partir da constatação do panorama da sustentabilidade como conceito amplo, destaca-se o papel determinante desempenhado pelo impacto do espaço construído 2 na demanda global por recursos naturais.

Grande parte das atividades humanas que impactam o meio ambiente tem ligações com a indústria da construção civil (CIB, 2002), e essa indústria e mesmo o espaço construído de modo geral tem impactos determinantes em aspectos econômicos, sociais e ambientais.

Devido à sua abrangência e escala de influência na economia, o espaço construído, em especial a indústria da construção civil, influencia a vida de uma parcela significativa de toda a população mundial.

As projeções mundiais estimam que a população do globo alcance 8 bilhões de pessoas por volta de 2025, sendo que quase todo o crescimento (98\%) será em países em desenvolvimento (UNEP, 2003). Esse fato chama a atenção para o grande aumento de demanda e conseqüente impacto do espaço construído nos países em desenvolvimento. Quase todo o crescimento populacional que se espera no planeta será em áreas pobres.

Devido ao grande consumo de recursos naturais (matérias-primas, energia etc.) e ao seu potencial de geração de resíduos, o espaço construído recebe grande parte da atenção global quando se tratam de questões ambientais ligadas à sustentabilidade.

\footnotetext{
${ }^{2}$ Referindo-se ao impacto ambiental do espaço construído, entende-se que estão contemplados ambos: 0 impacto ambiental [1] da indústria da construção civil e [2] do estoque construído e utilizado. Assim inclui-se tanto o impacto incorporado na construção de novos edifícios como também 0 consumo de energia dos edifícios em operação, por exemplo.
} 
A demanda ambiental gerada pelo espaço construído é preocupante em todo o globo. Segundo o UNITED STATES GREEN BUILDING COUNCIL (USGBC) (2006d), somente nos EUA os edifícios são responsáveis por 36\% do total de energia usada, $65 \%$ do consumo de eletricidade, 30\% das emissões de GREEN HOUSE GASES (GHGs), 30\% do uso de matérias-primas, 30\% dos resíduos gerados anualmente e $12 \%$ do consumo de água potável.

Nesse contexto, diversas iniciativas se destacaram, especialmente a partir da década de 90 , no sentido de se criar ferramentas para medir esses impactos e incentivar práticas mais sustentáveis de projeto, construção, uso e desconstrução do espaço construído. Em especial, iniciativas como a do Building Research Establishment (BRE) do Reino Unido, que desenvolveu, implementou e divulga o uso do sistema BREEAM (Building Research Establishment Environmental Assessment Method) para avaliar a sustentabilidade de edifícios, principalmente de escritórios. O BREEAM tem como formato um checklist com requisitos que devem ser alcançados para que o projeto avaliado ganhe pontos. A partir de uma pontuação mínima, o projeto é certificado em uma gradação de notas/categorias crescente.

Na França, a iniciativa do Haute Qualité Environnementale - HQE - leva o conceito de avaliação a diante com a possibilidade de adaptar a avaliação do desempenho ambiental ao perfil de contexto de cada empreendimento, permitindo que os projetos foquem as realidades específicas de seu entorno e situação.

Em meio a outras iniciativas, o United States Green Building Council (USGBC) criou o sistema LEED (Leadership in Energy and Environmental Design) com uma proposta análoga. No sistema LEED a partir de uma pontuação equivalente a $38 \%$ dos pontos disponíveis, o projeto é considerado certificado e a partir daí pode alcançar 4 níveis de categoria, em ordem crescente: CERTIFIED, SILVER, GOLD e a mais alta PLATINUM.

Com o apoio de diversas instituições e contando com a colaboração de órgãos governamentais, o LEED se firmou nos EUA como o sistema de avaliação mais influente e vem "exportando" essa influência para outros países. O Brasil, aparentemente, no caminho dessa influência, serve de meio para que o sistema norte-americano seja utilizado e disseminado sem, no entanto, comprovadamente responder de maneira consistente às demandas nacionais.

A iniciativa deste trabalho vem abordar esse cenário por meio da análise crítica do objeto LEED $^{\mathrm{TM}}$, e das perspectivas de sua inserção no país.

\subsection{JUSTIFICATIVA}

Tendo em vista o papel determinante do impacto do espaço construído nos três aspectos básicos - ambiental, social e econômico - em todo o mundo e no Brasil, a abordagem proposta se justifica como resposta à aplicação e disseminação do uso do sistema LEED no Brasil. A análise do panorama traçado será desenvolvida ao longo deste trabalho de modo a demonstrar a pertinência da abordagem proposta, mas destacam-se de antemão considerações a respeito da influência do LEED no mundo e no Brasil, como também fatores para seu aparente sucesso no seu país de origem. 
Quanto ao impacto do espaço construído nas questões econômicas, sociais e ambientais no mundo, alguns fatos ilustram a escala dessa questão.

[1] Depois da queima de combustíveis fósseis, a produção de cimento é o principal agente antropogênico a contribuir nas emissões de gases do efeito estufa (GHGs) (CIB, 2002, p.13).

[2] Todos os anos uma nova área equivalente a todo o estado do Rio de Janeiro (aprox. 40.000 $\mathrm{km}^{2}$ ) é ocupada por urbanização no mundo (CIB, 2002, p.15).

[3] A indústria da construção civil é a maior empregadora no mundo com 111 milhões de empregados sendo que 3/4 desses estão nos países em desenvolvimento (CIB, 2002, p.15).

[4] Em quase qualquer país desenvolvido e mesmo em alguns países em desenvolvimento, como o Brasil, a indústria da construção civil responde por aprox. 10\% de todo PIB (CIB, 2002, p.16).

Como se vê, o espaço construído responde por uma grande parcela de toda a demanda humana por recursos naturais e com o fim da era de abundância de recursos, como pregam alguns pesquisadores, os ideais de sustentabilidade se firmaram como uma resposta a essa constatação. A partir desse ponto um grande movimento se consolidou com a união de numerosas iniciativas de diversos tamanhos e abrangências alinhadas com esses ideais.

Sistemas de avaliação da sustentabilidade são uma conseqüência natural na busca pelos ideais mencionados e a dinâmica de uso e disseminação do LEED $^{\mathrm{TM}}$, como um dos sistemas com maior potencial para influenciar a indústria da construção brasileira, apresenta-se como pertinente objeto de pesquisa nesse momento. Essa importância é ilustrada por fatos relacionados com:

[1] a Influência do sistema LEED no mundo; e

[2] a influência do sistema LEED no Brasil.

Sendo alguns deles:

- O LEED é usado para certificar edifícios públicos americanos nas diferentes esferas de poder;

- O sistema é usado para certificar empreendimentos de grande expressão nacional no seu país de origem como a reconstrução do World Trade Center em Nova Iorque;

- O USGBC — instituição que criou e divulga o uso do LEED — deu origem ao World Green Building Council que por sua vez incentiva a criação de conselhos nacionais em outros países como México e Canadá além de incentivar a adaptação do sistema LEED nesses países;

- No Brasil já constam pelo menos 5 projetos em vias de certificação; e

- A Petrobrás, maior empresa nacional, usou o sistema LEED como referência no projeto de seu centro de pesquisas no Rio de Janeiro. 


\subsection{OBJETO}

A partir das constatações da importância do impacto da indústria da construção civil e com base nos fatos que ilustram a efetiva inserção do uso do sistema LEED no país este trabalho tomou como objeto:

\section{O sistema LEED e sua inserção no Brasil.}

A relação do sistema LEED com a realidade nacional é de especial importância também pelas críticas ao sistema que fazem referência à sua incompatibilidade com as demandas nacionais.

\subsubsection{CONTEXTO ACADÊMICO DO OBJETO}

Esse objeto recorta o tema maior — a sustentabilidade do espaço construído — em um aspecto diretamente relacionado com a prática profissional do arquiteto e com a dinâmica de produção física das cidades. O trabalho se insere no contexto do Programa de Pós-graduação da FAU USP como uma ramificação de trabalhos predecessores, com especial atenção ao papel de:

- Roberta Kronka MÜLFARTH (2002) — com sua tese de doutoramento sobre Arquitetura de Baixo Impacto Humano e Ambiental; e

- Joana GONÇALVES (2003) — com sua tese de doutoramento sobre A sustentabilidade do edifício alto: uma geração de edifícios altos e sua inserção urbana

- Enquanto MÜLFARTH (2002) cria o arcabouço conceitual que embasou o desenvolvimento deste trabalho, GONÇALVES (2003) retrata a realidade de aplicação dos sistemas de avaliação e sua influência no Brasil.

Destaca-se ainda a relação deste trabalho com outras iniciativas dentro do Laboratório de Conforto Ambiental e Eficiência Energética (LABAUT) da FAU USP, notadamente o desenvolvimento atual por parte da pesquisadora Andrea BAZARIAN de sua dissertação de mestrado focando o percurso histórico da relação entre as inovações tecnológicas relacionadas ao uso da água, energia e materiais de construção com os sistemas de avaliação de impacto ambiental e com os projetos da chamada arquitetura sustentável.

Ainda na Universidade de São Paulo (USP), pesquisadores desenvolvendo linhas de pesquisa na Escola Politécnica (POLI USP) guardam relação com este trabalho focando o impacto ambiental do espaço construído e formas de avaliação desse impacto, destacando-se entre eles:

- CARDOSO, Francisco F. - a competitividade setorial e sustentabilidade do ambiente construído focando os sistemas de gerenciamento de qualidade em construtoras de edifícios;

- JOHN, Vanderley e AGOPYAN, Vahan - a sustentabilidade de materiais, componentes e matérias-prima na indústria da construção civil. 
- SILVA, Vanessa Gomes — avaliação da sustentabilidade do espaço construído.

As contribuições das duas escolas são complementares, e podem ser retratadas sucintamente da seguinte forma: enquanto a Escola Politécnica se concentra no impacto da indústria da construção civil por meio da gestão do processo de projeto e do processo de construção, a FAU USP se concentra no impacto do espaço construído por meio da perspectiva do projeto de arquitetura e do projeto urbano, identificando a contribuição potencial da figura do arquiteto e urbanista.

Ainda, na Universidade Federal de Santa Catarina sob a orientação do professor Roberto LAMBERTS, a pesquisadora Michele Fossati atualmente desenvolve no seu doutoramento mais uma proposta de ferramenta para avaliação da sustentabilidade de edifícios brasileiros.

\subsection{OBJETIVOS}

A partir da análise do sistema LEED e sua inserção no Brasil, objeto desta pesquisa, o trabalho tem por objetivo principal:

\section{Embasar a análise crítica do sistema LEED relacionada com sua inserção no Brasil.}

Como decorrência o trabalho embasará a elaboração de algumas diretrizes para iniciativas nacionais, regionais e/ou locais de avaliação da sustentabilidade do espaço construído e de incentivo a práticas mais sustentáveis.

\subsection{MÉTODO}

Visando a análise crítica proposta este trabalho seguiu um encadeamento metodológico partindo de questões generalistas de ambientação e contexto para os aspectos específicos relacionados diretamente ao objeto LEED e sua inserção no país desenvolvidos na seguinte ordem:

\subsubsection{IMPACTO AMBIENTAL DO AMBIENTE CONSTRUÍDO}

Panorama sintético sobre o impacto do ambiente construído no mundo e no Brasil em suas dimensões ambiental e sócio-econômica.

Elaborado com base na revisão bibliográfica.

Fontes de destaque: Nações Unidas, Global Footprint Network, FGV, entre outros.

\subsubsection{SUSTENTABILIDADE E DESENVOLVIMENTO SUSTENTÁVEL}

Análise da sustentabilidade e do desenvolvimento sustentável como resposta ao modelo de desenvolvimento linear.

Elaborado com base na revisão bibliográfica.

Fontes de destaque: Nações Unidas, MÜLFARTH Roberta Kronka, SILVA Vanessa Gomes, entre outros. 


\subsubsection{SISTEMAS DE AVALIAÇÃO DA SUSTENTABILIDADE AMBIENTAL}

Relação dos sistemas de avaliação da sustentabilidade de maior destaque.

Elaborado com base na revisão bibliografia.

Fontes de destaque: Panorama abrangente elaborado por SILVA (2003) Vanessa Gomes, GONÇALVES Joana, entre outros.

\subsubsection{O SISTEMA LEED ${ }^{\mathrm{TM}}$}

Análise pormenorizada do objeto LEED ${ }^{\mathrm{TM}}$ : origem, histórico, sistema de avaliação etc.

Elaborado com base em revisão bibliográfica.

Fontes de destaque: USGBC, BUILDING DESIGN \& CONSTRUCTION, entre outros.

\subsubsection{PROJETOS CERTIFICADOS PELO LEED - BANCO DE DADOS}

Produção e análise de um banco de dados com o perfil de certificação de todos os edifícios certificados pelo LEED-NC entre 2001 e 2005, totalizando 263 projetos.

Elaborado com base nos perfis de certificação públicos fornecidos pelo USGBC.

Fontes de destaque: USGBC.

\subsubsection{INSERÇÃO DO SISTEMA LEED NO BRASIL}

Elaboração de análise da inserção do sistema LEED no Brasil.

Elaborado com base na revisão bibliográfica, entrevistas, banco de dados de projetos, entre outros.

Fontes de destaque: reunião das fontes utilizadas ao longo do trabalho e dados primários obtidos em entrevistas. 


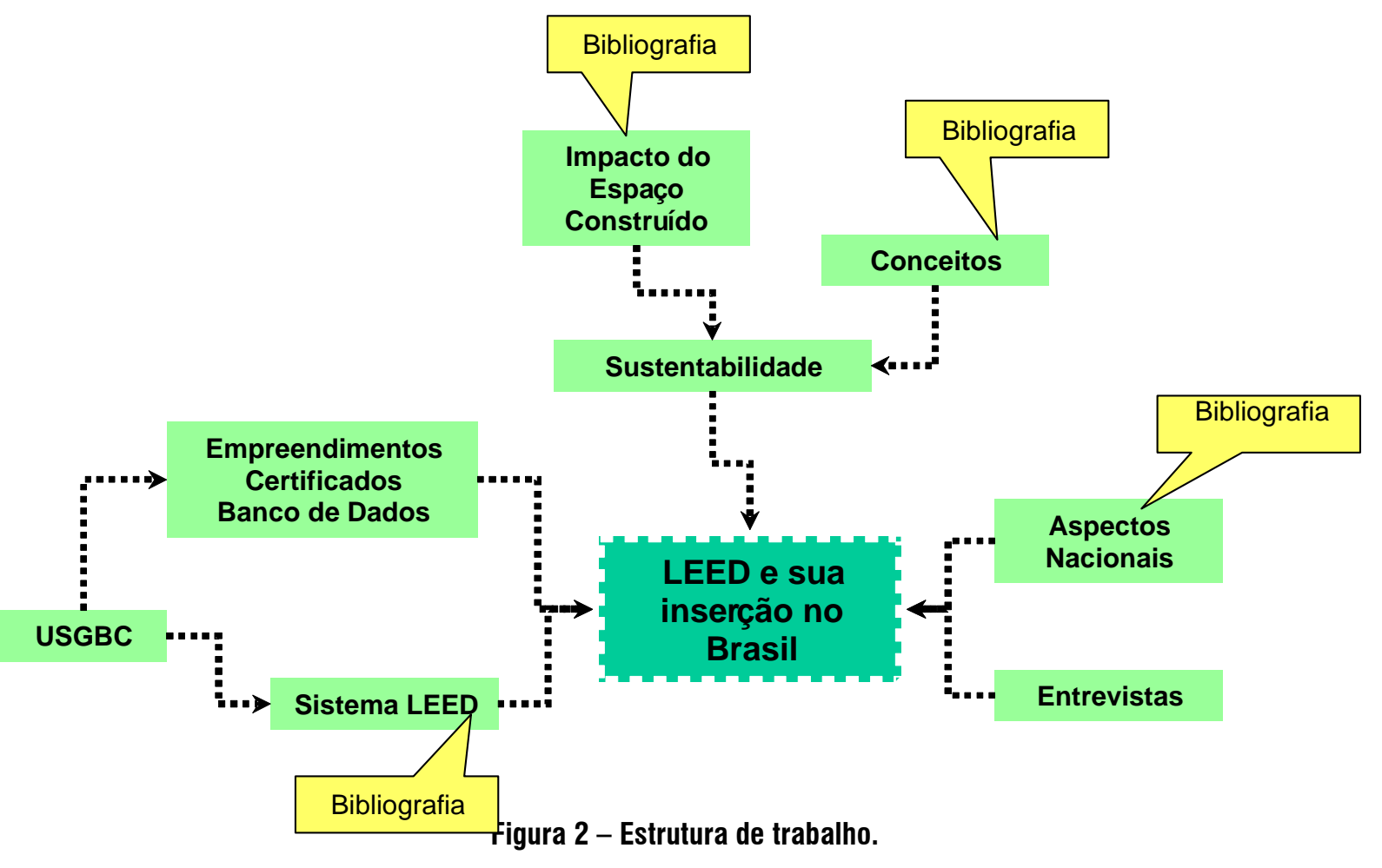




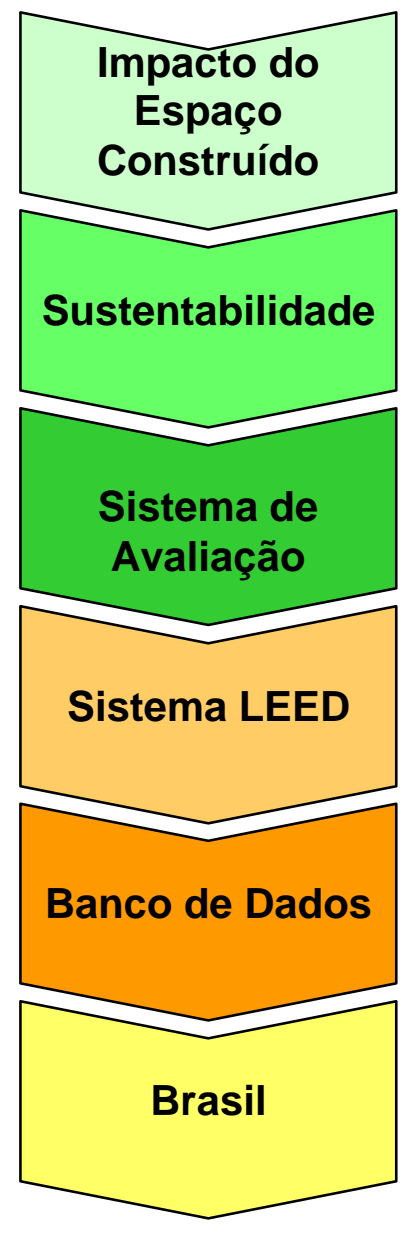

Constatação do Impacto do

Espaço Construído

Sustentabilidade e

Desenvolvimento

sustentável.

Como avaliar a

sustentabilidade?

Sistema norte-americano

Histórico de Certificações.

A inserção no Brasil.

Figura 3 - Encadeamento Metodológico.

A partir do encadeamento proposto foi possível dividir o desenvolvimento deste trabalho em duas partes: [1] Embasamento teórico (reunindo principalmente as referências bibliográficas) e [2] Base Empírica (reunindo principalmente as contribuições desenvolvidas nesse trabalho). 


\section{[CAPÍTULO 2] EMBASAMENTO TEÓRICO}

Partindo de conceitos generalistas e concluindo com aspectos específicos deste trabalho a elaboração deste embasamento compõe o cenário para as contribuições diretas da pesquisa.

\subsection{IMPACTO DO ESPAÇO CONSTRUÍDO}

Como princípio motivador desta pesquisa, o impacto ambiental e sócio-econômico do espaço construído no mundo e, mais particularmente, no país recebe grande atenção pelo seu papel determinante no modelo de desenvolvimento estabelecido.

Grande parte das atividades humanas que impactam o meio ambiente tem ligações com a indústria da construção civil (CIB, 2002) e com o uso do estoque construído: portanto, segundo a definição aqui utilizada, o espaço construído tem um determinante papel no impacto dos assentamentos humanos no planeta.

A definição desse impacto negligenciou, até meados do século $\mathrm{XX}$, a real dimensão social e ambiental em detrimento somente da dimensão econômica.

Como já extensivamente relatado por diversas publicações (BRUNTLAND, 1987; NSSD, 2003; UNITED NATIONS, 1992 apud SILVA, 2003 e EVANS, 2001 apud MÜLFARTH, 2003) a sustentabilidade objeto da Agenda 21, Agenda 21 for Sustainable Construction in Developing Countries etc. é, 
principalmente, uma resposta às pressões ambientais mundiais de vulto, tais como a crise energética da década de 70 que teve efeitos mais drásticos nos países desenvolvidos, consumidores mais intensos de combustíveis fósseis como o petróleo.

Respondendo por algo em torno de $50 \%$ de toda a demanda por recursos naturais e $50 \%$ de todos os resíduos produzidos pela atividade humana no planeta (EDWARDS, 2003), o espaço construído é o foco de atenção de inúmeros agentes alinhados com os ideais de sustentabilidade. Com essa perspectiva alguns dos impactos econômicos, sociais e ambientais do espaço construído são relacionados a seguir:

\subsubsection{IMPACTO SÓCIO-ECONÔMICO}

O Impacto sócio-econômico do espaço construído no mundo hoje é determinante no passo do desenvolvimento econômico mundial considerando-se a exploração de matérias-primas, o transporte de materiais de construção, o consumo de energia, o mercado de produtos imobiliários etc.

O Banco Mundial estima que somente os gastos com infra-estrutura serão de US\$2 Trilhões até 2018, sendo que os países em desenvolvimento responderão por quase metade de toda essa soma (UNEP, 2003).

No Brasil, o prognóstico do déficit habitacional ilustra o potencial de crescimento da indústria da construção civil e do impacto do espaço construído como um todo. Em 2003 esse déficit era de 7,280 milhões de moradias, o que representava $15 \%$ do total de domicílios do país, sendo que 3,1 milhões de domicílios localizavam-se em favelas. Os estados mais urbanizados do país (São Paulo, Rio de Janeiro e Minas Gerais) concentram o maior déficit - 38\% do total do país - sendo que o estado de São Paulo sozinho responde por 23\% do total do país (dados de 2003 em FGV, 2005c). Nos últimos 10 anos esse déficit tem aumentado e o crescimento relativo foi de 16,5\% nessa década (FGV, 2005c).

Como pilar da economia nacional, sabe-se que apesar de sucessivas quedas nos últimos anos o setor da construção no Brasil foi responsável por 6,5\% de todo o PIB do país. Englobando a indústria de materiais de construção e demais fornecedores de insumos esse número sobe para 14,5\% do PIB (FGV, 2005a).

Quanto à carga tributária, a construção civil é o segundo maior contribuinte do país, ficando atrás somente do comércio. Observando que o seu potencial de contribuição ainda pode aumentar substancialmente pelo fato de que, devido à grande informalidade do setor — em 2003 somente a minoria $(40 \%)$ das empresas do setor eram formais (FGV, 2005b) - grande parte da arrecadação vem somente do ICMS (aprox. 40\% da arrecadação total) (FGV, 2005a). Esse mesmo potencial fica claro quando se constata que as empresas formais de construção no país pagam em média três vezes mais imposto do que as informais (FGV, 2005b).

Devido à sua abrangência e escala de influência na economia, o espaço construído, em especial a indústria da construção civil, influencia a vida de uma parcela significativa de toda a população mundial. 
Como empregadora de força de trabalho, a indústria da construção gera aproximadamente $7 \%$ de todo o emprego mundial, sendo que 3/4 desse montante está nos países em desenvolvimento (CIB, 2002).

No Brasil os números confirmam o perfil internacional. Em 2003, o número de empregados no setor foi de 3,77 milhões de pessoas, o que representava 5,6\% da população economicamente ativa (PEA) do país (FGV, 2005b).

\subsubsection{IMPACTO AMBIENTAL}

A demanda ambiental gerada pelo espaço construído é preocupante em todo o globo. Segundo o USGBC (2006), somente nos EUA os edifícios são responsáveis por 36\% do total de energia usada, $65 \%$ do consumo de eletricidade, 30\% das emissões de GHGs, 30\% do uso de matérias primas, 30\% dos resíduos gerados anualmente e $12 \%$ do consumo de água potável.

Essa demanda tende a aumentar. O Banco Mundial estima que em 2015 mais da metade de todo o estoque de edifícios residenciais e comerciais da China será de edifícios construídos depois de 2000 (UNEP, 2003). Construções residenciais “informais" representam entre 20-30\% de todo o crescimento urbano nas maiores cidades dos países em desenvolvimento (UNEP, 2003, 5p).

Um bom instrumento para se determinar o impacto ambiental dos materiais na indústria da construção é a "Mochila Ecológica3" que descreve a quantidade total de material extraído da natureza para se obter uma unidade de material puro (utilizável). Por exemplo, para o aço a "mochila ecológica" é expressa pela razão de 14:1 — ou seja, para cada 14 toneladas de solo extraído das minas, 1 tonelada de aço é produzida. No caso de metais raros como ouro ou platina a razão pode chegar a 350.000:1 (WALLBAUM, 2003). Ainda assim, considerando o ciclo de vida do elemento, materiais como o aço apresentam um amortizador de impacto devido ao seu alto potencial de reuso e reciclabilidade.

No Brasil o impacto do espaço construído sobre o meio ambiente segue os mesmos termos. Aproximadamente $1 / 4$ de toda a energia elétrica que é produzida no país é gasta nas residências, sendo que o consumo residencial e o comercial respondem juntos por quase $40 \%$ de toda a demanda elétrica nacional (MINISTÉRIO DE MINAS E ENERGIA, 2003). Faz sentido entender que quase metade de toda a demanda nacional por eletricidade e o impacto decorrente disso tem relação direta com o ambiente construído.

\subsection{SUSTENTABILIDADE - CONCEITOS E DEFINIÇÕES}

Como resposta ao modelo de desenvolvimento linear estabelecido - ilustrado de maneira contundente pelo impacto do espaço construído - a idéia de sustentabilidade como conhecida hoje se desdobrou na forma de movimentos, iniciativas, conceitos e expressões. Seguindo os movimentos considerados de vanguarda os conceitos se multiplicaram em diferentes áreas do conhecimento. Apesar dos

\footnotetext{
${ }^{3}$ Ecological rucksack (tradução literal).
} 
avanços na sedimentação de termos e definições relacionadas com o tema são relacionados aqui, com base nas referências bibliográficas, os mais significativos no escopo deste trabalho.

Notadamente, a discussão sobre o uso de termos associados com sustentabilidade fez com que, por exemplo, nos EUA fosse criada uma norma que estabelece diretrizes de como devem ser usados os termos relacionados com a questão ambiental (ex. ambientalmente preferível ${ }^{4}$ ) em anúncios publicitários. Isso aponta potencialmente duas tendências: [1] cada vez se dá mais importância para a imagem ambiental de determinados serviços e produtos e [2] esse é ainda um assunto indefinido ou plural o suficiente para permitir diferentes interpretações dos termos relacionados com o tema (FEDERAL TRADE COMMISSION, 1998). Mesmo a International Standard Organization (ISO) tem uma norma específica para esse tema ${ }^{5}$.

É possível ir mais longe nessa reflexão observando a contribuição de HAGAN (2001) definindo sustentabilidade como algo instável por princípio: “The term 'sustainable' is, therefore, unstable, largely because of the instability of point of view" (HAGAN, 2001, p. 3 grifo nosso).

Isso fica mais claro quando observamos a contribuição de HAGAN (2001)

Mesmo as definições estabelecidas e divulgadas por instituições como as Nações Unidas não satisfazem objetivos específicos como, por exemplo, ensinar novos arquitetos a praticar e disseminar esses mesmos conceitos por meio de seu exercício profissional (MANSY, 2005, p. 933-934).

A essência plural desse movimento que reúne desde iniciativas globais até ações locais incentiva a proliferação e apropriação de termos e conceitos muitas vezes pouco fundamentados, funcionais e/ou satisfatórios.

Nesse item são apresentadas definições pertinentes ao tema sustentabilidade adotados com base na pesquisa bibliográfica, iniciando-se pela própria idéia de sustentabilidade.

\subsubsection{SUSTENTABILIDADE E DESENVOLVIMENTO SUSTENTÁVEL}

A World Commission on Environment and Development (WCED ${ }^{\circ}$ ) cunhou a definição de desenvolvimento sustentável mais difundida e aceita (BRUNDTLAND, 1987):

"Desenvolvimento econômico e social que atenda as necessidades da geração atual sem comprometer a habilidade das gerações futuras atenderem as suas próprias necessidades".

Dessa forma a relação entre os termos sustentabilidade, desenvolvimento sustentável, construção sustentável etc., segundo CIB (2002) seria:

O objetivo é sustentar e manter viva a espécie homo sapiens.

\footnotetext{
${ }^{4}$ Environmentally preferable (Tradução livre do autor).

${ }^{5}$ ISO 14021 - Environmental Labels and Declarations - Self-Declared environmental claims

${ }^{6}$ Também conhecida como Comissão Brundtland, em menção a Gro Harlem Brundtland, coordenadora dos trabalhos e então Primeira-Ministra da Noruega.
} 
Sustentabilidade é a condição que permitiria alcançar o objetivo.

Desenvolvimento sustentável é o tipo de desenvolvimento que precisamos procurar para alcançar o estado de sustentabilidade. Esse estado de sustentabilidade é um contínuo processo de equilíbrio dinâmico.

Assentamentos humanos sustentáveis são as cidades, vilas e/ou comunidades que nos permitem viver de uma maneira que suporte o estado de sustentabilidade.

Urbanismo sustentável é o processo amplo de criar assentamentos humanos sustentáveis, especialmente cidades. Sendo que, para ROGERS (2001), o resultado disso deva ser uma cidade: justa, bonita, criativa, ecológica, fácil, compacta e diversificada.

Construção sustentável significa que os princípios do desenvolvimento sustentável estão aplicados ao ciclo de construção da extração e beneficiamento das matérias primas, ao planejamento, ao projeto e construção do edifício ou infra-estrutura, até a sua desconstrução final e gerenciamento dos resíduos resultantes.

Para o BRE (2001) a palavra sustentabilidade que se refere à habilidade de sustentar, manter, perpetuar, era tradicionalmente usada nos negócios em termos de fatores econômicos relativos à sobrevivência de uma empresa: sua perpetuação a partir do bom equilíbrio entre seus ganhos e suas perdas econômicas.

Com o fim da era de abundância de recursos — influenciada fortemente pela crise energética dos anos 70 — “construção sustentável” se tornou um termo amplamente difundido e vai além do aspecto econômico. A construção sustentável inclui assuntos pertinentes ao impacto ambiental e social também. Dessa forma, um empreendimento para ser sustentável precisa alcançar "lucros" obrigatoriamente nas três áreas: econômica, ambiental e social (BRE, 2001). Sendo que — segundo ROGERS (2001) - mesmo a avaliação da sustentabilidade econômica, tão familiar à maioria das pessoas, precisa passar por uma revisão:

"Existe uma necessidade imediata de um novo conceito holístico de avaliação econômica. A sustentabilidade pode ser vista como um medida de eficiência, desde que definida por critérios complexos, amplos e de longo prazo, em lugar de critérios simples, estreitos e de curto prazo. Sustentabilidade é assim uma nova ordem de eficiência econômica, e que beneficia a todos os cidadãos, em vez de beneficiar alguns poucos em detrimento de muitos" (ROGERS, 2001, p. 154)

A busca do equilíbrio entre a dimensão [1] econômica, [2] social e [3] ecológica é chamada de Triple Bottom Line of Sustainability (Tripé da Sustentabilidade ou, ainda, Sustentabilidade Tripolar).

SACHS por sua vez (SACHS, 1994 apud MÜLFARTH, 2002) divide a abrangência do conceito de sustentabilidade em 5 aspectos:

- Sustentabilidade Social

- Sustentabilidade Econômica 
- Sustentabilidade Espacial

- Sustentabilidade Cultural

- Sustentabilidade Ecológica

Mas mantendo-se a divisão tripolar a mais habitual.

Até algum tempo atrás, alguns autores chamavam a atenção para o uso do termo "sustentabilidade" com diferentes acepções, o que provocou um certo desgaste e que veio alimentando a sua substituição, em alguns casos, por outras expressões consideradas mais recentes em contraposição ao cenário de fundo estabelecido, mesmo que tenham, essencialmente sentidos distintos. Expressões como: Arquitetura Verde, Arquitetura Bioclimática, Arquitetura Ecológica, entre outros. "Sem nenhum consenso, estes termos foram utilizados constantemente trazendo ainda mais incertezas" (COOK, 2001, apud MÜLFARTH, 2002, $33 p)$.

Mesmo a definição do Royal Institute of British Arcbitects (RIBA, 2000) para desenvolvimento sustentável:

"Desenvolvimento que aumenta a qualidade de vida e serve de objetivo para atingir eqüidade global na distribuição dos recursos da Terra por meio da conservação do seu capital natural e alcançando reduções significantes e permanentes em todas as formas de poluição especialmente a emissão de gases do efeito estufa." (RIBA, 2000, tradução livre do autor $)^{7}$

Não ajuda muito no trabalho do arquiteto, por exemplo.

Devido à abrangência da definição (BRUNDTLAND, 1987) ou à falta de especificidade (RIBA, 2000), MANSY (2005) sugere a seguinte definição de sustentabilidade para ser usada no âmbito do ambiente acadêmico de uma faculdade de arquitetura:

"Sustentabilidade é uma abordagem de projeto que mantém o balanço com o meio ambiente e a continuidade do desenvolvimento." (tradução livre do autor) (MANSY, $2005)^{8}$

Focando a idéia central de sustentar HAGAN (2001) apresenta uma definição de sustentabilidade associada com arquitetura definida simplesmente como:

“(...) arquitetura que contribui para permitir à natureza nos sustentar fisicamente,(...)” (HAGAN, 2001, p. 16, tradução livre do autor $)^{9}$

Assim, de certa forma, observam-se variações sobre a definição mais difundida de BRUNDTLAND sem que no entanto nenhuma corrompa seu valor estabelecido.

\footnotetext{
${ }^{7}$ Development which raises the quality of life and serves the goal of achieving global equity in the distribution of the Earth's resources whilst conserving its natural capital and achieving significant and sustained reductions in all forms of pollution especially emissions of greenhouse gases.

${ }^{8}$ Sustainability is a design approach that maintains both a continuing development and a balance with the environment.

${ }^{9}$ (...) architecture which contributes to allowing nature to physically sustain us(...)
} 


\subsubsection{EDIFÍcIOS “VERDES” E OUTRAS EXPRESSÕES}

MANSY (2005) relaciona algumas expressões que refletem o interesse e o foco da sociedade no tema amplo da sustentabilidade do ambiente construído:

- sustainable architecture,

- sustainable design,

- green architecture,

- environment-friendly architecture,

- solar architecture,

- low-energy architecture,

- energy-efficient design,

- bigh performance buildings,

- eco-design,

- ecological design,

- low-impact development,

- smart growth,

- passive design,

- energy-conscious design,

- climatic design,

- bioclimatic design,

- environmentally-intelligent,

- eco-effective, etc. e considera saudável esse processo de criação de expressões já que na história todo novo movimento experimentou certo conflito em busca de sua própria identidade.

Para HAGAN (2001) o termo green architecture deu lugar ao termo environmental architecture que por sua vez, atualmente, dá lugar ao termo sustainable architecture ${ }^{10}$.

Após a Conferência da Rio 92 o conceito de Green Design - design que considera os benefícios para o ambiente global - migrou para Sustainable Design - design que considera as dimensões econômica, social e ambiental (CESANO, 2002).

10 "Arquitetura Verde", "Arquitetura Ambiental" e "Arquitetura Sustentável", respectivamente (tradução livre do autor). 
Para a ASHRAE (GRUMMAN, 2003 apud GOWRI, 2004) o desenho verde ${ }^{11}$ é definido como aquele que é consciente e respeita a natureza e a ordem natural das coisas; é um desenho que minimiza os impactos negativos do homem no entorno natural, materiais, recursos, e processos que prevalecem na natureza.

O USGBC tem focado a expressão "alto desempenho" quando qualifica edifícios fazendo a expressão "edifício verde" perder espaço pelo fato de que a primeira responde aos três aspectos do tripé da sustentabilidade.

\subsubsection{ARQUITETURA DE BAIXO IMPACTO HUMANO E AMBIENTAL}

Em sua pesquisa sobre o impacto ambiental e humano da arquitetura MÜLFARTH (2002) define sustentabilidade como:

“... uma forma de promover uma busca de maior igualdade social, valorização dos aspectos culturais, maior eficiência econômica e um menor impacto ambiental na distribuição eqüitativa da matéria-prima, garantindo a competitividade do homem e das cidades." (MÜLFARTH, 2002, p7)

Como extensão do seu conceito de sustentabilidade, para MÜLFARTH (2002) a arquitetura sustentável seria:

“... uma forma de promover uma busca de maior igualdade social, valorização dos aspectos culturais, maior eficiência econômica e um menor impacto ambiental nas soluções adotadas nas fases de projeto, construção, utilização, reutilização e reciclagem da edificação, visando a distribuição eqüitativa da matéria-prima, garantindo a competitividade do homem e das cidades." (MÜLFARTH, 2002, p8).

O conceito é flexível por poder caracterizar a arquitetura, o projeto, o objeto construído, o processo de desenvolvimento e uso do objeto etc.

Porém, o conceito descrito não faz referência direta a um dos aspectos mais significativos da sustentabilidade: a ação de sustentar, perpetuar. Garantir às futuras gerações a mesma disponibilidade de recursos que dispomos hoje.

\subsubsection{AGENDA VERDE X AGENDA MARROM}

Seguindo a idéia de que a sustentabilidade varia conforme o ponto de vista (leia-se "contexto") a busca por uma cidade sustentável, por exemplo, "requer respostas particulares, guiadas, sim, por princípios e objetivos comuns, mas não determinadas por estes” (HAGAN, 2001, p. 178, tradução livre do autor $)^{12}$. A estrutura de prioridades para o desenvolvimento sustentável em países desenvolvidos e em

\footnotetext{
${ }^{11}$ Green design.

${ }^{12}$ These (sustainable cities) require particular responses, guided, yes, by general principles and aims, but not determined by them.
} 
desenvolvimento tem grandes distinções. A essas estruturas de prioridades diferentes denominaram-se Agenda Verde e Agenda Marrom ${ }^{13}$ (CIB, 2002).

Agenda Verde se concentra em reduzir o impacto ambiental da produção urbana, do consumo e da produção de resíduos nos recursos naturais e ecossistemas. A Agenda Marrom se concentra nos problemas da pobreza e do desenvolvimento, enfatizando a necessidade de reduzir os riscos ambientais à saúde e à qualidade de vida. Portanto a Agenda Verde tem mais relação com os países desenvolvidos enquanto a Agenda Marrom tem mais relação com os países em desenvolvimento.

\begin{tabular}{|l|l|l|}
\multicolumn{2}{l}{ Agenda Marrom } & Agenda Verde \\
\hline Preocupação chave & Bem-estar humano & Bem-estar do ecossistema \\
\hline Prazo & Imediato & Longo \\
\hline Escala & Local & Local para global \\
\hline Preocupação com & Grupos pobres & Gerações futuras \\
\hline Visão da natureza & Manipular e usar & Proteger e trabalhar junto \\
\hline Serviços ambientais & Providenciar mais & Usar menos \\
\hline
\end{tabular}

Tabela 1 - Quadro Comparativo entre Agenda Verde e Agenda Marrom (fonte: CIB, 2002)

\subsubsection{SUSTENTABILIDADE E DESENVOLVIMENTO SUSTENTÁVEL}

O conceito de desenvolvimento sustentável adotado neste trabalho é especificamente aquele divulgado pela World Commission on Environment and Development (WCED) (BRUNDTLAND, 1987), devido ao consenso em torno do mesmo e principalmente por descrever com precisão o aspecto da perpetuação da evolução humana.

"Desenvolvimento econômico e social que atenda as necessidades da geração atual sem comprometer a habilidade das gerações futuras atenderem as suas próprias necessidades".

Para MANSY (2005) a sustentabilidade como abordagem de desenho depende estritamente do contexto. O condicionamento do contexto local: seu clima, cultura, economia, disponibilidade de recursos etc. é, portanto, parte do conceito. Também, para este autor, a sustentabilidade ambiental somente não faz bons edifícios. É preciso atingir alto nível de qualidade também quanto à função, à estética e à durabilidade, por exemplo.

\subsubsection{ARQUITETURA SUSTENTÁVEL}

Por extensão ao conceito de desenvolvimento sustentável, a Arquitetura Sustentável seria uma das posturas expressas pela busca de soluções sustentáveis, ou seja, soluções que geram desenvolvimento sem comprometer a disponibilidade de recursos das futuras gerações.

\footnotetext{
${ }^{13}$ Green Agenda e Brown Agenda, respectivamente. Observa-se também que também é usada a expressão Agenda Azul aos assuntos que se referem à questão estratégica dos recursos hídricos.
} 
Essa postura seria expressa na forma de se projetar espaços construídos. No entanto é possível entender que o conceito pode ser expandido para outras atividades como a construção, o uso, o gerenciamento do mesmo espaço etc. Dessa forma, um profissional de arquitetura pode ter uma postura sustentável especificando um elemento de construção de baixa energia incorporada; seu poder de influência mostra seus limites quando se imagina que o agente construtor pode ainda assim usar, por exemplo, mão-deobra infantil ilegal ou não controlar a geração de resíduos no canteiro. Assim, talvez o projeto pudesse até ser chamado de sustentável, mas a construção e o edifício não mereceriam a mesma denominação.

É possível ainda dividir o conceito de arquitetura sustentável segundo o grau de sustentabilidade. Separando os empreendimentos em "verde claro", "verde mediano" e "verde escuro"14 (EDWARDS, 2005) para distinguir aqueles cujas [1] soluções são viáveis em pouco tempo, [2] soluções serão viáveis durante a vida útil do edifício e [3] soluções que são independentes das redes atuais e gerarão mais recursos e energia ao longo da vida útil do edifício do que ele gastou para ser construído.

\subsection{SISTEMAS DE AVALIAÇÃO}

Com o foco da indústria da construção civil em alguns países desenvolvidos, principalmente no norte da Europa, em aspectos relacionados à sustentabilidade do espaço construído, a demanda por formas de avaliar, mesmo que de maneira simplificada, o desempenho de edifícios e empreendimentos segundo esses aspectos incentivou a criação de diversos sistemas de avaliação ao redor do mundo.

Instituições tradicionais como o BRE e novas organizações como o USGBC criaram na década de 90 sistemas próprios para avaliar a sustentabilidade de edifícios e, ao mesmo tempo, incentivar a disseminação e evolução de princípios sustentáveis no panorama da indústria da construção civil.

Outras iniciativas de menor abrangência foram criadas e desenvolvidas por centros de pesquisa (CASBEE), empresas do ramo (SPeAR ${ }^{\mathrm{TM}}$ ), associações setoriais (HK-BEAM) etc.

Neste trabalho estão relacionados alguns dos sistemas mais populares em uso e divulgados no mundo. Observa-se, no entanto que existem iniciativas nacionais para a elaboração de sistemas de avaliação da sustentabilidade do espaço construído, em especial para a tipologia de edifícios de escritório, tidos como vetores em potencial para a implementação de tais sistemas. Como iniciativas nacionais destacam-se a contribuição de SILVA (2003) e GONÇALVES (2003) que propuseram um sistema de avaliação e indicadores de desempenho, respectivamente.

Enquanto SILVA (2003) contribuiu, especialmente, com a estrutura e temas de avaliação, GONÇALVES (2003) focou a criação de indicadores e sua aplicação em casos reais ao redor do mundo.

No entanto, reitera-se que o foco deste trabalho foi voltado para sistemas de avaliação efetivamente utilizados pelo mercado.

\footnotetext{
${ }^{14}$ Light green, mid green e dark green, respectivamente.
} 
Os sistemas considerados na pesquisa focam a escala do edifício, mas indicadores de diversas escalas influenciam o espaço construído e a indústria da construção civil no mundo. Desde a Organização das Nações Unidas na escala nacional, passando pela iniciativa do Construction Related Sustainability Indicators (CRISP) para todo o setor da construção civil até chegar aos sistemas como o LEED e o BREEAM na escala do edifício.

Com base na elaboração de SILVA (2003) foram relacionados os sistemas mais conhecidos de avaliação. Antes de ser um acervo de sistemas, instituições e ferramentas computacionais usados na avaliação da sustentabilidade do espaço construído, essa lista é um reconhecimento das iniciativas mais divulgadas e significativas. Nessa breve listagem são apresentados os sistemas mais presentes nas bibliografias consultadas.

\begin{tabular}{|c|c|}
\hline BREEAM & $\begin{array}{l}\text { Building Research Establishment Environmental Assessment } \\
\text { Method, Reino Unido. Sistema criado pelo BRE em } 1990 . \\
\text { Considerado o sistema mais antigo e que influenciou grande parte } \\
\text { dos sistemas posteriores, inclusive o LEED }{ }^{\mathrm{TM}} \text {. }\end{array}$ \\
\hline BEPAC & $\begin{array}{l}\text { Building Environmental Performance Assessment Criteria, Canada. } \\
\text { Sistema baseado no BREEAM que praticamente não foi usado, } \\
\text { mas deu origem ao GBC. }\end{array}$ \\
\hline GBC & $\begin{array}{l}\text { Green Building Challenge. Consórcio de iniciativas que criou, em } \\
\text { 1998, a ferramenta GBTool para avaliar edifícios. Tem como meta } \\
\text { abordar as características locais de cada local onde é aplicado. }\end{array}$ \\
\hline LEED $^{\mathrm{TM}}$ & $\begin{array}{l}\text { Leadership in Energy and Environmental Design. Sistema criado } \\
\text { pelo USGBC em } 2000 \text {, fortemente difundido nos EUA e com } \\
\text { influência na criação de outros sistemas pelo mundo. }\end{array}$ \\
\hline CASBEE & $\begin{array}{l}\text { Comprehensive Assessment System for Building Environmental } \\
\text { Efficiency. Japão. Introduzido em } 2002 .\end{array}$ \\
\hline HKBEAM & $\begin{array}{l}\text { Hong Kong Building Environmental Assessment Method. Iniciado } \\
\text { em } 1996 \text { inspirado no BREEAM. É uma iniciativa privada da The } \\
\text { Real Estate Developers Association of Hong Kong. }\end{array}$ \\
\hline Ecoprofile & $\begin{array}{l}\text { Sistema oficial de avaliação da Noruega. Coordenado pela } \\
\text { Byggforsk (Instituto Norueguês de Pesquisa de Edifícios). }\end{array}$ \\
\hline Miljöstatus & $\begin{array}{l}\text { Environmental Status. Sistema sueco de avaliação. Iniciado em } \\
\text { 1995, começou a atividade em 1997, sendo que, em 2002, já } \\
\text { estava na versão } 4 \text { e contava com aproximadamente } 2000 \\
\text { edifícios avaliados. }\end{array}$ \\
\hline NABERS & $\begin{array}{l}\text { National Australian Building Environmental Rating System. } \\
\text { Sistema de avaliação australiano, iniciado em } 2001 \text {, e com versão } \\
\text { piloto a ser lançada em 2003. Avaliação de edifícios de escritório e } \\
\text { residências. }\end{array}$ \\
\hline HQE & $\begin{array}{l}\text { Haute Qualité Environnementale. Sistema oficial francês de } \\
\text { avaliação de diversos tipos de edifícios. Em 2002, entrou em teste. }\end{array}$ \\
\hline $\mathrm{SPeAR}^{\mathrm{TM}}$ & $\begin{array}{l}\text { Sustainable Project Appraisal Routine, criado pela empresa de } \\
\text { engenharia Arup Group. Sistema privado de acesso e uso restrito } \\
\text { à empresa, usado para a avaliação da sustentabilidade de } \\
\text { edifícios. }\end{array}$ \\
\hline BEES $\AA$ & $\begin{array}{l}\text { Building for Environmental and Economic Sustainability. Software } \\
\text { produzido por Barbara Lippiatt no National Institute of Standards } \\
\text { and Technology nos EUA. Permite avaliar o desempenho } \\
\text { econômico e ambiental na escolha de materiais de construção. }\end{array}$ \\
\hline $\begin{array}{l}\text { Green } \\
\text { Globes }\end{array}$ & $\begin{array}{l}\text { Canadá. Sistema on-line de avaliação que faz parte do } \\
\text { BREEAM/Green Leaf. Uma versão para o Reino Unido foi lançada } \\
\text { em 2002. }\end{array}$ \\
\hline
\end{tabular}




\subsubsection{BREEAM - BUILDING RESEARCH ESTABLISHMENT ENVIRONMENTAL ASSESSMENT METHOD, REINO UNIDO}

A instituição responsável pelo sistema é o Building Research Establishment (BRE). Criado em 1990 pelo BRE, é considerado o mais antigo dos sistemas de avaliação como entendemos hoje e que embasou o desenvolvimento dos sistemas subseqüentes.

O sistema é atualizado regularmente a cada 3-5 anos. É usado em todo o Reino Unido com versões desse sistema adaptadas para o Canadá (BEPAC) e Hong Kong (HKBEAM).

Estima-se (SILVA, 2003) que entre 30\% e 40\% dos novos edifícios de escritório do Reino Unido sejam submetidos a esta avaliação anualmente. O sistema tem como usos:

- Edifícios de Escritório (seu uso original).

- Residências (com o nome de EcoHome).

- Edifícios Comerciais.

- Edifícios Industriais.

- Edifícios Educacionais.

- Edifícios para Saúde (por meio do NEAT - NHS Environmental Assessment Tool).

\subsubsection{BEPAC - BUILDING ENVIRONMENTAL PERFORMANCE ASSESSMENT CRITERIA, CANADA}

A Instituição responsável é o Instituto de Arquitetura da Universidade da Colúmbia Britânica em parceria com o BRE. Sua primeira versão para uso concluída em 1993 mas o programa também foi encerrado nesse mesmo ano.

Baseado no sistema BREEAM, o BEPAC tem seu uso restrito aos edifícios comerciais novos ou existentes, e é usado na província da Columbia Britânica, no oeste do Canadá. O BEPAC optou por diminuir o número de itens avaliados porém tornando-os mais detalhados e abrangentes (SILVA, 2003). Esse sistema tem uma aplicação prática pouco expressiva, mas que serviu como embrião do Green Building Challenge de 1996.

\subsubsection{GBC - GREEN BUILDING CHALLENGE}

O GBC é um consórcio internacional sob a coordenação da seqüência de conferências Sustainable Building (SB) que, por sua vez, foi absorvida pela iiSBE (International Iniciative for Sustainable Built Environment) em 2000. O GBC foi iniciado em 1996 sendo que a primeira conferência foi em Vancouver, Canadá em 1998. 
A avaliação é feita por meio de um software - GBTool — que utiliza indicadores de sustentabilidade. Divulgado em todo o mundo por meio das conferências internacionais, o sistema tem a meta ambiciosa de responder às particularidades de todos os lugares onde se deseja aplica-lo. Na prática, seu uso encontra grande obstáculo pela falta de dados consistentes sobre o real desempenho ambiental de materiais e processos de construção. Tem seu uso restrito à aos edifícios comerciais novos ou existentes.

\subsubsection{LEED - LEADERSHIP IN ENERGY AND ENVIRONMENTAL DESIGN, ESTADOS UNIDOS}

A instituição responsável pelo LEED é o USGBC nos Estados Unidos.

Criado pelo USGBC (fundado em 1993), o LEED entrou em operação em 2000 em sua versão 1.0. Hoje se encontra na versão 2.2 e conta com aproximadamente 3 mil projetos registrados e 410 projetos certificados.

Assim como o BREEAM, o sistema concede créditos para o atendimento de critérios préestabelecidos. A certificação é válida por 5 anos, quando uma nova solicitação de avaliação deve ser solicitada. O sistema tem revisão regular a cada 3 ou 5 anos, ou quando o USGBC observa essa necessidade (como por exemplo, quando da revisão de uma regulamentação ou de alguma inovação técnica).

Segundo SILVA (2003):

“O LEED é provavelmente o método disponível (2003) mais amigável enquanto ferramenta de projeto, o que facilita a sua incorporação à prática profissional.” (SILVA, 2003, p. 54)

Com uma estrutura simples, a ponto de receber críticas, o sistema é baseado em especificações de desempenho, em vez de critérios prescritivos, e toma como referência princípios de normas e recomendações de organismos terceiros com credibilidade reconhecida como ASHRAE, ASTM, EPA e o DOE (SILVA, 2003).

Um dos aspectos de maior singularidade do LEED é seu papel como documento consensual aprovado por diversas categorias da indústria da construção civil, e endossado por instituições do governo norte-americano, universidades e instituições de classe, etc.

Tendo grande aceitação em seu país de origem e, influenciando o desenvolvimento de sistemas locais internacionalmente, o LEED se apresenta como um dos sistemas de maior influência e abrangência do mercado da construção internacional. Esse aspecto será avaliado posteriormente ao longo deste trabalho.

Com a disponibilização das versões LEED-NC (New Construction), LEED-EB (Existing Buildings) e LEED-CI (Commercial Interiors) o sistema abarca uma grande variedade de tipologias que incluem edifícios novos, edifícios existentes e projetos de interiores comerciais, respectivamente. Outras versões mais específicas estão em desenvolvimento ou já em fase de testes, sendo estas: LEED-CS (Core \& Shell), LEED- 
H (Homes) e LEED-ND (Neighborbood Development) para edifícios de escritórios ("núcleo e envoltória"), edifícios residenciais e condomínios, respectivamente.

\subsubsection{CASBEE - COMPREHENSIVE ASSESSMENT SYSTEM FOR BUILDING ENVIRONMENTAL EFFICIENCY, JAPÃO.}

Desenvolvido pelo Japan Sustainable Building Consortium e apresentado na conferência internacional Sustainable Building de 2002 em Oslo na Noruega, o CASBEEE apresenta quatro ferramentas para avaliar o projeto ou o edifício existente em estágios específicos de seu ciclo de vida. Cada ferramenta é destinada a um tipo de usuário bem definido, como por exemplo: o proprietário, o projetista, o usuário, o agente imobiliário etc.

Com pouca divulgação dos resultados, o sistema se concentra quase que estritamente no Japão e tem seu uso restrito aos edifícios comerciais novos e existentes.

\subsection{INDICAÇÕES DA INFLUÊNCIA DO LEED ${ }^{\mathrm{Tm}}$}

Quanto à influência do LEED no seu país de origem, os EUA, fica patente o seu papel como sistema mais difundido ao se analisar o fato de que diversas instituições governamentais na escala federal, estadual e municipal aderiram ao USGBC e criaram programas em parceria com o LEED ${ }^{\mathrm{TM}}$. Dentre elas estão as seguintes agências federais (BD\&C, 2003):

- U.S. Department of Health and Human Services;

- U.S. Department of State;

- U.S. Environmental Protection Agency (EPA);

- General Services Administration (GSA) - Agência que administra prédios públicos federais em todo os EUA;

- National Aeronautics and Space Administration (NASA);

- National Park Service - Agência que administra os parques federais;

- U.S. Department of Energy (DOE);

- Department of Defense;

- Department of the Navy;

- U.S. Air Force;

- U.S. Army;

$\mathrm{Na}$ escala de governo municipal e estadual destacam-se (BD\&C, 2003):

- Austin, Texas; 
- Seattle, Washington;

- Portland, Oregon;

- Santa Barbara,Califórnia;

- Estado da Califórnia;

- Estado de Nova Iorque;

- Estado de Maryland;

- Estado do Oregon;

O sistema tem se afirmado como diferencial no mercado norte-americano e é uma exigência em muitas regulamentações municipais. Mesmo filiais de empresas japonesas nos EUA adotam o LEED ${ }^{\text {TM }}$. A Toyota Motor Company construiu um grande centro administrativo nos EUA usando o LEED e alcançando o nível GOLD de certificação.

Quanto à exigência do LEED em nível local destaca-se o caso do Prefeito de Seattle que, em 2000, proclamou que todos os novos edifícios públicos na cidade devessem atingir a certificação com nível GOLD do LEED 2.0 e atualmente a prefeitura municipal fornece assessoria técnica à iniciativa privada especificamente para que os novos empreendimentos sejam certificados pelo LEED ${ }^{\text {TM15. }}$.

Recentemente foi anunciado que o conjunto do World Trade Center (um dos empreendimentos de maior visibilidade do mundo na atualidade) tem como objetivo alcançar o nível GOLD do sistema de certificação do USGBC em todo o conjunto que engloba: a Freedom Tower, World Trade Center Office Towers 2, 3, e 4; e também o the World Trade Center Memorial e o Memorial Museum (USGBC, 2006c).

\footnotetext{
${ }^{15} 0$ andamento das ações e as formas de incentivo estão disponíveis e recebem atualização constante na página <http://www.seatlle.gov>.
} 

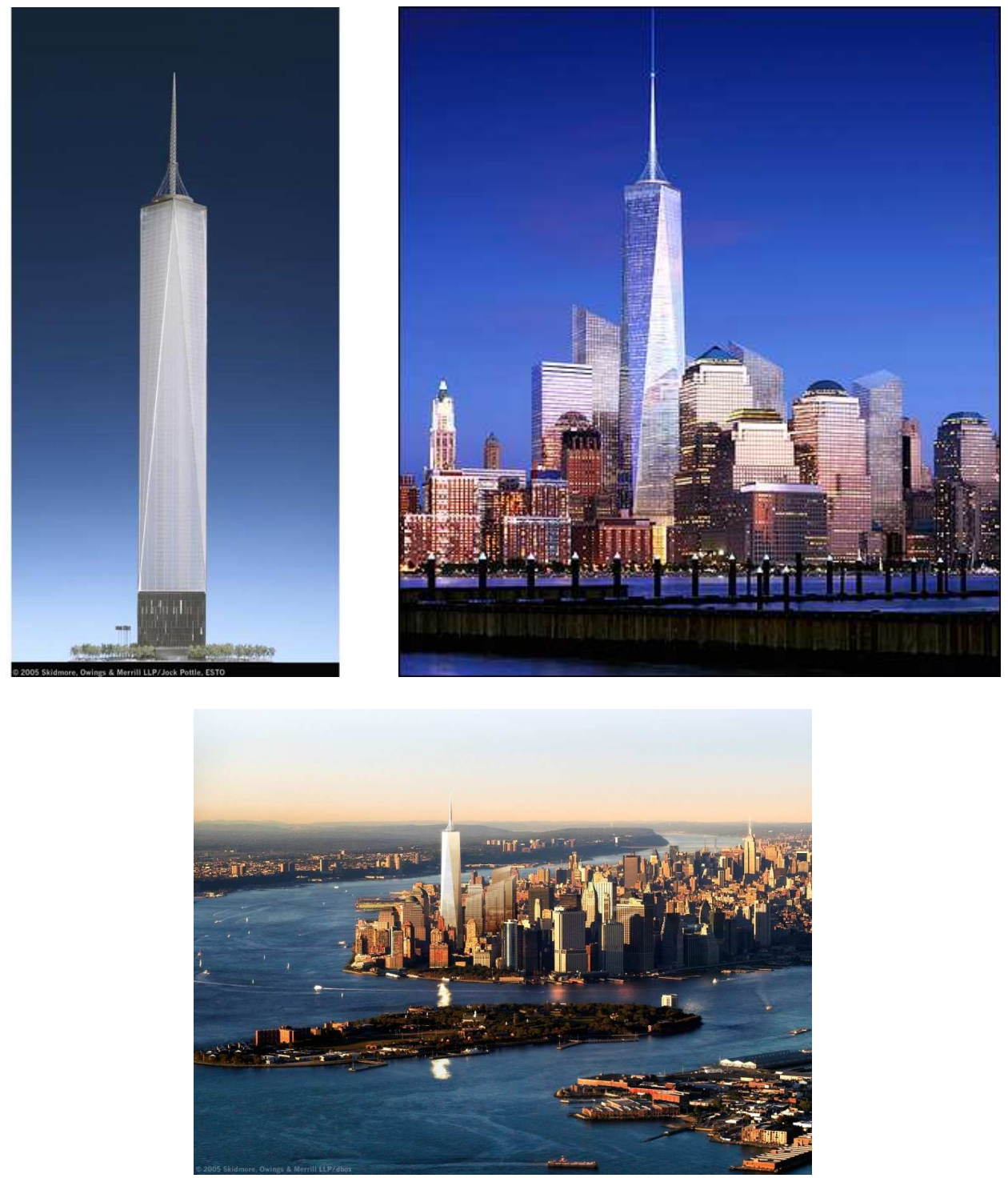

Figura 4 - Freedom Tower em Nova lorque (disponível em: <http://www.renewnyc.com/>)

\subsubsection{INFLUÊNCIA DO LEED NO MUNDO}

Pensado como uma instituição de convergência de informações e iniciativas, o USGBC foi criado ao redor de um consenso entre significativos agentes da indústria da construção civil americana (BD\&C, 2003). Esse consenso deu origem, então, a um sistema de avaliação da sustentabilidade ambiental - o LEED - com uma política explícita de ampliar a sua influência tanto nos EUA como internacionalmente (LEED STERRING COMMITTEE, 2003).

O USGBC já licenciou uma versão do LEED para ser usada no Canadá. O LEED-Canada já se encontra em operação e uma outra versão específica para o território canadense da Columbia Britânica já está em testes (BD\&C, 2003). Em Outubro de 2006 o país contava com 53 projetos certificados por algum sistema LEED dentre esses 19 com o LEED Canada-NC 1.0 (CAGBC, 2006). 
Está sendo desenvolvida uma versão do LEED para a Índia em associação com a Confederation of Indian Industries (CII) e o país já conta com edifícios certificados, em especial um edifício que hoje serve como sede do India Green Building Council, que alcançou o nível mais alto de certificação no LEED-NC 2.0, o nível Platinum (WILLIAMS, 2006).

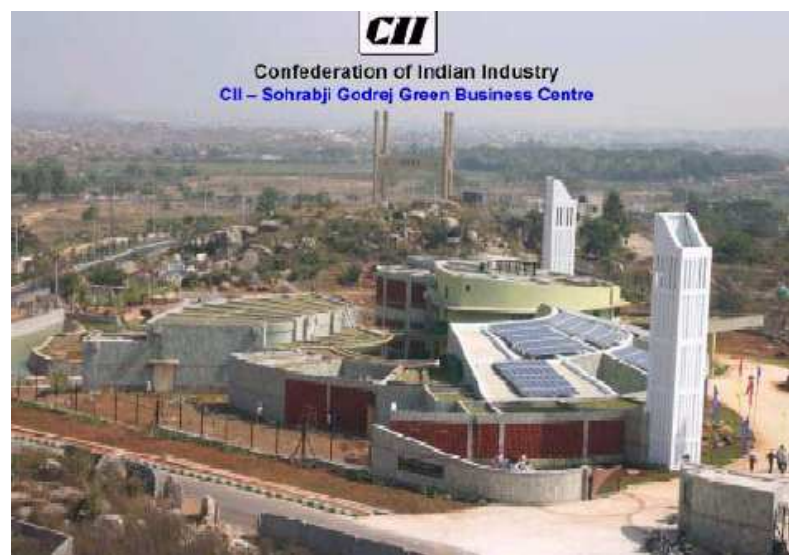

\section{Figura 5 - Sede do Índia Green Building Council certificado com o LEED-NC v2.0 nível Platinum (disponível em $<$ http://greenbusinesscentre.com/Documents/CII-Godrej+GBC.pdf $>$ )}

O LEED também inspirou a elaboração de um sistema de avaliação da sustentabilidade de residências chinês (ZHU, 2004).

Redes internacionais de hotéis têm grande interesse no uso de sistemas de avaliação estrangeiros ao redor do mundo, já que uma certificação dessa natureza é um diferencial estratégico para seu público internacional. A rede internacional de hotéis MARRIOTTT e a Universidade de Maryland, nos EUA, construíram um hotel com centro de conferências certificado pelo LEED (UMUC, 2005).

A iniciativa de se criar um conselho mundial para construção "verde" - World Green Building Council (WGBC) - por um dos fundadores do USGBC e idealizador do LEED - David Gottfried - permitiu e incentivou a criação de diversos centros similares ao USGBC ao redor do mundo. Esses centros trabalham, entre outras coisas, criando versões locais de sistemas de avaliação fortemente influenciados pelo LEED norte-americano, como é o caso do Canadá com o LEED Canada e a Índia com o LEED India em desenvolvimento. 


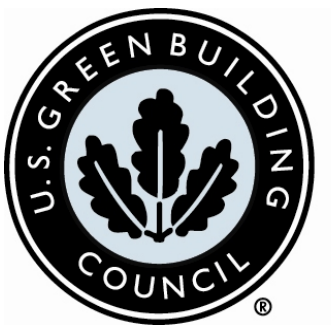

Figura 6 - Marca institucional do United States Green Building Council (USGBC, 2006).

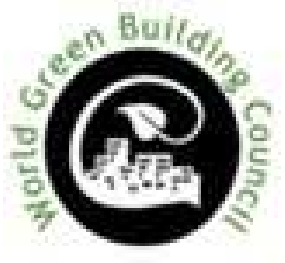

Figura 7 - Marca institucional do World Green Building Council (WGBC, 2006a).

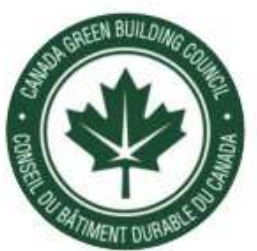

Canadá

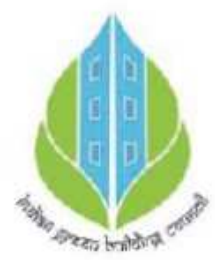

Índia

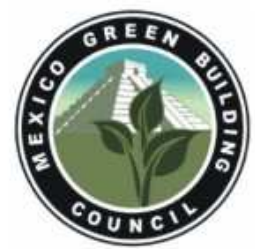

México

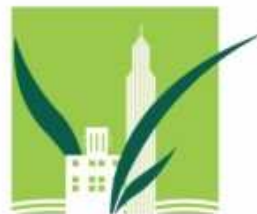

EmiratescBC

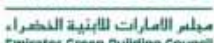

Emirados Árabes

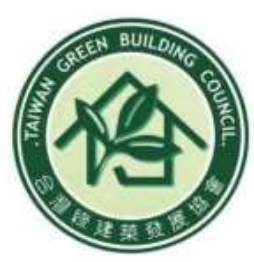

Taiwan green building council australia

\section{Austrália}

Figura 8 - Marcas institucionais dos Conselhos de Construção "Verde" nacionais (WGBC, 2006a).

\subsubsection{A INFLUÊNCIA DO LEED NO BRASIL}

A influência sócio-cultural dos EUA no Brasil tem diversos exemplos que já fazem parte do senso comum, especialmente na indústria da construção civil do Estado de São Paulo e na cidade de São Paulo.

Aqui se observam [1] especificações de edifícios de escritório sendo definidos por padrões norte-americanos, [2] empresas multinacionais com sede nos EUA implementando padrões de desempenho 
de seu país de origem, [3] mesmo materiais e elementos estéticos de arquitetura sendo explorados em edifícios de diversos usos usando referências norte-americanas, etc.

Para ilustrar essas questões vale citar os comentários de Andy Gruber ${ }^{16}$ em GONÇALVES (2003):

"No entendimento de Andy Gruber, o edifício de baixo impacto ambiental (o green building) para São Paulo segue o modelo e a filosofia de projeto que vem sendo elaborada nos Estados Unidos na última década, que é baseada no sistema LEEDTM" (GONÇALVES, 2003, p. 199).

O texto ainda comenta que:

"Paralelamente a isso, as pressões por uma gradual melhoria da eficiência energética e do desempenho ambiental global dos edifícios, se mostram como uma conseqüência futura natural.” (GONÇALVES, 2003, p. 199)

É importante destacar que o texto também faz referência ao que parece ser um dos maiores obstáculos para a disseminação de práticas sustentáveis no mercado de edifícios de escritório de alto padrão:

o custo.

"Segundo um grupo forte de investimentos no Brasil, a maior dificuldade para a implementação do LEED nos edifícios em São Paulo é ainda a falta de interesse do mercado local pelas questões de impacto ambiental.” (GONÇALVES, 2003, p. 199)

E ainda, em seqüência:

"A maior dificuldade local para a aplicação de novas idéias para a melhoria do desempenho energético e ambiental dos edifícios altos em São Paulo, na opinião de arquitetos e investidores, é a questão do custo.” (GONÇALVES, 2003, p. 199)

Considerando-se a possibilidade de que o LEED venha a ser difundido no Brasil como referência na elaboração de projetos de alto desempenho, são relacionados a seguir alguns fatos pertinentes:

[1] Grande parte das multinacionais instaladas no Brasil tem sua sede nos EUA, o que faz com que a política ambiental dessas mesmas empresas tenha grande alinhamento com instituições, agentes e iniciativas americanas. Sendo o LEED o sistema de avaliação mais influente e difundido nos EUA, é de se esperar que ele tenha mais probabilidade de ser inserido no país por essas empresas do que outros sistemas estrangeiros.

[2] Grandes empresas da indústria da construção civil internacional se uniram para formar o Sustainable Building and Construction Initiative (SBCI), a fim de promover práticas ambientais mais sustentáveis na indústria. A iniciativa tem uma política de incentivo aos sistemas de avaliação já instituídos, em especial os considerados como os três mais importantes: o BREEAM no Reino Unido, o HQE na França e o LEED nos EUA. Vale observar que 3 das 10

\footnotetext{
${ }^{16}$ Andy Gruber era, em 2003, representante da subsidiária brasileira - a Tishman Speyer e Método (TSM) — de uma das maiores incorporadoras e administradoras de edifícios de escritório do mundo: a Tishman Speyer. A representante no Brasil é sócia e administradora de edifícios de escritório no país, notadamente o Centro Empresarial Nações Unidas (CENU) e o conjunto Rochaverá Plaza (em construção).
} 
organizações fundadoras (Lafarge, Skanska, Sinotech, Arcelor, Monplaisir, Gravel, Martinet, Ademe, National Office of Potable Water (ONEP) e City of Madrid) são empresas multinacionais com subsidiárias no Brasil: a LAFARGE, a ARCELOR e SKANSKA.

[3] Dois dos conjuntos de edifícios de escritório de mais alto padrão do país — o Rochaverá em São Paulo e o Ventura Corporate no Rio de Janeiro - estão em processo de certificação do sistema LEED pela subsidiária brasileira de uma das maiores incorporadoras do mundo, a Tishman Speyer.

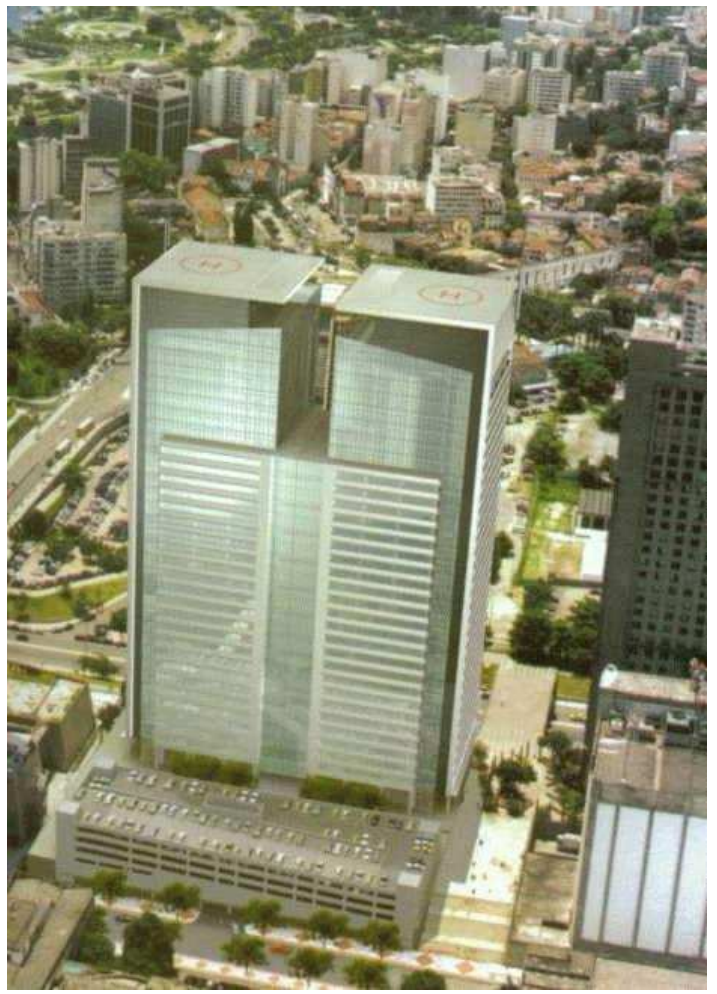

Figura 9 - Modelo eletrônico do Edifício Ventura Corporate. Empreendimento da Tishman Speyer no centro do Rio de Janeiro (EMPORIS BUILDING, disponível em: <http://www.emporis.com> acesso em: 02 de dezembro de 2006).

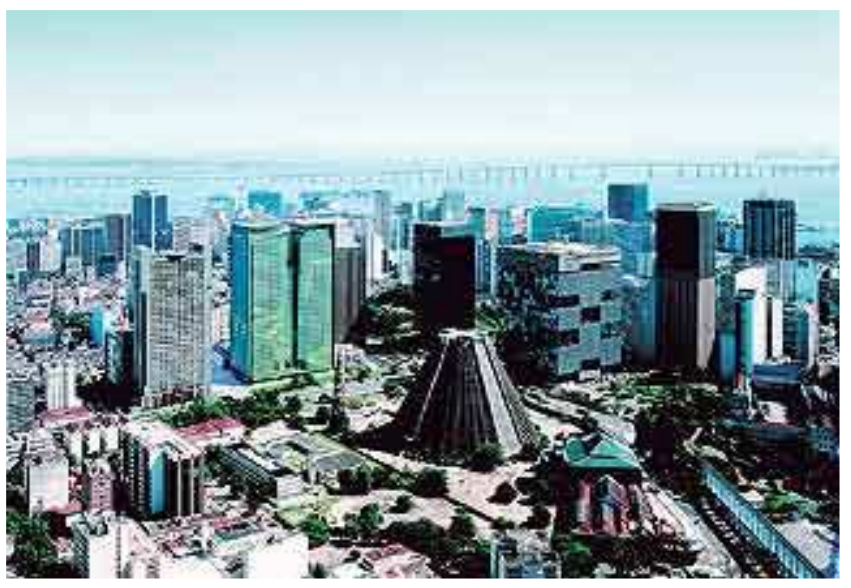


Figura 10 - Modelo eletrônico do Edifício Ventura Corporate e entorno. Empreendimento da Tishman Speyer no centro do Rio de Janeiro (EMPORIS BUILDING, disponível em: <http://www.emporis.com> acesso em: 02 de dezembro de 2006).
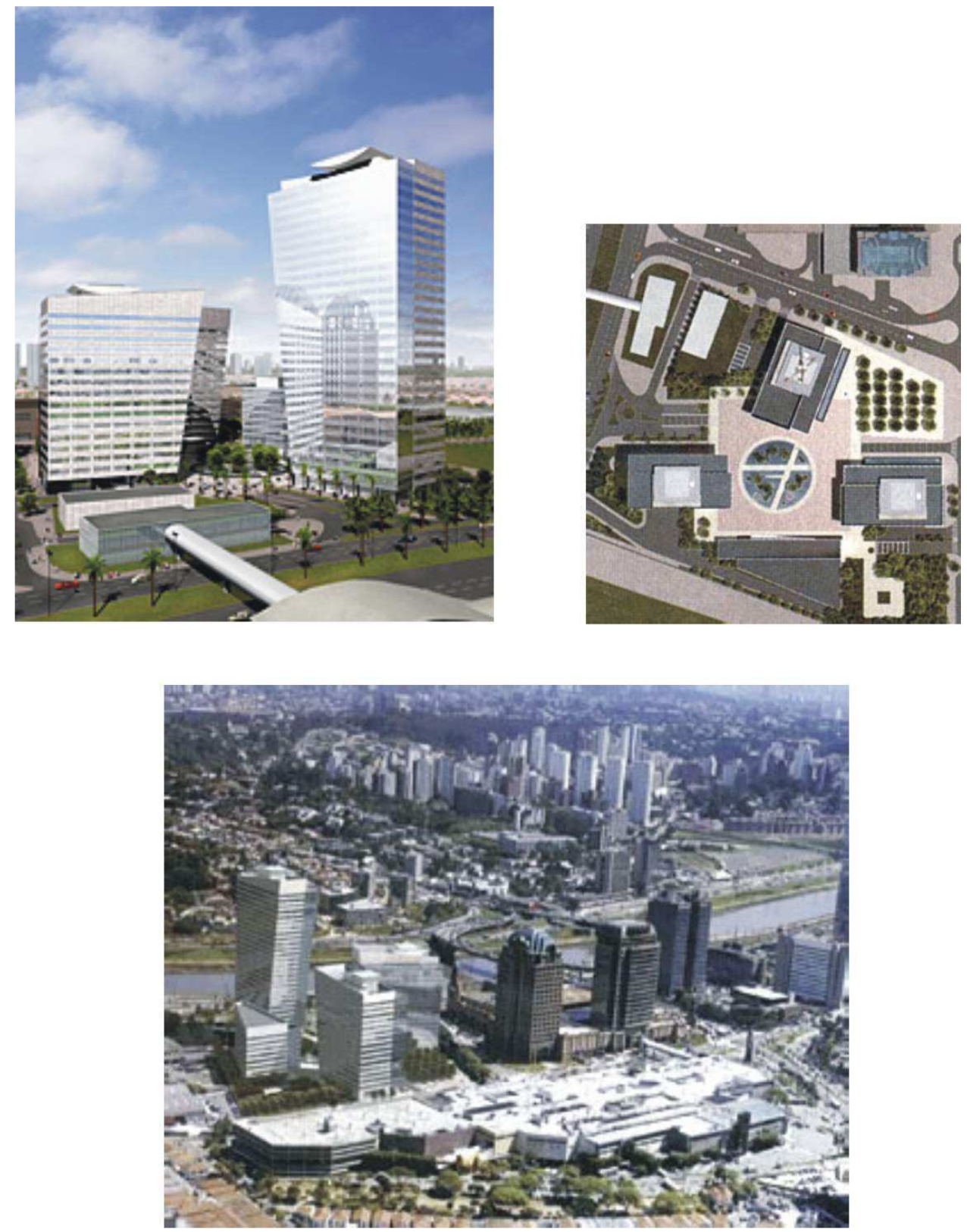

Figura 11 - Modelo Eletrônico do Edifício Rochaverá. Empreendimento da Tishman Speyer em São Paulo (EMPORIS BUILDING, disponível em: <http://www.emporis.com> acesso em: 02 de dezembro de 2006).

[4] A Petrobras, a maior empresa brasileira, elegeu o LEED para a certificação do projeto para o novo centro de pesquisas - CENPES II - projetado para a cidade do Rio de Janeiro (GONÇALVES, DUARTE, 2005). Apesar do projeto ainda não ser certificado, esse fato reforça o LEED como potencial presença no Brasil e ilustra uma situação típica de inserção do sistema norte-americano no país. Faz sentido entender que o uso do LEED pode ter grande sintonia com os interesses da empresa em valorizar sua imagem institucional no 
exterior, especialmente nos EUA, já que é uma das poucas empresas nacionais a ter suas ações negociadas na Bolsa de Valores de Nova Iorque (NYSE).
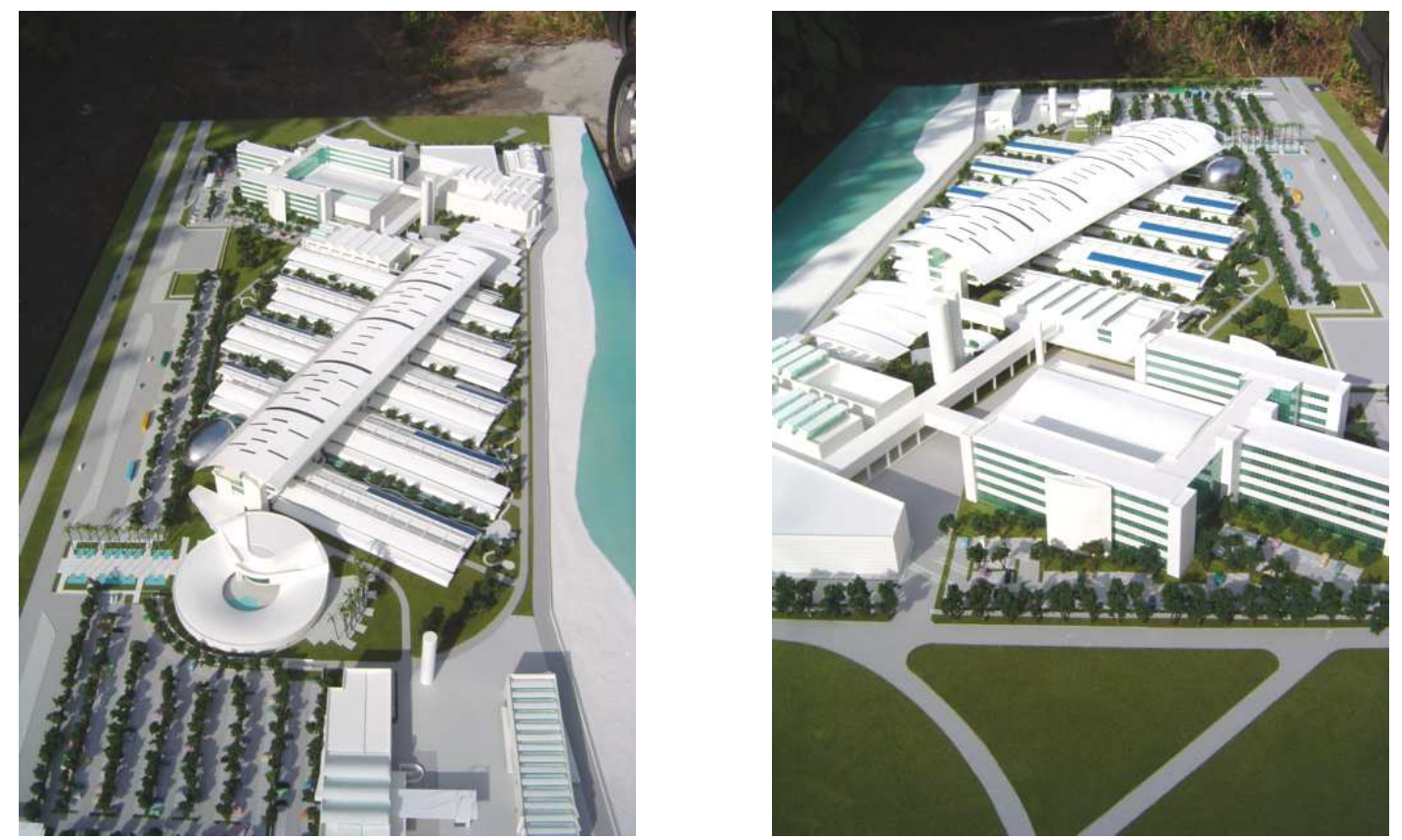

Figura 12 - Centro de Pesquisas da Petrobrás — CENPES II — na ilha do Fundão, Rio de Janeiro (LABAUT, 2006).

[5] Dentre outros empreendimentos brasileiros registrados para a certificação estão: o edifício comercial de escritórios Primavera Green Office em Florianópolis; a Seda da Serasa e o Edifício Eldorado Business Tower, ambos em São Paulo. Em Florianópolis o edifício comercial Primavera Green Office está em fase de desenvolvimento usando o LEED como "norteador do processo de projeto" (TRIANA, 2006). Esse empreendimento tem por objetivo ser certificado pelo LEED e usou os requisitos do sistema como base para a elaboração das diretrizes de projeto. 

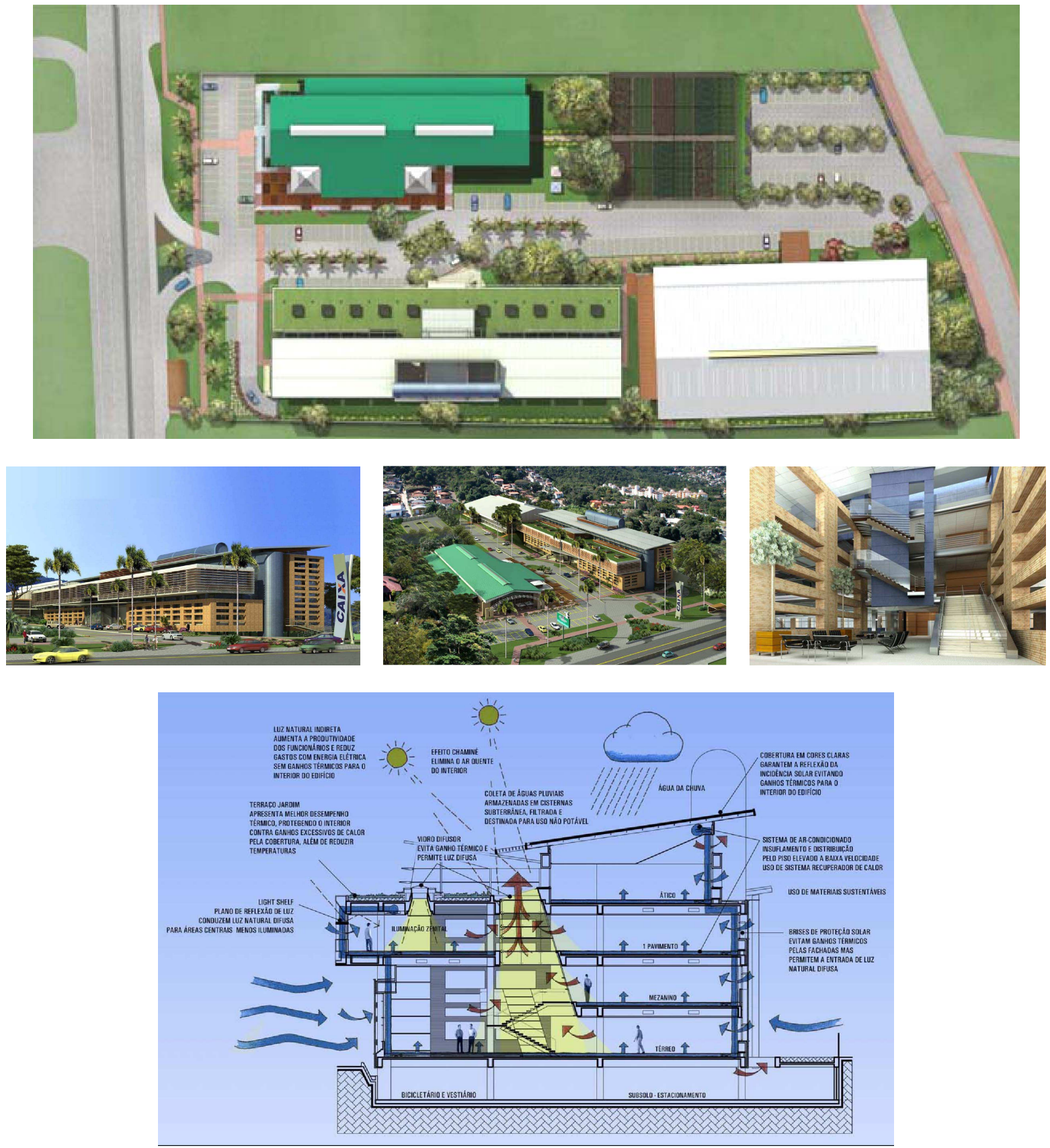

Figura 13 - Edifício Primavera Office Green em Florianópolis, SC. (LAMBERTS, 2006) 

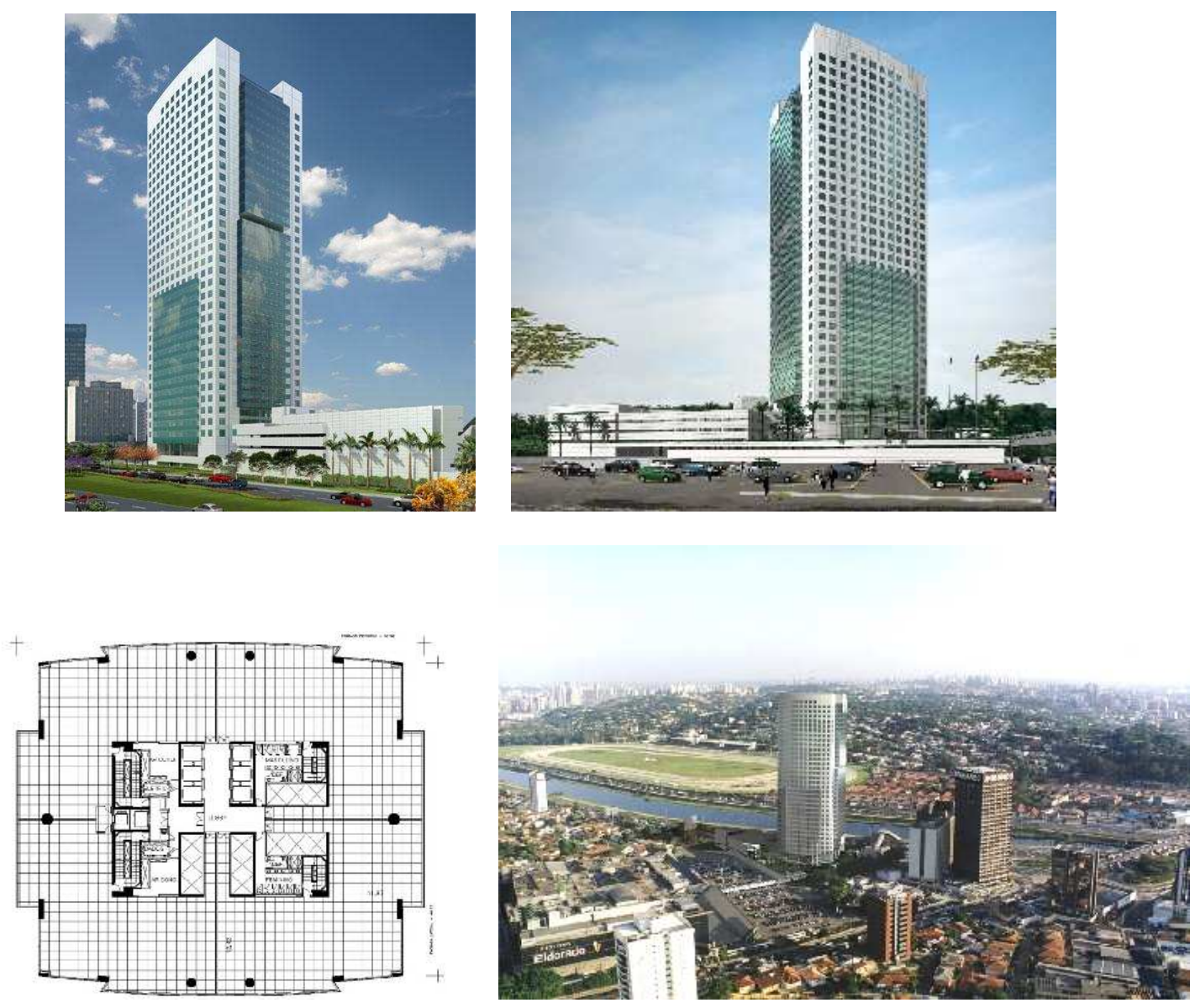

Figura 14 - Edifício Eldorado Business Tower em São Paulo, SP. (disponível em: $<$ http://www.cbrichardellis.com.br> acessado em: 28 de novembro de 2006).

[6] O uso de outros Sistemas de Avaliação no Brasil tem sido pouco divulgado, o que indica que, aparentemente, o LEED é um dos únicos até o momento.

Apesar de até o momento (dezembro de 2006) não constar nenhum empreendimento brasileiro certificado no Brasil cinco projetos aparecem como registrados em processo de certificação por algum sistema da família LEED (USGBC, 2006c). Sendo eles:

\begin{tabular}{llll}
\hline Eldorado Business Tower & Gafisa S/A & São Paulo, SP & LEED CS 2.0 \\
\hline Primavera Green Office & & Florianópolis, SC & LEED NC 2.1 \\
\hline Rochaverá Plaza & Tishman Speyer Properties & São Paulo, SP & LEED CS 2.0 \\
\hline Sede Serasa & Serasa & São Paulo, SP & LEED EB 2.0 \\
\hline Ventura Corporate Towers & Tishman Speyer Properties & Rio de Janeiro, RJ & LEED CS 2.0 \\
\hline
\end{tabular}

Tabela 2 - Lista pública de Projetos Registrados no USGBC para certificação (USGBC, 2006c). 


\subsubsection{FATORES PARA O APARENTE SUCESSO DO LEED ${ }^{\mathrm{Tm}}$}

Observando-se os motivos divulgados por autores independentes e pela própria instituição criadora do LEED ${ }^{\mathrm{TM}}$, o USGBC, para o aparente sucesso mercadológico desse sistema relacionam-se:

\subsubsection{SEU EFEITO CATALISADOR}

O LEED é tido com um grande divulgador/catalisador de princípios sustentáveis e boas práticas, mesmo que seja questionada a sua consistência como método de avaliação.

\subsubsection{CONSENSO NACIONAL}

Pelo menos em seu país de origem, o LEED apresenta um grande diferencial estratégico como elemento de consenso entre diversas classes de profissionais, órgãos governamentais das quatro esferas (nação, estado, condado e municípios), setores militares, agentes privados, centros de pesquisa, universidades, etc.

Um dos potenciais efeitos desse consenso é o fato de que, desde o seu nascimento, não se observaram notícias sobre o uso de outros sistemas de avaliação com o mesmo vulto em território americano.

\subsubsection{APOIO DE INSTITUIÇÕES PÚBLICAS CIVIS E MILITARES}

O apoio de instituições públicas civis e militares na divulgação e fortalecimento do uso do LEED nos EUA merece destaque particular pelo fato de que estas exercem um papel de determinante, tanto construindo e certificando edifícios - 2/3 de todos os projetos até 2003, segundo BD\&C (2003) - quanto fomentando e exigindo seu uso por meio de incentivos e regulamentos.

\subsubsection{CREDIBILIDADE}

Credibilidade conseguida por meio da associação da imagem institucional do LEED com agências do governo, associação de normas técnicas etc.

\subsubsection{WGBC - WORLD GREEN BUILDING COUNCIL}

A iniciativa de se criar o WGBC por um dos fundadores do USGBC e idealizador do LEED permitiu e incentivou a criação de diversos centros similares ao USGBC ao redor do mundo. Esses centros trabalham, dentre outras coisas, criando versões locais de sistemas de avaliação fortemente influenciados pelo LEED norte-americano, como é o caso do Canadá com o LEED Canada e a Índia com o LEED India em desenvolvimento.

Até o momento oito conselhos estão estabelecidos (WGBC, 2006b):

- Austrália - Green Building Council of Australia

- Canadá - Canada Green Building Council 
- Índia - Indian Green Building Council

- Japão - Japan Green Building Council

- México - Mexico Green Building Council

- Taiwan - Taiwan Green Building Council

- Estados Unidos - United States Green Building Council

- Emirados Árabes - Emirates Green Building Council

Também segundo o WGBC, outros conselhos encontram-se em desenvolvimento: Brasil, Chile, Grécia, Guatemala, Israel e Reino Unido. O que chama a atenção pelo fato do Reino Unido contar com um dos sistema mais antigos e bem sucedidos: o BREEAM.

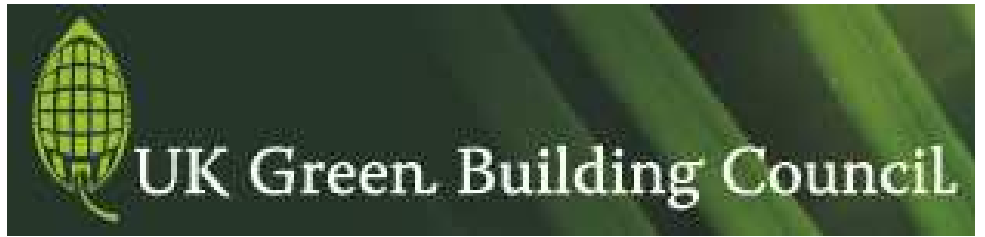

Figura 15 - Marca institucional do UK Green Building Council (disponível em: < http://www.ukgbc.org/> acessado em: 05 de dezembro de 2006)

\subsection{A INSERÇÃO dO LEEd NO PAís}

Neste item são relacionados aspectos que incentivam o uso do sistema de avaliação LEED no Brasil.

Considerando-se o fato de que o LEED já foi abordado em pelo menos dois empreendimentos de grande visibilidade nacional - o centro de pesquisas da Petrobras, o conjunto de escritórios do Rochaverá Plaza - faz sentido afirmar que, apesar de ainda não estar efetivada com um projeto plenamente certificado, a sua inserção já se iniciou da alguma forma. A disseminação do sistema, entendida como algo maior, mais intrincado e geograficamente abrangente, ainda não aconteceu. Porém, cabe observar que já é possível identificar fatores que possam viabilizar esse processo, sendo eles os seguintes vetores:

- Empresas Multinacionais

- Conselho Brasileiro para Construção "Verde"

- Afinidades com o Mercado

Seguem-se os itens pormenorizados:

[1] Empresas Multinacionais 
Esse vetor potencializante para uma eventual disseminação do uso do LEED no Brasil diz respeito ao papel de empresas multinacionais, provavelmente com suas sedes nos EUA, como divulgadoras do LEED no Brasil.

Essa empresas multinacionais funcionariam como um canal de comunicação de conceitos no sentido SEDE-SUBSIDIÁRIAS.

Grande parte das multinacionais instaladas no Brasil tem sua sede nos EUA, o que faz com que a política ambiental dessas mesmas empresas tenha grande alinhamento com instituições, agentes e iniciativas americanas. Sendo o LEED o sistema de avaliação mais influente e difundido nos EUA, é de se esperar que ele tenha mais probabilidade de ser inserido no país do que outros sistemas estrangeiros ou mesmo americanos.

Um cenário hipotético plausível seria o de uma empresa multinacional que já use o LEED na sua sede dos EUA e deseje aplicar, mesmo que precariamente, essa ferramenta no Brasil, para ter algum referencial de comparação do desempenho de todos os seus edifícios em um contexto internacional ou apenas como diferencial mercadológico.

[2] Conselho Brasileiro para Construção "Verde"

A criação de um Conselho Brasileiro para a Construção "Verde" nos moldes do WGBC, e com efetivos canais de comunicação com o USGBC, criaria o ambiente propício para o desenvolvimento de uma versão do LEED para a realidade nacional.

Um cenário hipotético plausível seria o de que esse BGBC (Brazilian Green Building Councit) usaria as iniciativas do Canadá e da Índia como referência e também desenvolveria uma versão LEED "Brazil". Cabe lembrar que pelo menos no Canadá e na Índia as versões do LEED sofreram adaptações pouco relevantes.

\section{[3] Afinidades com o Mercado}

Com sua política de responder às necessidades do mercado como ferramenta de marketing institucional, o LEED tem grande aceitação junto à iniciativa privada do seu país de origem e nos países que possuem versões licenciadas. Essa afinidade com o mercado também pode desempenhar um papel determinante no potencial de uso desse sistema no Brasil, dadas as evidências e à sintonia de alguns setores do mercado nacional da construção civil com os EUA e seus produtos. Como exemplos podemos citar [1] a importação, no Brasil, de projetos "fechados" para grandes empreendimentos imobiliários como também [2] o papel determinante de subsidiárias nacionais de grandes agentes imobiliários como a TishmanSpeyer.

Um dos aspectos significativos da afinidade entre o sistema LEED e o mercado da construção reside no fato de que, pela sua estrutura simples, linear, sem pesos e com perfil de créditos fixo, ele parece ao mercado a ferramenta adequada para comparações diretas entre empreendimentos os mais distintos, servindo assim ao propósito de ser um diferencial de mercado estratégico que gera competitividade (BD\&C, 2003). O fato curioso é que, nesse processo, o aspecto da competitividade retroalimenta a própria 
imagem institucional do sistema perante o mercado. Observa-se, no entanto, que, por mais força que tenha essa dinâmica, ela não prova, por si só, que o exercício dessas comparações seja de qualquer modo consistente e fundamentado.

Os fatos de que o LEED [1] é público, [2] tem seu material básico disponível gratuitamente pela internet, [3] pode ser considerado como relativamente de fácil aplicação e [4] tem o inglês como sua língua nativa também tem um efeito facilitador. 


\section{[CAPÍTULO 3] BASE EMPÍRICA}

\subsection{CONCEITOS E DEFINIÇÕES ADOTADOS}

A questão da sustentabilidade do espaço construído é essencialmente uma busca por formas mais eficientes de se lidar com os aspectos econômico, social e ambiental. A expressão Edifício de Alto Desempenho parece responder bem a essa idéia e por isso será adotada neste trabalho considerando-se que, independente de qualquer julgamento de mérito, o aparente grande potencial de influência do USGBC na divulgação e instituição da expressão "edifício de alto desempenho" terá papel significativo na sobrevivência da mesma.

Dessa forma, ao se falar em Edifício de Alto Desempenho refere-se a um espaço que foi projetado, construído, é usado, e será desconstruído tentando-se alcançar os mais altos níveis de eficiência nos três aspectos básicos da Sustentabilidade Tripolar, ou Tripé da Sustentabilidade (o Triple Bottom Line ambiental, social e econômico) visando a sustentabilidade, ou seja, garantir que as gerações futuras consigam suprir suas necessidades da mesma forma que nós, hoje.

No entanto, é preciso reforçar que para que algo seja tido como de Alto Desempenho é preciso que nenhum dos três aspectos básicos tenha sido negligenciado. Um edifício com alto desempenho ambiental e alto desempenho social que é inviável economicamente não pode ser considerado de alto desempenho. 
Essa expressão - Alto Desempenho - tem a flexibilidade necessária para se referir tanto a edifícios como produtos industriais, processos de produção, serviços, políticas públicas, enfim uma gama de ações e processos relacionados com todo o tipo de atividade humana sem a restrição do valor absoluto do termo SUSTENTÁVEL que obrigatoriamente está associado com a garantia de permanência no futuro.

De maneira didática, seria possível absorver o conceito de uma outra maneira. Tomando a economia como referência, e entendendo que capital financeiro é um recurso renovável, uma postura de alto desempenho econômico seria a de otimizar o uso de capital visando diminuir gastos e aumentar rendimentos, enfim, realizando lucros.

Desenhando uma analogia simples entre a dimensão econômica (que parece tão familiar) com as dimensões ambientais e sociais, poderia se tomar os recursos naturais como capital ambiental e o bemestar social ${ }^{17}$ como capital social. Várias referências, incluindo o BRE (2001) falam do grande potencial em se aplicar o conhecimento já desenvolvido para as questões econômicas (tão competitivas no ambiente de mercado capitalista) para as questões ambientais e sociais com a diferença de que muitas vezes ainda não é possível contar com um mercado "ambiental" ou "social" suficientemente maduro e competitivo.

A seguir, essa abordagem do tema Alto Desempenho é dividida em seus três componentes básicos segundo a divisão da sustentabilidade tripolar:

- Alto Desempenho Ambiental,

- Alto Desempenho Social,

- Alto Desempenho Econômico.

Nesse caso, a ordem escolhida (ambiental, social e econômico) expressa uma certa ordem cronológica e de prioridade que contrasta com a que usualmente se observa no mercado ${ }^{18}$. A questão ambiental viria em primeiro lugar pelo fato de que o ambiente natural estava aqui antes de se formarem as sociedades humanas; em seqüência tem-se a questão social antes da econômica, pelo fato de que a semente das sociedades humanas teve origem antes do surgimento da economia como a entendemos hoje ${ }^{19}$.

Não é consistente se falar em arquitetura sustentável pelo fato de que não se consegue definir ainda de maneira satisfatória o patamar absoluto de sustentabilidade segundo a própria definição da palavra, ou seja, a garantia da permanência. Os sistemas de avaliação se propõem a avaliar se estamos mais próximos ou não desse estado sem, no entanto, podermos afirmar afinal qual estado é esse (SILVA, 2003 p. 139).

\footnotetext{
${ }^{17}$ Bem-estar social neste caso em específico deveria ganhar um sentido amplo. Bem-estar social reuniria não somente as questões imediatas de saúde e educação mas, também, por exemplo, as questões de identidade cultural e histórica de uma comunidade, região e/ou país. Em um caso extremo nessa reflexão, uma língua indígena em extinção pode ser tratada como capital "social".

${ }^{18}$ No mercado, devido à competição capitalista, a questão econômica é tida como anterior e principal sobre as questões Ambientais e Sociais. Fica fácil constatar o fato ao se comparar a importância que se dá ao balanço financeiro anual de uma empresa sobre seus balanços anuais sociais e ambientais.

${ }_{19}$ Pode-se chegar à mesma conclusão usando uma abordagem diferente, a de necessidades básicas. Tomando as necessidades básicas elementares do homem como ponto de partida pode-se dizer: de nada valem as conquistas de bens de capital sem o bem-estar social e de nada vale 0 bem-estar social se não existe água para beber ou ar para respirar.
} 
Considerando isso fica clara a tendência de se referir à arquitetura de alto desempenho ambiental e não arquitetura sustentável.

O Alto Desempenho Ambiental significa ativamente buscar garantir às gerações futuras a mesma disponibilidade de recursos naturais de que se dispõe hoje. Poluir menos, usar menos energia, diminuir a demanda por matérias-primas, reciclar materiais de construção, etc. Como exemplo pode-se dizer que um edifício de Alto Desempenho Ambiental é pensado para usar materiais com baixa energia incorporada, economizar energia, permitir uma desconstrução com baixo incremento de energia, etc. O "lucro ambiental" é conseguido por meio da diminuição dos "empréstimos" de recursos naturais e, eventualmente, da geração de novos recursos (como por exemplo, aumentar a biodiversidade urbana e a área permeável de uma área já urbanizada por meio de uma reformulação de uso).

O Alto Desempenho Social significa melhorar o bem-estar humano por meio da saúde, educação e valorização da identidade cultural. Como exemplo, pode-se dizer que um edifício de Alto Desempenho Social busca "lucro social" quando melhora ou, pelo menos, não piora o bem-estar social da comunidade onde está inserido, valoriza a identidade local e o patrimônio histórico, evita a segregação espacial, etc.

O Alto Desempenho Econômico refere-se a melhorar a eficiência financeira do empreendimento, a valorização de capital, o retorno do investimento, etc. Como exemplo pode-se dizer que um edifício de Alto Desempenho Econômico é pensado para aumentar a produtividade dos seus ocupantes, diminuir custos com manutenção, valorizar o capital investido, aumentar a velocidade do retorno do investimento, diminuir a taxa de vacância, etc. O "lucro econômico", lucro financeiro ou simplesmente lucro resulta das estratégias e posturas implementadas no edifício que permitem diminuir custos e aumentar rendimentos, basicamente.

Devido à demanda global por recursos naturais ilustrada pelo grande impacto da indústria da construção civil, conclui-se que seria pertinente não alinhar tão proximamente sustentabilidade com equilíbrio. Vive-se hoje um grande desequilíbrio instituído. A humanidade exige mais da capacidade ecológica da biosfera do que esta é capaz de suprir. Para equilibrar a balança não basta apenas começar agora a igualar as demandas atuais à capacidade do planeta. Há que se procurar o desequilíbrio no outro prato da balança. São necessárias iniciativas que tenham um grande impacto positivo no outro extremo, aumentando a capacidade do planeta, além de somente diminuir as demandas atuais. Desta forma estaríamos mais perto de reparar o grande "saldo negativo" que já somos obrigados a administrar. Mais consistente com a realidade atual não seria equilibrar saldo e sim procurar realizar "lucros", grandes "lucros" nas três áreas essenciais que compõem o cerne do conceito de sustentabilidade: a área econômica, social e ambiental. É evidente que abordar qualquer questão que compreenda esses três aspectos tem obrigatoriamente um elevado grau de desafio e complexidade, mas, ao que parece, o "desequilibrio positivo" continuaria a ser o objetivo mais sensato. 
Analisando-se o histórico da evolução das questões e dos termos relacionados com a sustentabilidade do ambiente construído, é possível especular que o que se espera da evolução natural das questões de sustentabilidade é que elas se firmem cada vez mais, conforme se pronunciam as demandas sociais e ambientais no planeta, a exemplo das demandas econômicas que já vêm sendo enfrentadas com mais eficiência. Dessa forma a sustentabilidade que antes era considerada vanguarda em áreas como a arquitetura e o urbanismo, hoje tende a se tornar consenso e prática comum. De certa maneira pode-se dizer, basicamente, que vamos nos referir a Arquitetura de Alto Desempenho Ambiental, depois então a Arquitetura de Alto Desempenho (que considera ainda mais aspectos), para voltarmos a nos referir simplesmente à Arquitetura; indo da inovação até a incorporação dos conceitos de alto desempenho na prática comum, em um processo de transferência de tecnologia como se verifica em diversos outros processos e produtos. O esforço então seria o de fazer, por exemplo, com que um dia não fosse necessário usar termos como Alto Desempenho para caracterizar um projeto de arquitetura porque essa busca incessante e consistente pela alta eficiência estaria implícita.

\subsection{O SISTEMA LEED ${ }^{\mathrm{TM}}$}

$\mathrm{Na}$ busca por edifícios de alto desempenho ambiental uma iniciativa se destaca pela abrangência em um dos mercados de construção civil mais influentes do mundo: o norte-americano. O sistema de avaliação LEED é uma iniciativa do USGBC que certifica edifícios com uma nota de sustentabilidade ambiental de acordo com a quantidade de créditos que alcançados em um checklist de quesitos. Para os edifícios certificados, existe uma divisão em categorias, sendo elas CERTIFIED, SILVER, GOLD e PLATINUM da menor para a maior nota.

\subsubsection{HISTÓRICO DA INICIATIVA}

A origem do LEED como sistema de avaliação se confunde com a história do USGBC (BD\&C, 2003). Sob a iniciativa de alguns poucos agentes individuais ${ }^{20}$, durante a década de 80 , foram conduzidas reuniões com representantes do mercado de construção civil nos estados unidos, em associação com órgãos governamentais e associações de classes, dentre os quais destacam-se:

- American Institute of Arcbitects (AIA) Committee on The Environment,

- Rocky Mountain Institute,

- Greening America,

- Flack + Kurtz Engineering Consultants,

- Armstrong industries,

- Carrier Corporation,

\footnotetext{
${ }^{20}$ Em especial David Gottfried — um construtor e incorporador americano — e Michael Italiano — um advogado atuante na área ambiental.
} 
- Herman Miller Inc.,

- Interface Inc.,

- Department of Energy (DOE),

- The National Institute of Standards \& Technology (ASTM),

- Naval Facilities Engineering Command etc.

Em 1993, incorporados como United States Green Building Council (USGBC), esses agentes definiram como sua prioridade a criação de um sistema de avaliação da sustentabilidade por meio da American Society of Testing and Materials (ASTM).

Nos dois anos que se seguiram, os esforços de se criar o sistema de avaliação por meio da ASTM se mostraram frustrantes, na perspectiva do USGBC, devido ao alegado rigor e demora na sua elaboração.

Em 1995 foi abandonada a idéia de se elaborar o sistema por meio do ASTM em favor do desenvolvimento independente. Rob Watson, cientista de um Conselho de Defesa de Recursos naturais (NRDC) se tornou presidente do comitê responsável pela elaboração do LEED - Leadership in Energy and Environmental Design.

Pelos próximos três anos, o comitê de Watson considerou e rejeitou diversos sistemas de avaliação como: o Green Builder Program da cidade de Austin no Texas, o modelo canadense BEPAC e o Green Building Challenge.

Segundo BD\&C (2003), mesmo a escolha óbvia do sistema do BRE, o BREEAM, foi rejeitada pelos seguintes fatores: [1] precisava de uma grande infra-estrutura de assessores certificados oficiais para o país inteiro e também [2] focava muito a redução de emissões de $\mathrm{CO}_{2}$ enquanto o comitê do LEED desejava abordar um espectro maior de impactos energéticos.

Após uma sucessão de avanços e retrocessos, o USGBC aprovou, no final de 1998, o LEED em sua versão inicial 1.0. Em poucos meses um programa piloto foi lançado com o apoio do Federal Energy Management Program ${ }^{21}$ (FEMP). O esboço de um guia de referência foi elaborado para ajudar os interessados em participar, e edifícios totalizando mais de $93.000 \mathrm{~m}^{2}$ foram registrados no primeiro ano de atividade.

O programa-piloto mostrou as limitações do LEED 1.0. Segundo Watson, alguns dos 40 créditos que poderiam ser ganhos eram ou muito restritivos ou já eram práticas-padrão de mercado e os créditos relacionados com energia não tinham relação suficiente com o desempenho.

Com a constatação de que a versão 1.0 precisava ser revisada, foi elaborada a versão 2.0. Em 2000, o LEED 2.0 aumentou os créditos disponíveis para 69 e os limites para as diversas categorias -

\footnotetext{
${ }^{21} 0$ Federal Energy Management Program é uma iniciativa do governo federal norte-americano de melhorar a eficiência de seu CONSUMO de energia nos edifícios e instalações governamentais.
} 
BRONZE (agora CERTIFIED), SILVER, GOLd e PLATINUM — foram aumentados. O guia de referência também foi revisado e ampliado.

Em novembro de 2002, foi lançada a versão LEED 2.1, que já contava com o nome de LEED-NC (New Construction) mas não apresentava nenhuma mudança significativa na estrutura dos créditos ou de seus requisitos.

Na revisão da versão 1.0 para 2.0 do sistema LEED foi notado um fato curioso. O LEED mudou o nome da categoria BRONZE da versão 1.0 para simplesmente CERTIFIED (certificado) na versão 2.0. Como simples exercício de especulação, é interessante questionar se essa alteração se deve ao apelo mercadológico do mercado em preferir que um empreendimento seja considerado "certificado" ao invés de ser comparado com a medalha de bronze, a menos valorizada. Talvez dessa forma fosse evitada uma comparação constrangedora para a maioria dos empreendimentos certificados.

Como breve resumo histórico do LEED-NC, os fatos mais marcantes foram (USGBC, 2006):

[1] 1998 - Agosto: LEED-NC v1.0 é lançado pelo USGBC.

[2] 2000 - Março: LEED-NC v2.0 é lançado com alterações significativas de conteúdo.

[3] 2002 - Novembro: LEED-NC v2.1 é lançado com pequenas alterações principalmente no processo burocrático de certificação.

[4] 2005 - Novembro: LEED-NC v2.2 é lançado com atualizações de normas, definições mais claras e pequenas adaptações de conteúdo.

O USGBC, desde 2003, conta com o apoio de alguns agentes nos EUA, tais como:

- O General Services Administration (GSA) - organização federal que administra os edifícios públicos federais de todo o país - exige que todos os projetos alcancem a categoria SILVER do LEED ${ }^{\mathrm{TM}}$.

- A Marinha, o Exército e a Aeronáutica dos EUA adotam o LEED para o desenvolvimento dos projetos de seus edifícios novos e reformas, e estão adaptando o LEED para suas necessidades específicas.

- Empresas privadas Internacionais como a FORD, a Steelcase, a PNC Financial Services e a Toyota adotam o LEED ${ }^{\mathrm{TM}}$.

- Governos de Estados, Condados e Cidades nos EUA estão incorporando o LEED ${ }^{\mathrm{TM}}$, tanto na produção de edifícios públicos, como nas exigências legais para novas construções.

- Universidades americanas como, por exemplo, Mellon University, estão tornando o LEED padrão para novas construções em seus campi.

Em 2004 foram lançadas as versões do LEED específicas LEED-EB (Existing Buildings para edifícios existentes), LEED-CI (Comercial Interior para projetos de interiores comerciais) e LEED-CS (Core \& Shell 
para projetos de núcleo e casca como grandes edifícios comerciais de escritórios). Ainda as versões LEED-H (Homes para residências) e LEED-ND (Neighborhood Development para condomínios e loteamentos) estão em desenvolvimento.

Segundo o USGBC, existem na atualidade (maio de 2006) quase 3.000 projetos registrados e 410 certificados (337 LEED-NC, 26 LEED-EB, 40 LEED-CI e 7 LEED-CS). Dados de 2003 (BD\&C, 2003) mostravam que a metade dos projetos registrados no LEED (cerca de 48\%) eram do governo (federal, estadual e local). Dados mais recentes (USGBC, 2006b) mostram que a participação dos projetos do governo tem se mantido constante (cerca de 46\%).

\section{Quem está fazendo o LEED}

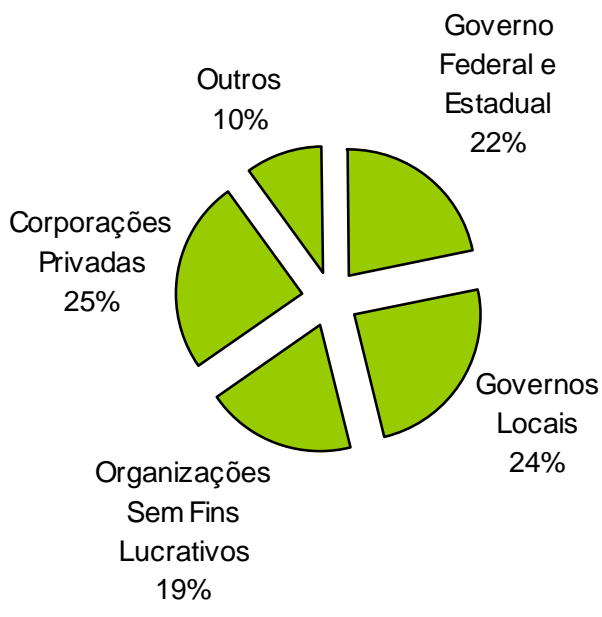

Gráfico 1 - Quem está fazendo o LEED (USGBC, 2006b)

O LEED foi licenciado para ser usado em todo o Canadá, e tem sido usado como referência para elaboração de sistemas locais de avaliação em outros países. A política de expansão internacional do LEED agora se expressa através do WGBC, como se vê na declaração do vice-presidente do LEED ${ }^{\mathrm{TM}}$, Nigel Howard:

O conselho do USGBC e seus profissionais determinaram que a melhor forma de trabalhar internacionalmente é por meio do World Green Building Council. (WILLIAMS, 2004, tradução do autor)

Recentemente a versão LEED-NC 2.2 foi lançada, mas também não apresenta alterações significativas na estrutura de créditos, apenas algumas revisões de desempenho (algumas normas foram atualizadas) e alterações na forma de se conseguir alguns créditos. 


\subsubsection{O LEED-NC}

O LEED-NC foi escolhido como objeto desta pesquisa pelo fato de que [1] é o sistema LEED mais antigo - o que permite traçar uma evolução histórica de seu uso — [2] é o sistema com maior número de projetos registrados e certificados e [3] é considerado o LEED mais versátil por poder ser aplicado quando nenhum dos outros produtos se enquadra no perfil do projeto.

\subsubsection{PROPOSTA E EVOLUÇÃO HISTÓRICA DO LEED'TM, SEGUNDO O USGBC}

Segundo o USGBC (2004) a missão do sistema é:

O LEED encoraja e acelera a adoção global de edifícios sustentáveis e práticas de desenvolvimento por meio da criação e implementação de padrões universalmente entendidos e aceitos, ferramentas e critérios de desempenho. (USGBC, 2004, tradução do autor $)^{22}$.

A proposta de política internacional do sistema é expressa no próprio manual de políticas do LEED $^{\mathrm{TM}}$, como meta estratégica, da seguinte maneira:

Consolidar o LEED como padrão para a prática de edifícios sustentáveis para nossas casas, edifícios não-residenciais e empreendimentos por todos os EUA e internacionalmente. (USGBC, 2004, p. 7, tradução do autor).

O LEED foi pensado para ser uma ferramenta de avaliação da sustentabilidade de fácil assimilação pelos diversos agentes relacionados com o espaço construído. Por causa disso, tem como característica ter iniciado (na versão 1.0) com algumas exigências que já faziam parte do padrão da indústria da construção e, a partir desse ponto, constantemente aumentar as exigências conforme o mercado for se adaptando.

O sistema já sofreu três revisões $(2.0,2.1$ e 2.2$)$ e a versão 3.0 já está sendo produzida.

Apesar do sistema ter se iniciado com exigências pouco orientadas ao desempenho, faz parte da política divulgada pelo USGBC tender a formas mais sofisticadas de avaliação. Mesmo conceitos de LCA já fazem parte de alguns créditos do sistema e tendem a ser incorporados de maneira mais abrangente e efetiva com o passar do tempo (LEWIS, 2003).

Pensado originalmente para catalisar a implementação de práticas sustentáveis no mercado da construção, a proposta do LEED é a de alcançar pelo menos $25 \%$ de todo o mercado da construção nos EUA, contaminando, a partir daí, todo o mercado americano.

22 "LEED encourages and accelerates global adoption of sustainable green building and development practices through the creation and implementation of universally understood and accepted standards, tools and performance criteria". 


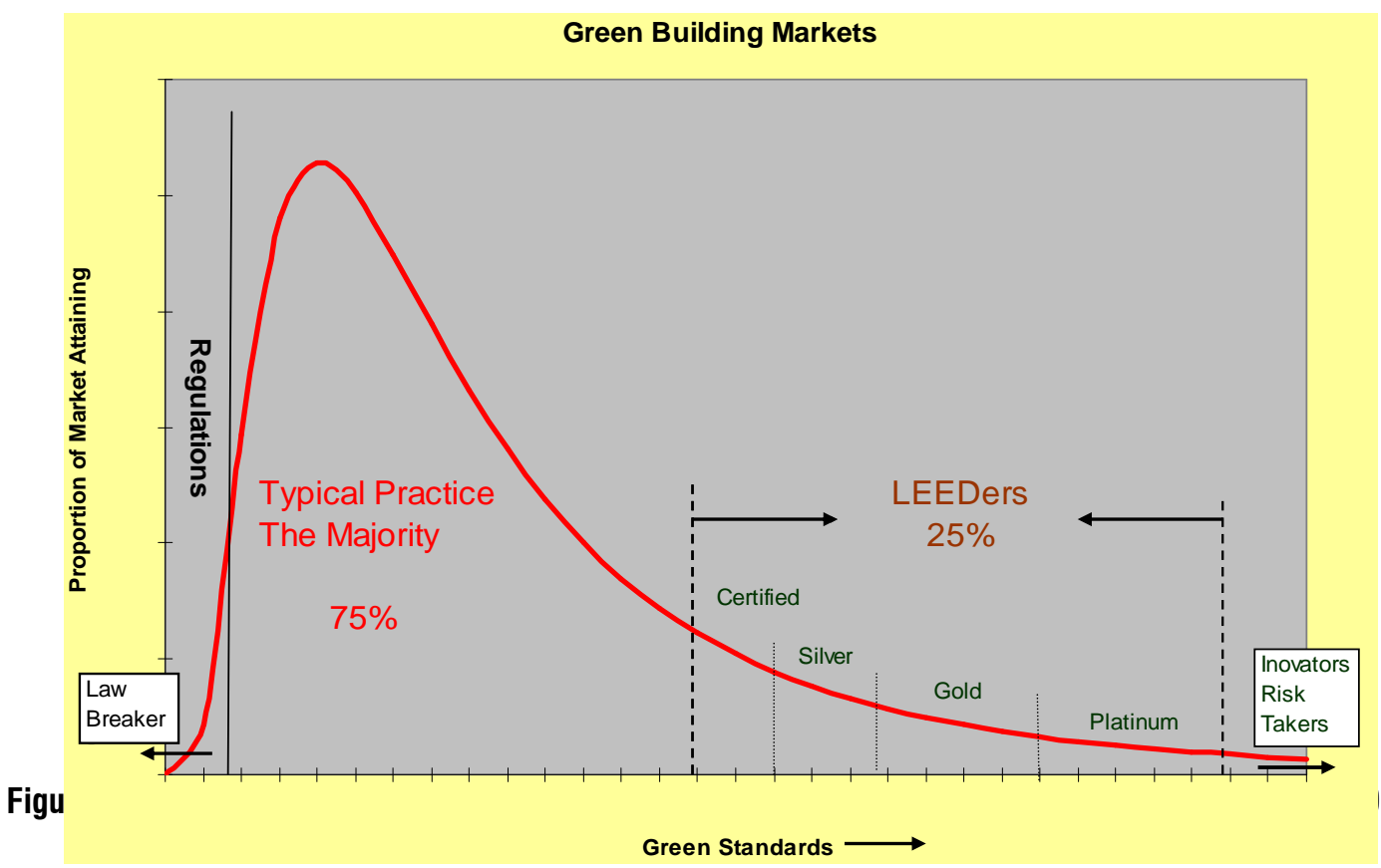

04).

Segundo LEWIS (2003), em 2003 a participação do LEED já alcançava 5\% de toda área construída de novos edifícios nos EUA.

\subsubsection{PONTUAÇÃO}

Ao todo são 65 itens de avaliação. Cada item avalia um aspecto diferente do empreendimento.

Entre os 65 itens de avaliação existem 7 que são pré-requisitos obrigatórios para a certificação e outros 58 créditos eletivos, ou seja, que podem ser escolhidos ou não para serem alcançados.

O LEED-NC tem 69 pontos possíveis de serem alcançados, divididos em 6 temas:

[1] Sustainable Sites com 14 pontos possíveis;

[2] Water Efficiency com 5 pontos possíveis;

[3] Energy \& Atmosphere com 17 pontos possíveis;

[4] Materials \& Resources com 13 pontos possíveis;

[5] Indoor Environmental Quality com 15 pontos possíveis e

[6] Innovation \& Design Process 5 pontos possíveis. 


\section{Onde estão os Pontos do LEED-NC por Tema}

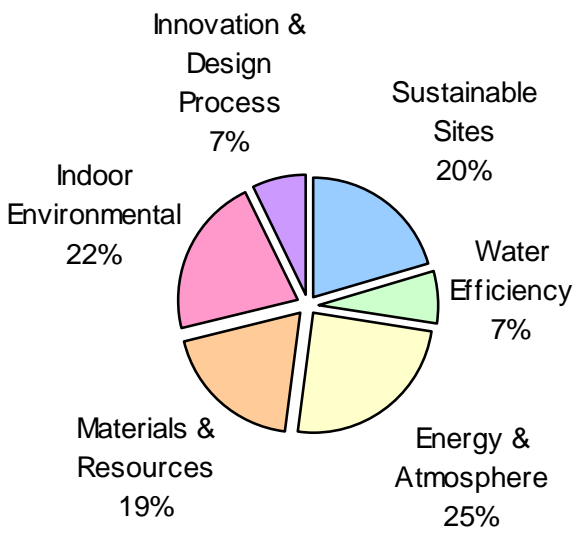

\section{Gráfico 2 - Pontos do LEED-NC por tema.}

Observa-se uma composição equilibrada dos créditos com exceção do tema relacionado à água (que perde espaço para o tema energia) e o tema de inovação, considerado extra.

A maioria dos créditos oferece apenas um ponto, mas uma minoria oferece mais pontos conforme são atingidos níveis maiores de desempenho.

\begin{tabular}{|cc}
\hline \multicolumn{2}{c}{ Itens } \\
\hline \multicolumn{2}{|c}{65} \\
\hline Pré-requisitos & Créditos Eletivos \\
\hline 7 & 58 \\
\hline Pontos & Pontos \\
\hline 0 & 69 \\
\hline
\end{tabular}

Tabela 3 - Tabela de Itens, Créditos e Pontos do LEED-NC.

Os Pré-requisitos não são divididos homogeneamente. Existem pré-requisitos apenas nos temas:

[1] Sustainable Sites com 1 pré-requisito;

[2] Energy \& Atmosphere com 3 pré-requisitos;

[3] Materials \& Resources com 1 pré-requisito e

[4] Indoor Environmental Quality com 2 pré-requisitos.

Finalmente, o tema relacionado com inovação não tem nenhum pré-requisito. Nenhum projeto é obrigado a inovar além do escopo do sistema. No entanto, chama a atenção que o tema 
relacionado ao uso da água não tenha nenhum pré-requisito, mesmo sendo considerada uma questão global do desafio da sustentabilidade no século 21.

Quanto aos objetivos específicos de cada tema são listados (USGBC, 2006a):

[1] Sustainable Sites,

- Ocupar somente terrenos apropriados.

- Reusar edifícios ou terrenos existentes.

- Proteger áreas naturais ou reservadas à agricultura.

- Reduzir a necessidade do uso de automóveis.

- Proteger ou restaurar áreas naturais.

[2] Water Efficiency,

- Reduzir a quantidade de água consumida no edifício.

- Reduzir a demanda municipal por tratamento de água e esgoto.

[3] Energy \& Atmosphere,

- Estabelecer eficiência energética e desempenho de sistemas.

- Otimizar eficiência energética.

- Encorajar fontes de energia renováveis e alternativas.

- Apoiar protocolos de proteção à camada de ozônio.

[4] Materials \& Resources,

- Usar materiais com menor impacto ambiental.

- Reduzir e gerenciar entulho e lixo.

- Reduzir a quantidade material necessário.

[5] Indoor Environmental Quality,

- Garantir boa qualidade do ar interno.

- Eliminar, reduzir e gerenciar as fontes de poluição do ar interna.

- Garantir conforto térmico e controlabilidade de sistemas.

- Prover contato dos ocupantes internos com o ambiente externo.

[6] Innovation \& Design Process.

- Reconhecer desempenhos excepcionais em qualquer dos créditos alcançados. 
- Reconhecer inovação de desenho em categorias não especificamente abordadas pelo LEED.

\subsubsection{CATEGORIAS}

As certificações do LEED foram divididas em 4 categorias de acordo com a pontuação alcançada:

CERTIFIED - pontuação mínima de 26 (38\% dos créditos).

SILVER - pontuação mínima de 33 (48\% dos créditos).

GOLD - pontuação mínima de 39 ( $57 \%$ dos créditos).

PLATINUM - pontuação mínima de 62 (75\% dos créditos).

Faixas de Notas LEED-NC x Quantidade de Créditos

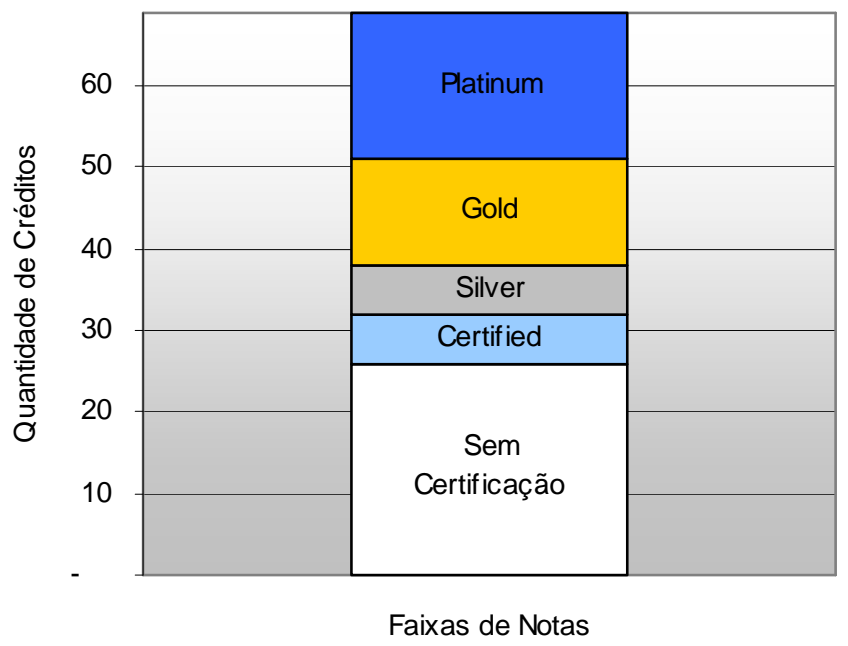

Gráfico 3 - Faixa de Notas (Categorias) do LEED-NC X Quantidade de Créditos.

As faixas de notas do LEED-NC vão aumentando de tamanho progressivamente. O nível Certified diz respeito a uma faixa estreita de 6 créditos (entre 26 e 32) enquanto o nível mais alto Platinum diz respeito a uma faixa larga de 18 créditos (entre 52 e 69). As amplas margens das notas mais altas se apresentam como indício do partido de avaliação orientado ao mercado. As notas mais desejadas vão ao encontro da média dos projetos.

Com menos da metade dos créditos $(26 / 69$ créditos $=37 \%)$ o LEED-NC já certifica o projeto. O sistema aceita desempenho com menos da metade da nota possível e mesmo se forem zerados temas inteiros. 


\subsubsection{CRÍTICAS AO LEED ${ }^{\mathrm{TM}}$}

Neste item são relacionadas as principais críticas ao sistema LEED ${ }^{\mathrm{TM}}$, identificadas ao longo da revisão bibliográfica, por diferentes autores. A base de referência do sistema LEED recebe críticas quanto à sua consistência, aplicabilidade e abrangência. As críticas focam tanto diretamente o sistema de avaliação quanto indiretamente, ao questionar a consistência das normas às quais o LEED faz referência.

O fato do LEED fazer referência ao uso do Forest Stewardship Council - FSC como exigência em um de seus créditos ${ }^{23}$, adotando como exigência um sistema de certificação de origem da madeira, neste caso para minimizar o impacto ambiental do uso desse material, pode esconder inconsistências. A certificação da madeira não garante, por exemplo, a manutenção da biodiversidade, ponto estratégico da questão ambiental nacional, pelo fato de que mesmo florestas plantadas em áreas originalmente de mata nativa recebem a mesma certificação (RAMETSTEINER, 2003, p. 92 e 97).

O fato do LEED ser fortemente baseado em normas americanas recebe críticas quando da sua aplicação fora dos EUA.

No caso brasileiro onde a inserção do LEED já é observada algumas críticas focam a consistência do uso das normas relacionadas no sistema.

Indagado a respeito do potencial de contribuição do uso do sistema LEED no pais ROMERO (2006) destaca o fato de que, na área estratégica de eficiência energética, o uso das normas ASHRAE como referência de desempenho tem um saldo positivo pelo fato de que não possuímos equivalentes nacionais. ROMERO destaca ainda a vantagem de que "são normas de desempenho", ou seja, estipulam patamares de qualidade a serem atingidos.

Para VITTORINO (2006) apesar de sua aplicação não representar um desafio técnico propriamente dito as normas ainda assim precisariam passar por uma revisão e deveriam ser inseridas como exigências aos poucos devido a distância entre seus níveis de desempenho e a realidade nacional. Particularmente, a ASHRAE 62.1-2004 de qualidade do ar interno "não é incoerente (para a realidade nacional)", a ASHRAE 90.1-2004 de eficiência energética precisaria de revisões especialmente nos quesitos de resistência térmica e a ASHRAE 55-2004 de conforto poderia ser utilizada, já que, de certa forma "O ser humano é o mesmo". Para LAMBERTS (2006), em comparação com sua versão anterior a ASHRAE 552004 apresenta melhorias em relação a sua aplicação no Brasil mas concorda que a ASHRAE 90.1-2004 está muito longe da realidade brasileira. Em sua opinião "a falta de normas brasileiras para dar suporte" é o aspecto mais negativo do sistema em relação as demandas nacionais mas este tem também o aspecto positivo de se transformar "em um foco para a equipe de projeto quando usado desde o inicio e principalmente quando o incorporador quer isto"

\footnotetext{
${ }^{23}$ Crédito 7 - Certified Wood — do tema Materials \& Resources.
} 
Quanto ao uso das normas estrangeiras no país ROZENDO (2006) ${ }^{24}$ afirma que algumas normas do LEED já são utilizadas no Brasil por profissionais especializados e outras, aceitam certo grau de adaptação às condições brasileiras. Em sua opinião, de maneira geral, o uso do sistema não deveria ser descartado por ausência de um equivalente nacional. Principalmente porque o sistema tem, em sua opinião, um impacto positivo no desempenho das construções.

Essa opinião sobre o impacto positivo no Brasil é compartilhado por ORNSTEIN (2006) que ressalta que essa introdução é positiva "caso não tenhamos outro procedimento mais adequado a nossa realidade para substituí-lo". E, também complementa afirmando que o sistema pode ter alguma aproximação com o modelo de Avaliação Pós-Ocupação (APO) nos quesitos de medição de desempenho e funcionamento de sistemas mas tem "pouca relação com a aferição da satisfação dos usuários". Essa aferição é um aspecto muito importante numa APO e faria diferença em relação a uma pontuação "fria" mesmo que baseada em critérios rigorosos.

Uma das críticas mais consistentes em oposição ao uso internacional do LEED como ferramenta de avaliação diz respeito à característica de países em desenvolvimento (entre eles o Brasil) que convivem com problemas de concentração de renda de grande magnitude. No Brasil, essa concentração de renda faz com que, em um mesmo país, a questão ambiental tenha sintonia tanto com a Agenda Marrom — focada nas questões sociais - quanto na Agenda Verde — focada na sustentabilidade ambiental (ANDRADE, 2005; CIB / UNEP-IETC, 2002 e SILVA, 2003, p. 123). Sendo o LEED um sistema pensado e mantido segundo o foco somente na Agenda Verde, ele apresenta uma abordagem insuficiente para a realidade desses países. Usando como referência a consulta pública realizada por SILVA (2003) no ano de 2003 a agentes do mercado da construção na cidade de São Paulo, observa-se que aspectos de [1] desempenho social, [2] desempenho econômico e [3] comprometimento e proatividade tiveram suas importâncias estabelecidas em níveis equivalentes à gestão do processo e ao desempenho ambiental. Nesse aspecto o conceito de Green Building relacionado com a Agenda Verde vem perdendo espaço no Brasil para o conceito de sustentabilidade, que é considerado mais amplo por envolver aspectos sociais, econômicos e ambientais (JOHN, 2006, p. 23).

\footnotetext{
${ }^{24}$ Entrevista com Saulo Rozendo — engenheiro civil, consultor em tecnologia da construção e LEED accredited professional brasileiro — profissional responsável por consultorias para certificação LEED de diversos empreendimentos nacionais.
} 


\section{Pesos obtidos por Consulta Pública}

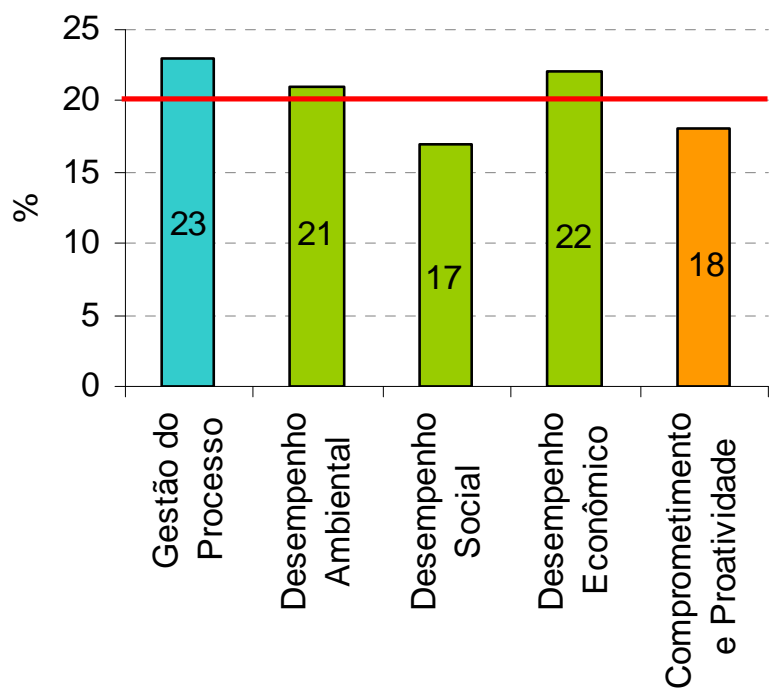

\section{Gráfico 4 - Pesos Obtidos em Consulta Pública sobre Sustentabilidade do Espaço Construído (reproduzido do trabalho realizado por SILVA, 2003)}

Outra crítica identificada considera que o LEED foca seus créditos em aspectos da sustentabilidade que são difíceis de serem mensurados. Segundo a divisão proposta por JOHNSON (2000) para as diversas camadas de custos e benefícios de um empreendimento, aproximadamente $40 \%$ dos créditos do LEED tem benefícios na primeira camada (Custo Total), relativamente fáceis de serem mensurados, enquanto que os benefícios dos créditos restantes estão em camadas com um grau de dificuldade maior de serem mensurados. Dessa forma grande parte do incentivo ao desenvolvimento de práticas sustentáveis encontra poucos subsídios para confrontar demandas de mercado. 


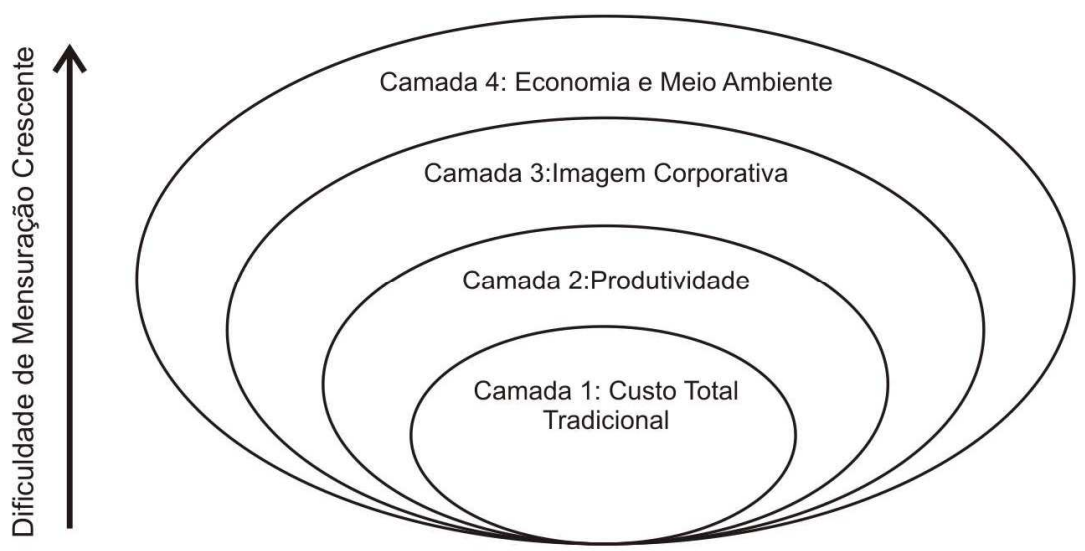

Figura 17 - Divisão de Custos e Benefícios (reproduzido e traduzido de JOHNSON, 2000).

\section{LEED Completo}

\section{Economia \&}

Meio

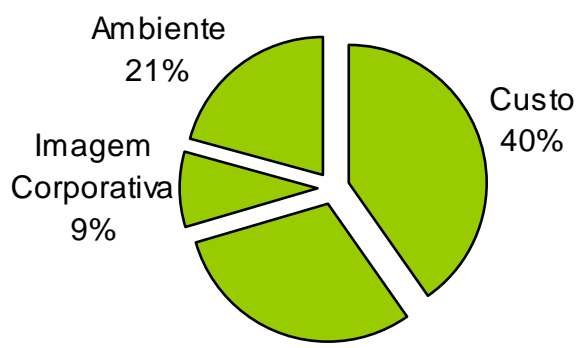

Produtividade

$30 \%$

\section{Gráfico 5 - Número de Créditos para cada camada de benefício para o sistema LEED como um todo (segundo divisão proposta por JOHNSON, 2000).}

O próprio conceito de sistema de avaliação a partir de um checklist é questionado. Segundo BALL (2002), em contraposição ao LEED e outros sistemas similares, a proposta de gerenciamento ambiental da ISO 14000 seria mais indicada para a avaliação do impacto ambiental de um edifício pelo fato de que o gerenciamento controlaria de maneira mais efetiva o impacto ambiental ao longo de toda a vida útil do edifício, e não somente no momento da avaliação. No entanto, apesar da certificação do LEED-NC ${ }^{\text {TM }}$ ter uma validade específica de 5 anos é possível certificar o empreendimento regularmente usando-se outro sistema específico, o LEED-EB (Existing Buildings).

O sistema LEED pode, ainda, encobrir a quantidade real de impacto ambiental de um determinado edifício, já que mesmo edifícios de tamanhos muito diferentes como, por exemplo, um com $20.000 \mathrm{~m}^{2}$ e outro com $2.000 \mathrm{~m}^{2}$ podem receber exatamente a mesma classificação, mesmo tendo nitidamente impactos diferentes (OLGYAY, 2004). 
Hoje o sistema LEED não pode ser considerado adequado para responder às particularidades locais fora de seu país de origem. Na sua adaptação para uso na Índia pelo India Green Building Council (WGBC, 2006c) foram solicitadas 4 alterações, 1 exclusão e 1 adição de créditos. Como exemplo, podemos citar o pedido de exclusão do crédito do LEED original que incentiva a inserção em áreas já urbanizadas, já que na Índia a legislação local estipula densidades máximas justamente para incentivar o desenvolvimento no sentido contrário, ou seja, em áreas suburbanas devido ao esgotamento da capacidade de infra-estrutura nas grandes cidades do país.

Como críticas à estrutura do LEED 2.1., observam-se em BD\&C (2003) os seguintes fatos:

[1] Os créditos do LEED oferecidos para os materiais manufaturados num raio de 500 milhas (aproximadamente $800 \mathrm{~km}$ ) de distância do empreendimento tinham como intenção original incentivar o uso de materiais do contexto local com menor impacto ambiental. Porém, ele pode acabar trabalhando no sentido contrário, não incentivando uso de matérias do contexto local, mas apenas privilegiando materiais com baixa energia incorporada pelo transporte.

[2] O crédito oferecido por contratar um profissional certificado pelo LEED fazia sentido como incentivo no começo do programa, quando havia deficiência de profissionais certificados nos EUA, o que hoje parece ser desnecessário.

[3] Um ponto pode ser ganho pelo fato do empreendimento fornecer reabastecimento com combustíveis alternativos, e a maioria dos projetos consegue isso disponibilizando pontos de recarga para carros elétricos, mesmo sabendo que em toda a América do Norte existem apenas 1.700 veículos elétricos em circulação. Esse crédito poderia ser alterado por fornecer incentivos ao uso de carros híbridos, por exemplo.

[4] O crédito oferecido para a disponibilização de estacionamento para bicicletas e chuveiros é visto por BD\&C (2003) como algo que produz relativamente muito pouco benefício.

[5] Não existe nenhum pré-requisito para a eficiência no uso da água. Um projeto pode ser certificado sem demonstrar nenhuma preocupação especial com o uso da água.

[6] O pré-requisito do LEED que exige áreas para fumantes faz pouco sentido, já que os edifícios novos estariam se adaptando rapidamente com políticas de proibição de fumantes nos espaços internos.

Como observa GOWRI (2004), o sistema LEED apresenta uma grande flexibilidade por permitir que os projetistas foquem especificamente nos créditos que desejam alcançar. Porém, constata-se que, teoricamente, um projeto poderia zerar diversos temas, ou seja, não conseguir nenhum crédito além dos pré-requisitos, e ainda assim ser certificado e receber o rótulo de "green Building” pelo LEED ${ }^{\mathrm{TM}}$.

Exemplo 1: teoricamente um projeto poderia zerar os temas Sustainable Sites (14 créditos), Materials \& Resources (13 créditos) e Indoor Environmental Quality (15 créditos) e ainda assim alcançar a certificação na categoria CERTIFIED. 
Exemplo 2: teoricamente um projeto poderia zerar os temas: Energy \& Atmosphere (17 créditos) e Indoor Environmental Quality (15 créditos) e ainda assim alcançar a certificação na categoria SILVER.

Exemplo 3: teoricamente um projeto poderia zerar Water Efficiency (5 créditos), Materials \& Resources (13 créditos) e Indoor Environmental Quality (15 créditos) e ainda assim alcançar a certificação na categoria SILVER.

Exemplo 4: teoricamente um projeto poderia zerar Sustainable Sites (14 créditos) e Materials \& Resources (13 créditos) e ainda assim alcançar a certificação na categoria GOLD.

Exemplo 5: teoricamente um projeto poderia zerar Water Efficiency e ainda assim alcançar a certificação na categoria PLATINUM, a categoria mais alta do sistema.

O sistema HQE francês até permite que sejam escolhidos os créditos que serão alcançados em detrimento de outros, desde que devidamente justificados levando-se em conta, por exemplo, as condicionantes do entorno. No entanto a inconsistência do sistema de pontuação do LEED nesse aspecto é fazer isso de modo não transparente. Por exemplo, mesmo em uma região com graves e históricos problemas de reservas de água potável é perfeitamente possível construir um edifício que alcance a mais alta categoria de pontuação do sistema LEED — a categoria Platinum — sem que no entanto ele tenha qualquer preocupação com o uso racional desse recurso.

Em YUDELSON (2005), diversas críticas recorrentes ao sistema LEED são identificadas, entre elas: [1] o excesso de burocracia para a certificação e [2] a falta de consistência nos benefícios divulgados dos projetos certificados etc. Apesar do problema do excesso de burocracia ter apresentado significativas aprimoramentos com a versão 2.2 a questão dos benefícios ainda é significativa.

O LEED também é criticado por reconhecer a inclusão de um profissional certificado no processo, mas não incentivar a integração das equipes formadas para o projeto-construção-avaliação de um empreendimento (RILEY, 2003).

\subsubsection{RESUMO DAS CRÍTICAS}

Considerando-se as críticas observadas, elas podem ser agrupadas nos seguintes aspectos:

- Normas de referência do LEED — as normas às quais o LEED faz referência para estipular parâmetros de desempenho têm seu papel e contribuição questionadas.

- Deficiência na Agenda Marrom - por ter sido pensado originalmente para responder estritamente às questões da Agenda Verde, pertinentes ao seu ambiente de origem, o LEED se mostra inadequado para abordar situações típicas de países subdesenvolvidos ou em desenvolvimento.

- Dificuldade de medir a qualidade e quantidade de benefícios ao meio e para o empreendimento - por concentrar seus benefícios em aspectos de difícil mensuração 
como, por exemplo, a imagem corporativa de um empreendimento, o LEED fornece poucos recursos para responder às demandas imediatistas de mercado.

- O sistema pode encobrir a quantidade real de impacto ambiental de grandes empreendimentos - por permitir que empreendimentos de tamanhos completamente díspares obtenham a mesma classificação e possam, em tese, ser comparados diretamente. Dessa forma o sistema pode encobrir o real potencial de impacto de um projeto.

- Ele permite algumas discrepâncias e desequilibrios muito claros — o sistema pode permitir, por exemplo, que um projeto possa ser certificado sem dar nenhum foco no uso da água.

\subsubsection{ANÁLISE DO LEED-NC}

Com base na estrutura de pontuação e nas exigências dos itens do sistema LEED-NC na sua última versão (v2.2) é possível identificar aspectos significativos de seu escopo de avaliação e efeito sobre o objeto avaliado.

O LEED-NC faz referência a um corpo normativo específico de seu país de origem (EUA) para estabelecer requisitos de desempenho em quase metade dos seus itens de avaliação. Sendo que as referências mais significativas são fornecidas pela American Society of Heating, Refrigerating and Air-Conditioning Engineers (ASHRAE). Essas normas aparecem como referência em 10 dos 65 itens de avaliação (1/4 de todas as normas exigidas). As mais utilizadas são a ASHRAE Standard 90.1-2004 sobre eficiência energética, a ASHRAE Standard 55-2004 sobre conforto térmico e a ASHRAE Standard 62.1-2004 sobre qualidade do ar.

\section{Precisa de Norma Específica}

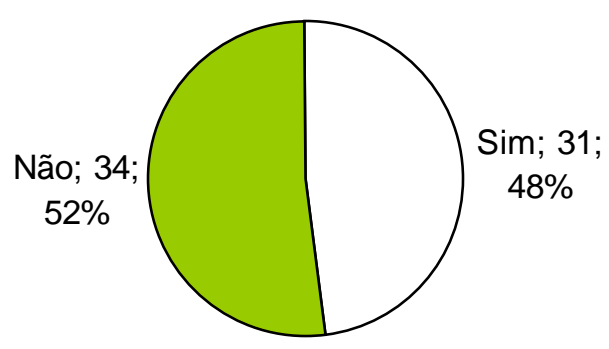

Gráfico 6 - Quantidade de itens do LEED-NC que exigem adequação a alguma norma específica.

Dos 65 itens avaliados pelo LEED (7 pré-requisitos e 58 créditos eletivos) aproximadamente metade não fazem referência à nenhuma norma técnica específica quanto à exigência de um determinado nível de desempenho. Para os demais itens, o LEED faz referência a mais de 30 normas de instituições americanas. Os temas de créditos que mais usam normas para estabelecer o desempenho almejado são o relacionado a energia (EA - Energy \& Atmosphere) e o relacionado com a qualidade do ar interno (IEQ Indoor Environmental Quality) sendo a instituição ASHRAE a que tem mais normas listadas. 
As referências às normas são atualizadas conforme o corpo normativo recebe revisões.

Entre a versão 2.1 e 2.2 algumas atualizações foram realizadas, notadamente as substituições das versões antigas da ASHRAE 90.1 e 55 pelas suas equivalentes mais novas (2004).

No entanto, a análise das maiores alterações nos créditos do LEED-NC versão 2.2 em relação à versão anterior 2.1 mostra que de um total de 26 créditos alterados, a metade sofreu alterações consideradas facilitadoras, ou seja, que permitem meios alternativos ou menor nível de exigência na obtenção de determinado ponto. Associando essa informação com o fato de que aproximadamente apenas 35\% dos créditos alterados aumentaram o nível de exigência constata-se que, aparentemente, o sistema não está cumprindo o seu papel de liderar o mercado rumo a níveis mais elevados de desempenho ambiental. Ao que parece o sistema está se adaptando ao mercado e não o inverso. Vale lembrar que desde a versão piloto 1.0 o sistema adotou alterações facilitadoras nos créditos que alegadamente são considerados tão restritivos que virtualmente ninguém consegue alcançá-los. No entanto o que se destaca é o fato de que a maioria dos créditos sofreu adaptações facilitadoras e não o inverso.

\section{Mudanças v2.1 para v2.2}

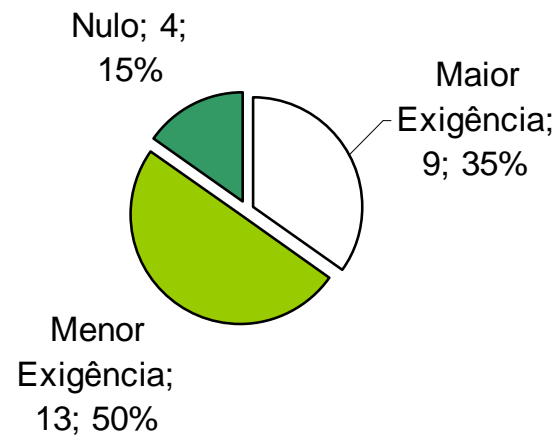

Gráfico 7 - Mudanças na atualização do LEED-NC v2.1 para v2.2 (USGBC, 2006c).

Com o objetivo de avaliar o topo (25\%) do mercado de construção "verde" em seu país de origem, o LEED tem a intenção de apresentar como constante desafio ao padrão de construções estabelecido. A inserção do LEED no Brasil desperta o mesmo interesse em saber o quanto o sistema pode ser desafiador para a realidade brasileira.

Como uma primeira aproximação da questão e com base nos estudos realizados, este trabalho classificou em 3 níveis de desafio (técnico e/ou econômico) os itens de avaliação do sistema tendo em mente a realidade dos grandes empreendimentos imobiliários na cidade de São Paulo e ouvindo a contribuição de alguns entrevistados. 
A classificação proposta foi dividida em ordem crescente de nível de desafio da seguinte maneira:

[1] Simples ou Desafio Nulo;

[2] Baixo Desafio e

[3] Alto Desafio.

O resultado inicial indica um certo grau de equilíbrio quanto ao nível de desafio global do sistema; no entanto, uma análise pormenorizada (a seguir no Quadro Geral Comentado) permite identificar elementos pontuais dessa primeira análise.

\section{Nível de Desafio no Brasil}

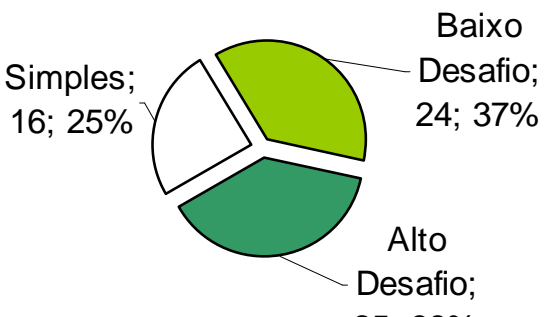

$25 ; 38 \%$

\section{Gráfico 8 - Nível de Desafio dos itens para serem alcançados com um projeto nacional hipotético.}

Apesar de não ter como foco o apoio ao processo de projeto, o LEED de fato influencia o desenvolvimento de empreendimentos que têm como intenção a certificação no sistema. Analisando-se as exigências e o foco de cada crédito específico também foi possível elaborar um panorama indicando quais etapas e agentes de produção têm maior relação com determinado crédito. O resultado mostra que, mesmo em uma primeira aproximação da questão, fica patente o papel determinante das etapas anteriores de projeto e dos agentes diretamente relacionados com essas etapas.

A análise indica como são determinantes para o resultado final da avaliação o papel dos agentes Clientes/Empreendedores (1/3 dos itens do sistema) e Projetistas (mais da metade dos itens), devido ao fato de concentrarem juntos quase $90 \%$ de todos os itens disponíveis no sistema. O potencial determinante dos projetistas é reforçado também pelo fato de que somente os créditos desses agentes seriam suficientes para que o empreendimento alcançasse o segundo nível de certificação mais alto do sistema: a categoria SILVER. Isso se deve ao fato de que algumas soluções exigidas pelo sistema envolvem aspectos diretamente relacionados ao conceito geral de um empreendimento e/ou seu custo final (área útil, 
equipamentos especiais, partido volumétrico, áreas livres, conforto térmico, iluminação natural, etc.). Soluções como o aumento de área livres ou o aproveitamento de um espaço construído aumentam suas chances de viabilização conforme se antecipa sua consideração no processo de projeto.

\section{Itens X Etapas}

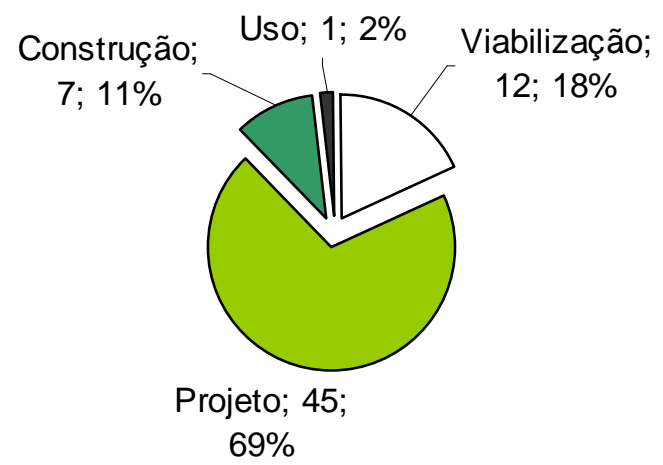

Gráfico 9 - Em qual etapa da cadeia de produção o item deve ser observado.

Itens X Agente

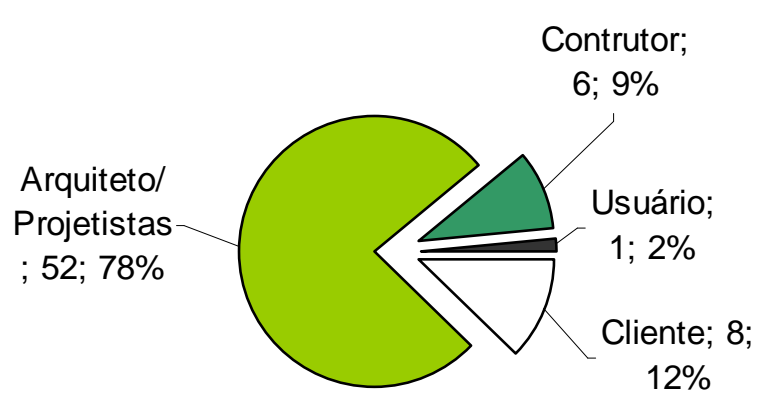

\section{Gráfico 10 - Qual agente da cadeia de produção influencia de maneira mais determinante cada item.}

As soluções empregadas para que sejam alcançadas as exigências do sistema também colaboram para ilustrar o papel determinante da etapa de projeto. A análise classificou a solução possível para cada item entre:

[1] Material de Construção. 
Soluções relacionadas com a escolha, disponibilidade e custo dos elementos construtivos (ex. uso de elementos reciclados, com baixa emissão de Compostos Orgânicos Voláteis ${ }^{25}$, fabricados localmente ou rapidamente renováveis).

[2] Serviço ou Equipamento Especializado.

Soluções relacionadas com a contratação de serviços ou instalação de equipamentos especializados (ex. aproveitamento de áreas contaminadas, sistemas de monitoramento da qualidade do ar, sistema de produção de energia renovável no local, etc.)

\section{[3] Projeto.}

Soluções relacionadas com o aprimoramento do projeto do edifício e com alterações de grande porte em sua configuração, envoltória, composição volumétrica, etc. (ex. aumento de áreas permeáveis, aproveitamento de estoque construído, otimização da iluminação natural, etc.).

O resultado mostra uma predominância das soluções de projeto (mais da metade das soluções) sobre os outros dois tipos. Isso se deve também à necessidade de avaliações antecipadas de projeto para a viabilização da maior parte das soluções.

\section{Tipos de Solução}

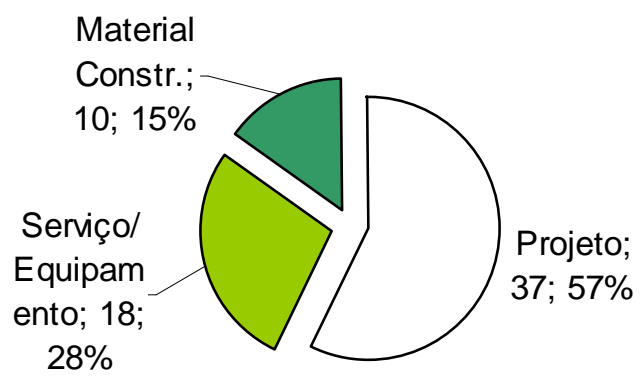

Gráfico 11 - Qual tipo de solução técnica tem maior relação com 0 item.

\subsection{EXEMPLOS DE PROJETOS CERTIFICADOS}

Com base na lista de projetos certificados pelo LEED-NC nas suas versões 2.0, 2.1 e 2.2. foi possível ilustrar a expressão arquitetônica dos edifícios certificados. A seguir foram selecionados projetos certificados pelo LEED-NC apresentados em ordem de nível de certificação (Certified, Silver, Gold e Platinum):

${ }^{25}$ VOCs na sigla em inglês Volatile Organic Compounds. 


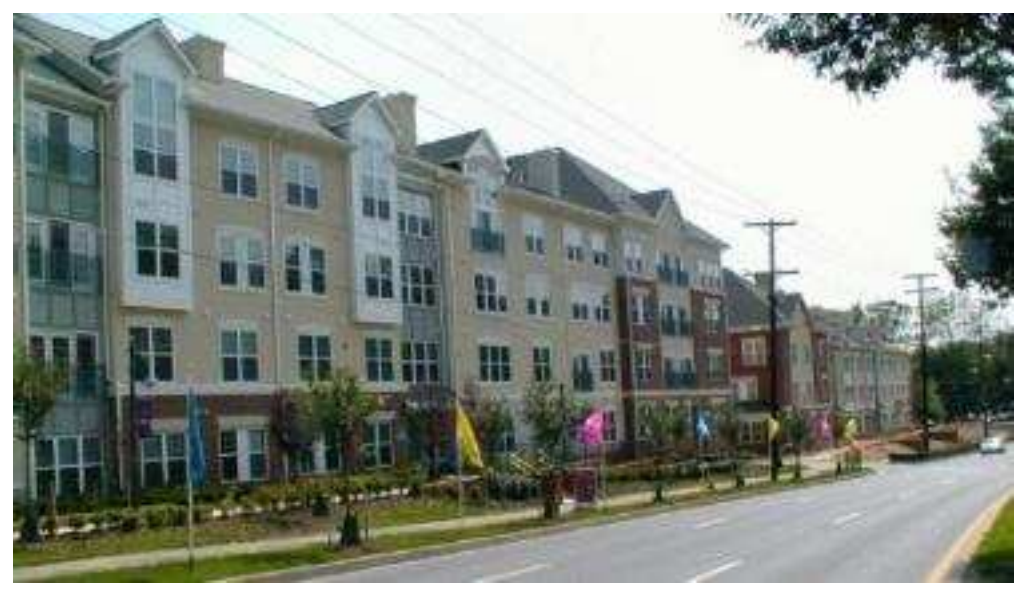

Figura 18 -Blair Town. (disponível em: <http://leedcasestudies.usgbc.org> acesso em: 02 de dezembro de 2006)

Nome: Blair Towns

Cidade: Silver Spring

País: EUA

Certificação: Certified

Função: Residencial

Comentários: Edifício residencial com apartamentos de padrão médio. Edifício contemporâneo com reprodução estética de edifícios históricos.
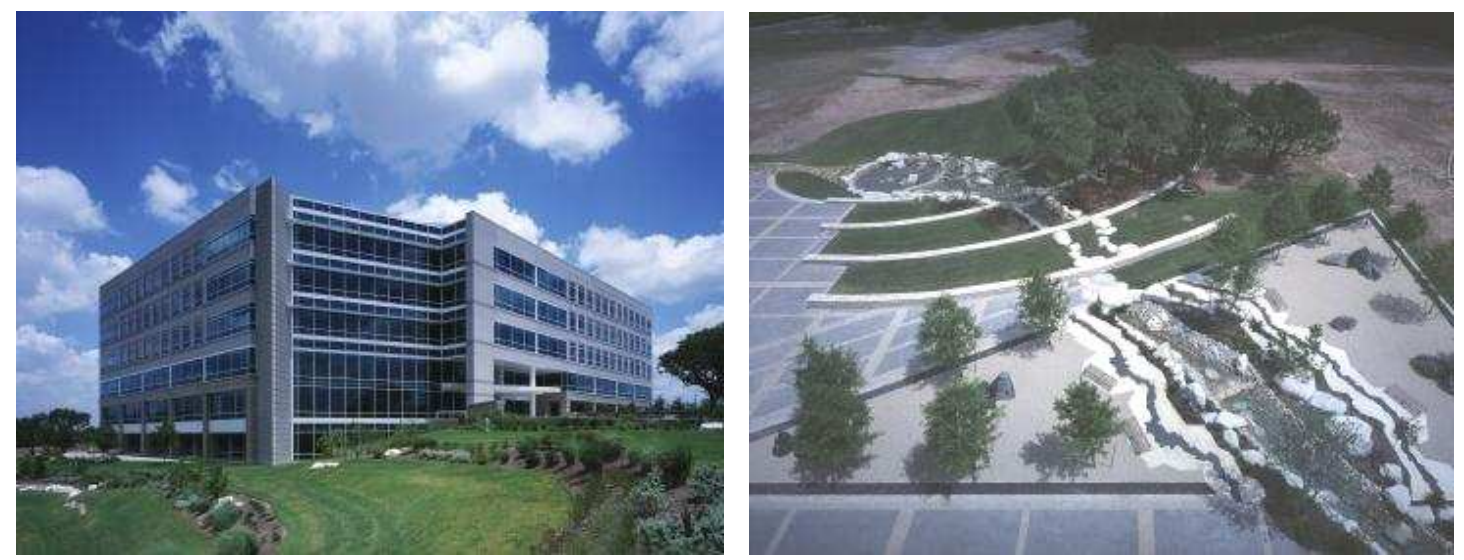

Figura 19 - IBM Tivoli System. (disponível em: <http://leedcasestudies.usgbc.org > acesso em: 02 de dezembro de 2006)

Nome: IBM Tivoli System

Cidade: Austin

País: EUA

Certificação: Certified 
Função: Corporativo

Comentários: Sede da IBM em Austin, Texas. Sede Corporativa de grande porte.
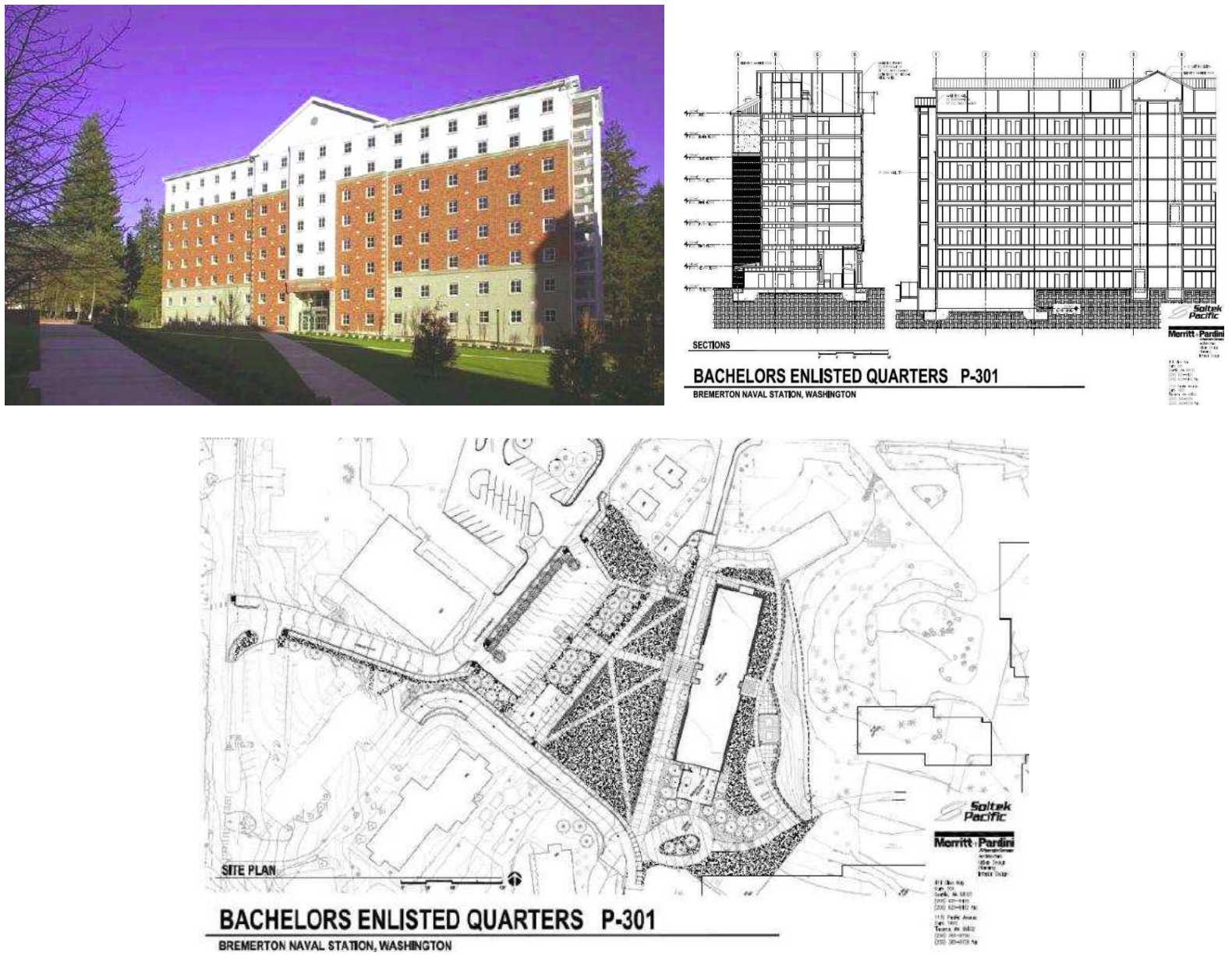

Figura 20 - Bachelors Enlisted Quarters. (disponível em: <http://leedcasestudies.usgbc.org> acesso em: 02 de dezembro de 2006)

Nome: Bachelor Enlisted Quarters Building 1044

Cidade: Bremerton

País: EUA

Certificação: Certified

Função: Institucional

Comentários: Alojamento para soldados da Marinha americana. 

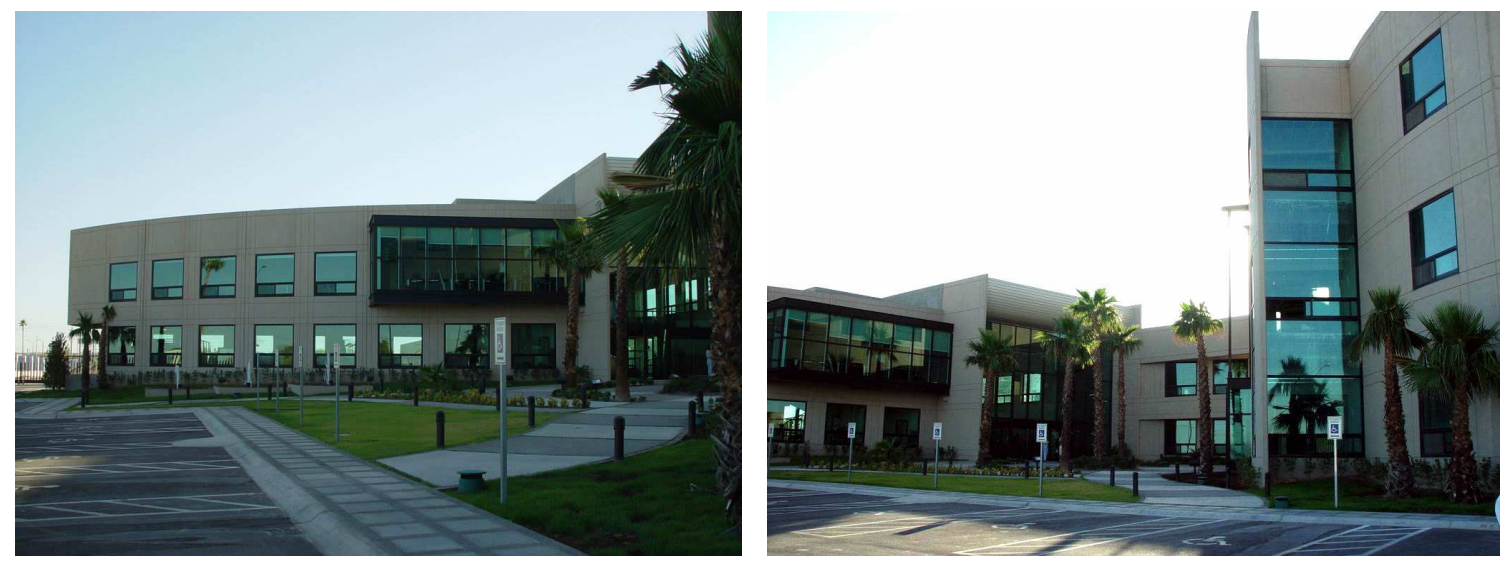

Figura 21 - Centro Internacional de Negócios - CIN. (disponível em: <http://www.tilt-up.org/awards/2003/cin.htm> acesso em: 02 de dezembro de 2006)

Nome: Centro Internacional de Negócios CIN

Cidade: Ciudad Juarez

País: México

Certificação: Certified

Função: Comercial Escritórios

Comentários: Edifício comercial de escritórios corporativos.
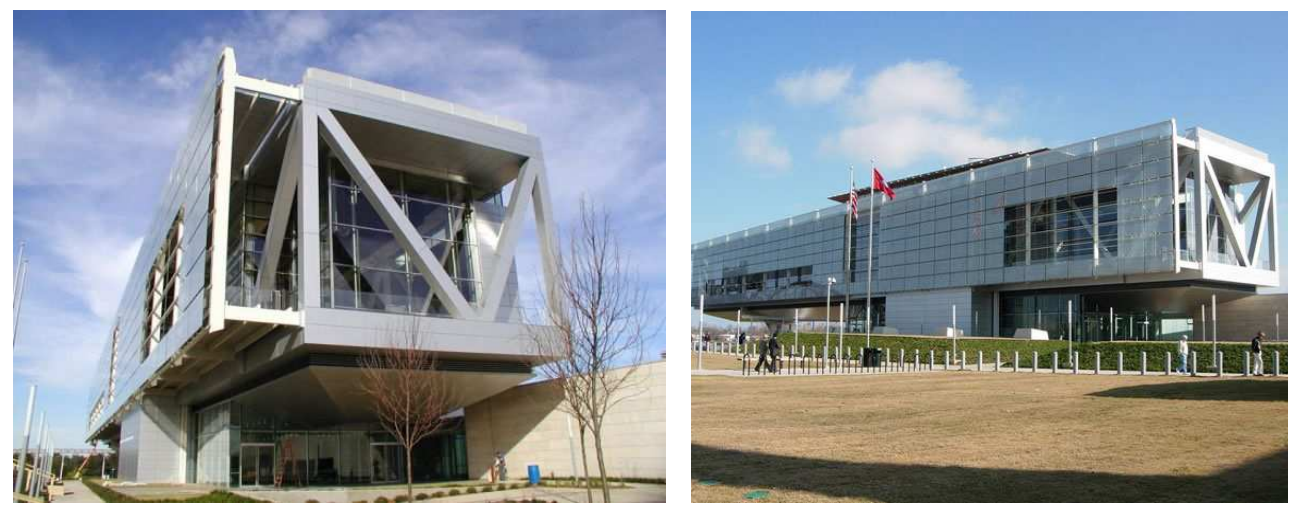

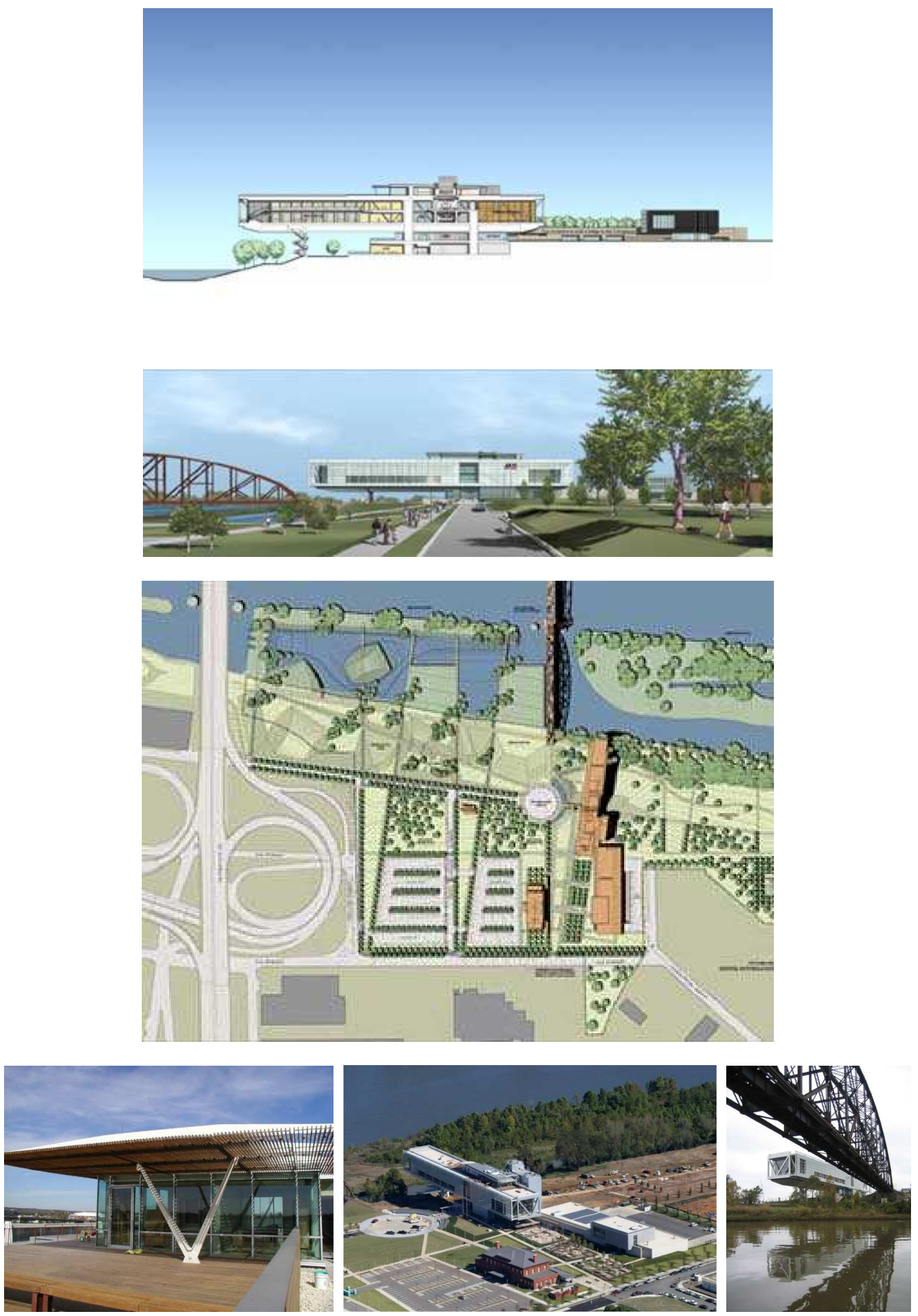

Figura 22 - William Jefferson Clinton Presidential Center (disponível em: <http://www.clintonfoundation.org> acesso em: 02 de dezembro de 2006) 
Nome: William Jefferson Clinton Presidential Center

Cidade: Little Rock

País: EUA

Certificação: Silver

Função: Institucional

Comentários: Biblioteca e sede da Fundação do ex-presidente americano Bill Clinton.
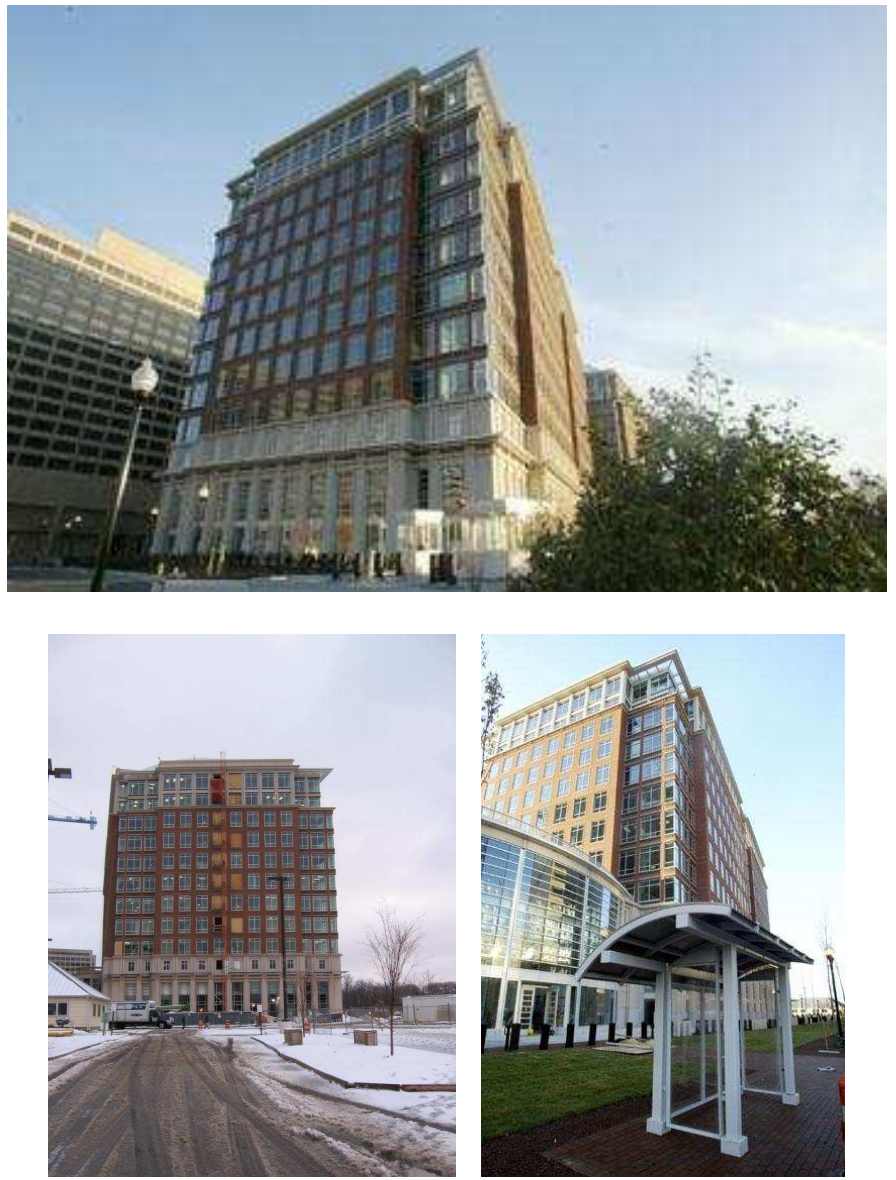

Figura 23 - One and Two Potomac Yard (disponível em: <http://leedcasestudies.usgbc.org> acesso em: 02 de dezembro de 2006)

Nome: One and Two Potomac Yard

Cidade: Arlington

País: EUA

Certificação: Gold

Função: Comercial de Escritórios 
Comentários: Edifício comercial de escritórios ocupado por escritórios do governo federal americano.
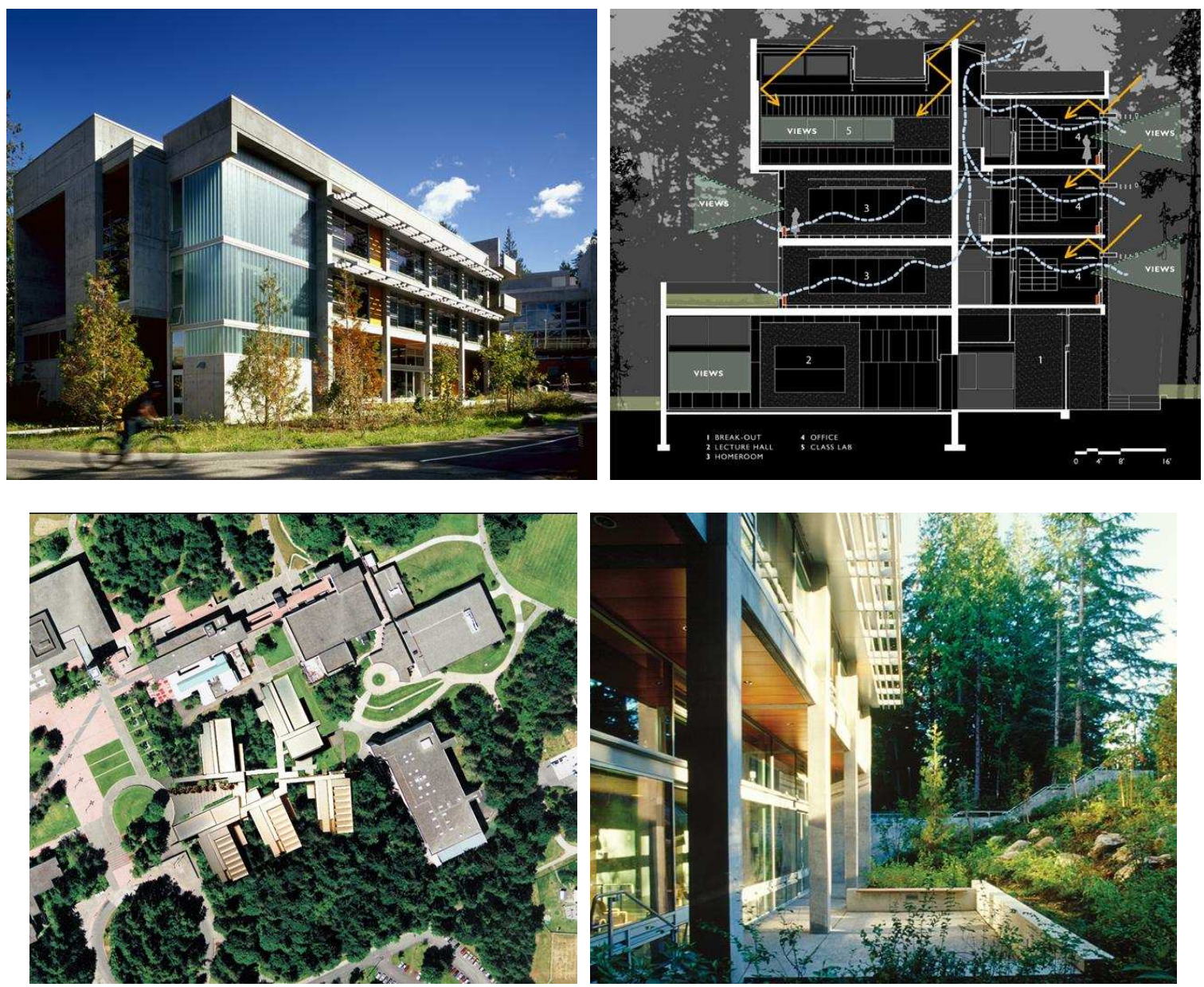

Figura 24 - Seminar II (disponível em: <http://leedcasestudies.usgbc.org > acesso em: 02 de dezembro de 2006)

Nome: Seminar II

Cidade: Olympia

País: EUA

\section{Certificação: Gold}

Função: Institucional

Comentários: Centro de Conferências da Universidade "The Evergreen State College" no estado de Washington. 

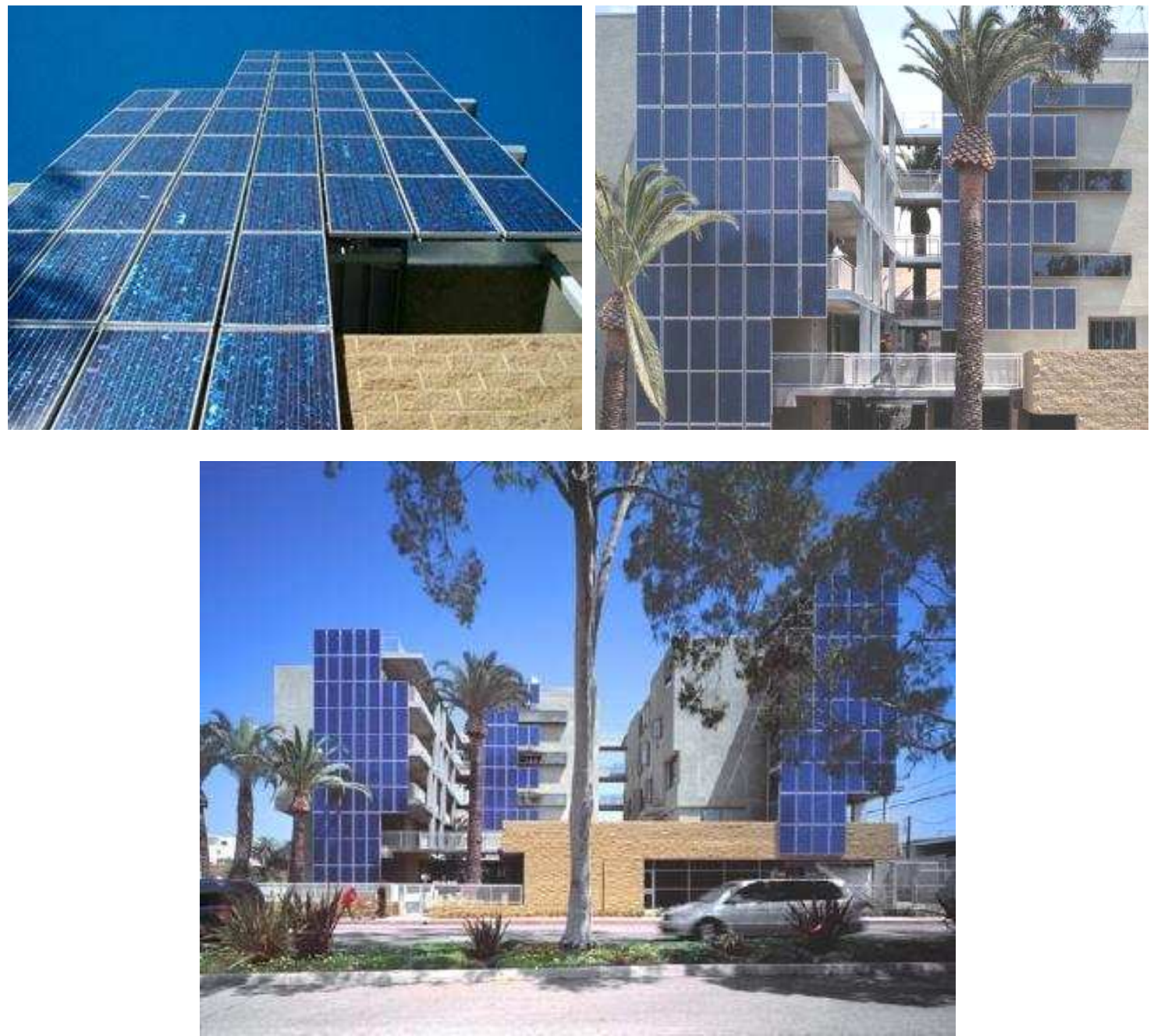

Figura 25 - Colorado Court Affordable Housing (disponível em: <http://leedcasestudies.usgbc.org > acesso em: 02 de dezembro de 2006)

Nome: Colorado Court Affordable Housing

Cidade: Santa Mônica

País: EUA

Certificação: Gold

Função: Residencial

Comentários: Condomínio de Apartamentos. 


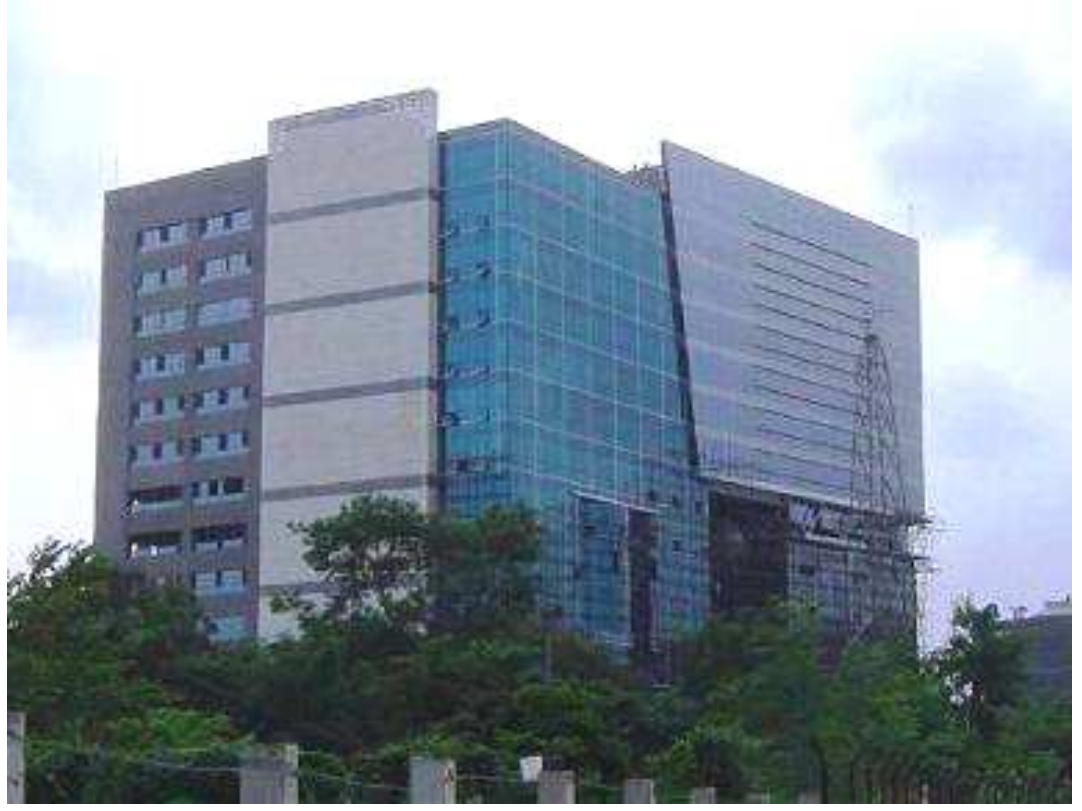

Figura 26 - Technopolis (disponível em: <http://leedcasestudies.usgbc.org> acesso em: 02 de dezembro de 2006)

Nome: Technopolis

Cidade: Kolkata

País: Índia

Certificação: Gold

Função: Comercial Escritórios

Comentários: Edifício comercial de escritórios com foco no mercado de Tecnologia da Informação (TI).
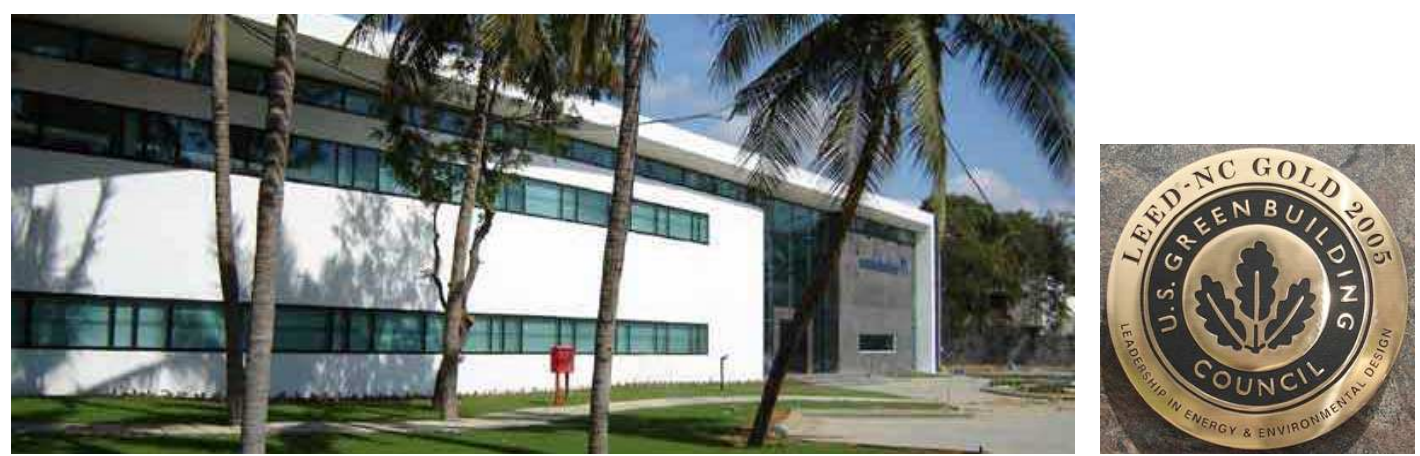

Figura 27 - Grundfos Pumps (disponível em: <http://www.grundfos.com> acesso em: 02 de dezembro de 2006)

Nome: Grundfos Pumps

Cidade: Chennai 
País: Índia

Certificação: Gold

Função: Corporativo

Comentários: Sede Administrativa de Indústria de Bombas de Água.
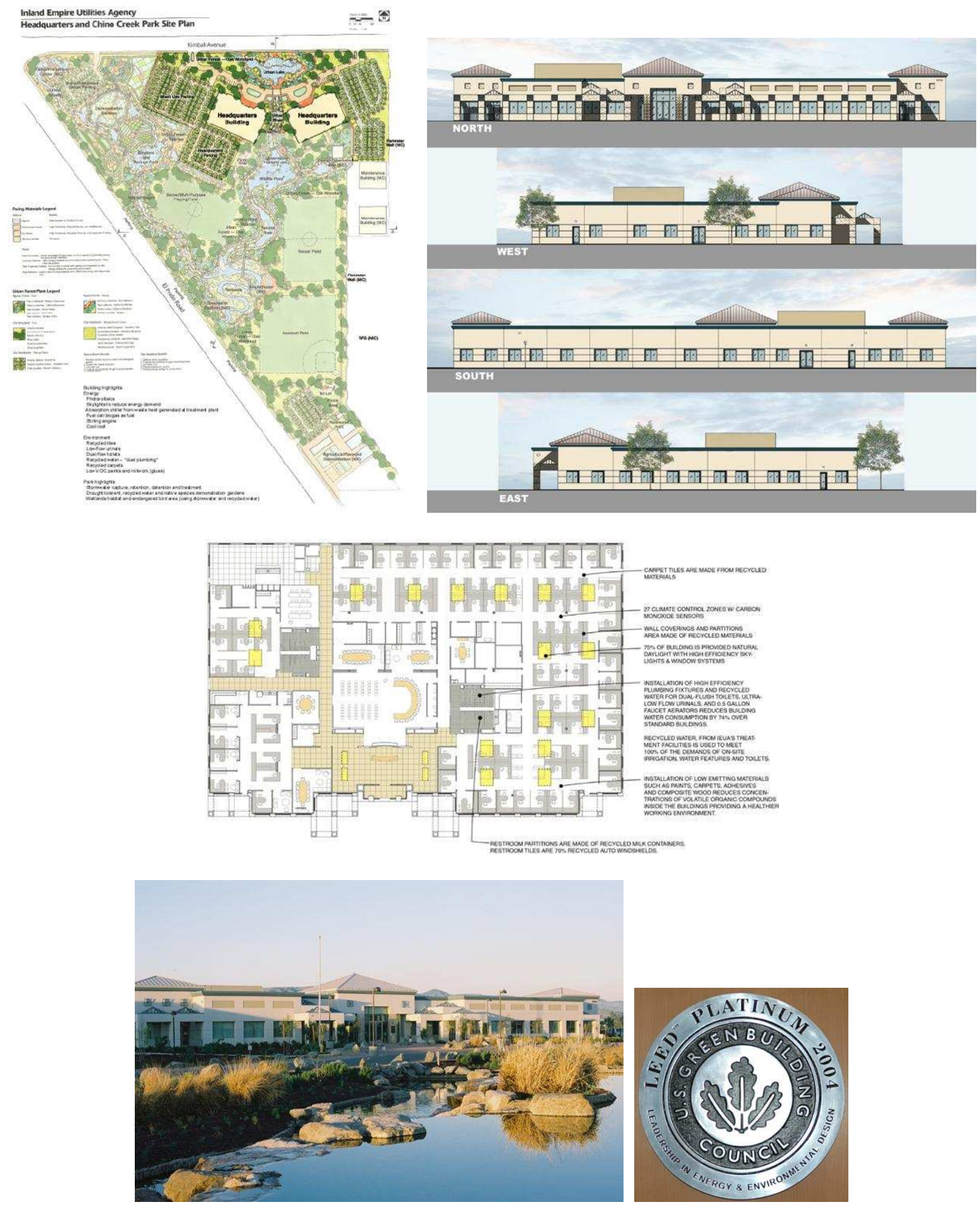
Figura 28 - Inland Empire Utilities Agency Headquarters Buildings (disponível em: $<$ http://leedcasestudies.usgbc.org > acesso em: 02 de dezembro de 2006)

Nome: Inland Empire Utilities Agency Headquarters Buildings

Cidade: Chino

País: EUA

Certificação: Platinum

Função: Institucional

Comentários: Sede de empresa de tratamento de água.
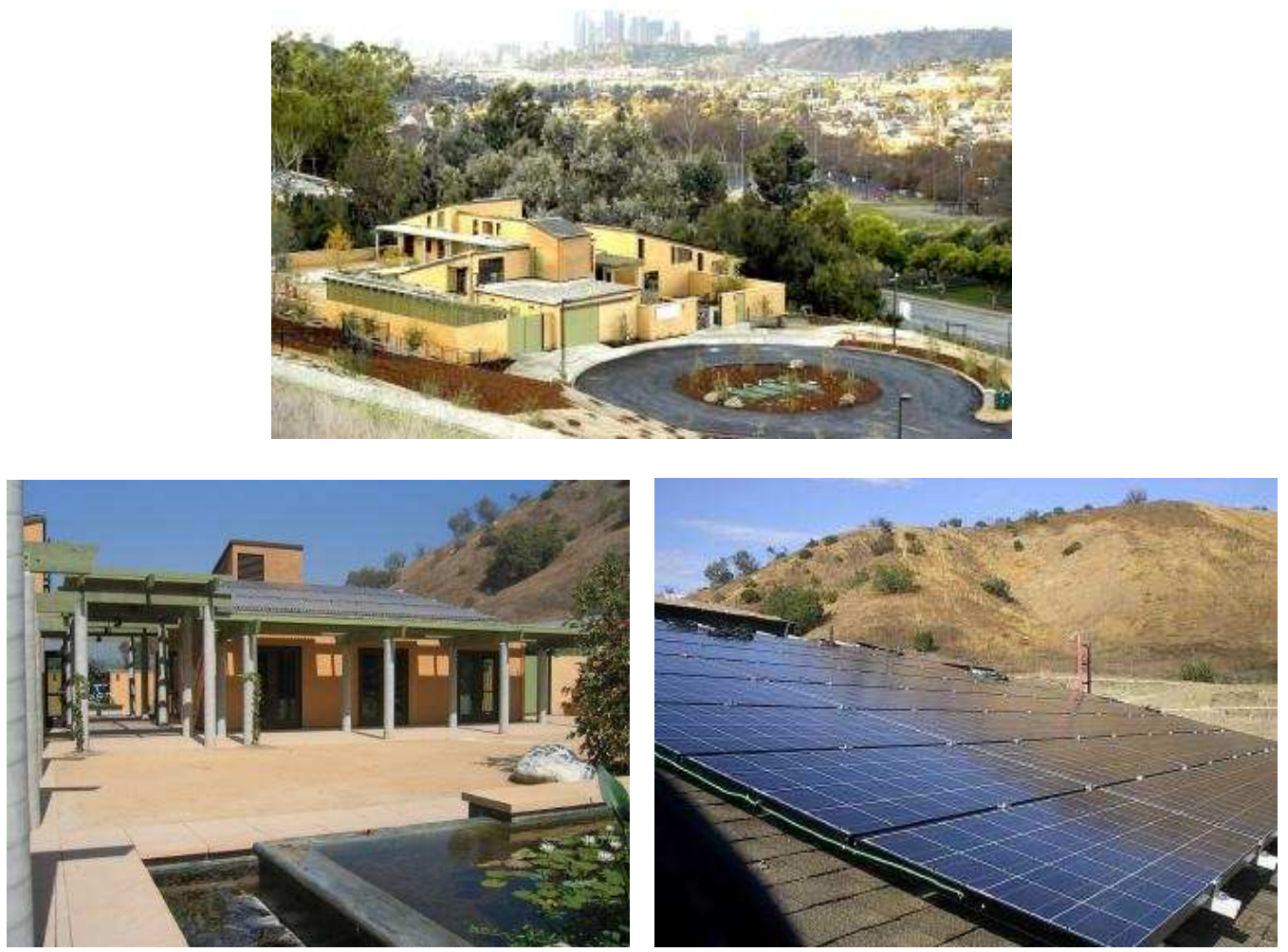

Figura 29 - Audubon Center at Debs Park (disponível em: <http://leedcasestudies.usgbc.org> acesso em: 02 de dezembro de 2006)

Nome: Audubon Center at Debs Park

Cidade: Los Angeles

País: EUA

Certificação: Platinum

Função: Institucional 
Comentários: Edifício para educação ambiental de fundação sem fins lucrativos.

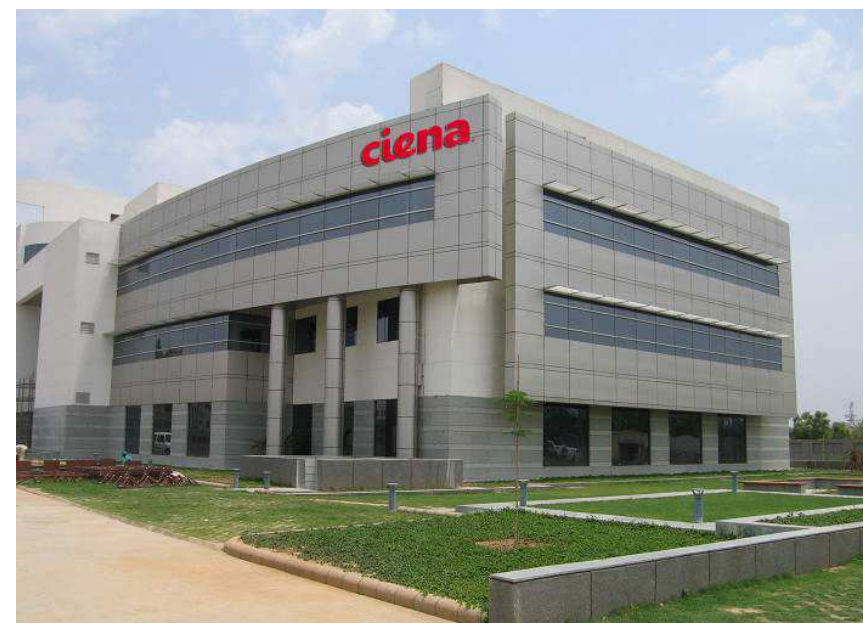

Figura 30 - Gurgaon Development Centre (disponível em: <http://leedcasestudies.usgbc.org> acesso em: 02 de dezembro de 2006)

Nome: Gurgaon Development Centre

Cidade: Gurgaon

País: Índia

Certificação: Platinum

Função: Corporativo

Comentários: Sede indiana de empresa multinacional de TI.
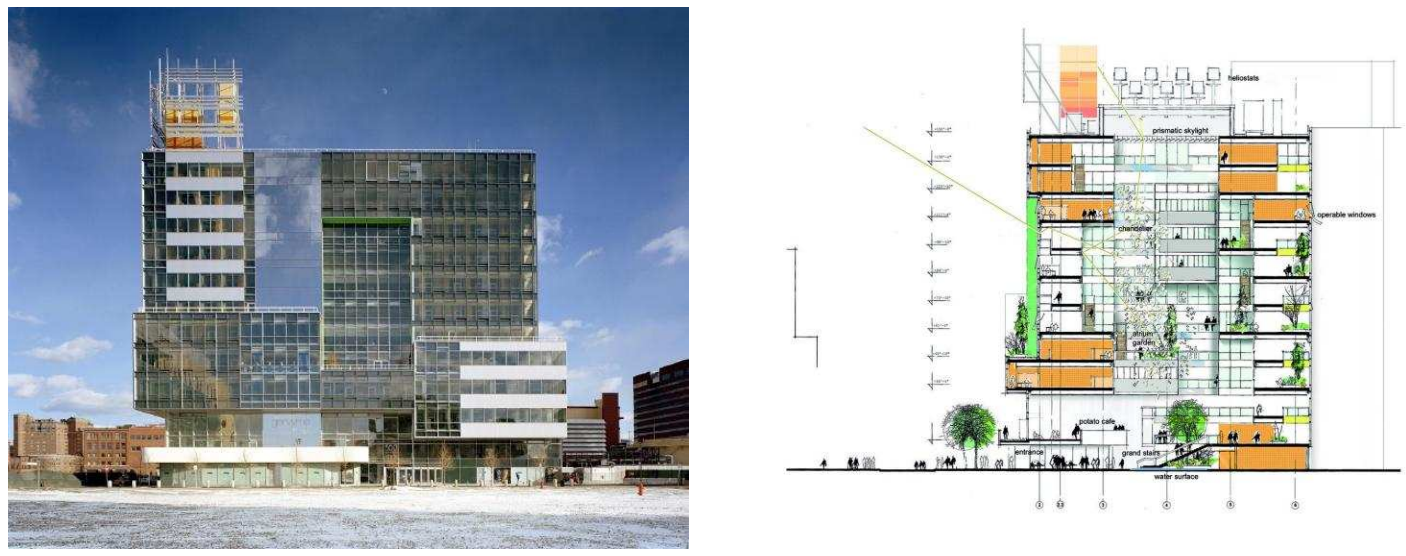

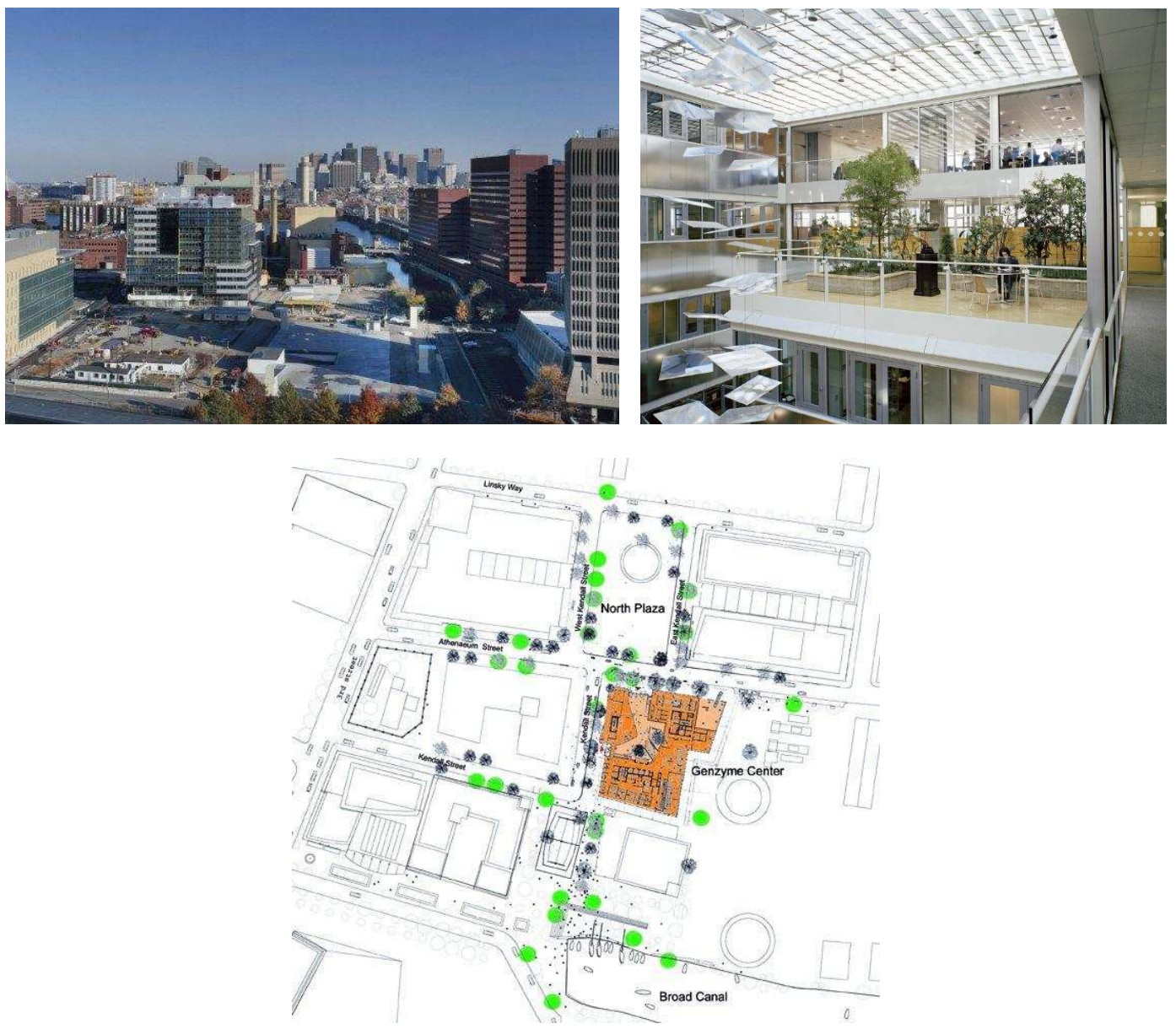

Figura 31 - Genzyme Center (disponível em: <http://leedcasestudies.usgbc.org > acesso em: 02 de dezembro de 2006)

Nome: Genzyme Center

Cidade: Cambridge

País: EUA

Certificação: Platinum

Função: Corporativo

Comentários: Sede Administrativa de empresa de Biotecnologia.

No panorama apresentado destacam-se os seguintes aspectos:

[1] A seleção procurou representar a proporção de edifícios certificados em relação às suas funções. Nota-se o predomínio de edifícios institucionais seguidos de sedes corporativas e por último os edifícios comerciais. Essa divisão também tende a se manter em relação aos níveis de certificação, ou seja, edifícios institucionais e sedes corporativas tendem a ter notas maiores que os edifícios comerciais. 
[2] Nota-se a certificação pelo LEED não acontece necessariamente em edifícios com feições contemporâneas. Mesmo projetos com características estritamente convencionais, para a sua realidade de mercado, são certificados (ex: Blair Town, Bachelors Enlisted Quarters, One and Two Potomac Yard, Inland Empire Utilities Agency — esse último alcançando o mais alto nível de certificação possível, o Platinum).

[3] Mesmo projetos com feições associadas com edifícios de alto desempenho ambiental não apresentam necessariamente certificações com níveis elevados (ex. IBM Tivoli Systems certificado no nível mais baixo do sistema apesar de ser um empreendimento com extensa área verde e com a configuração que se convencionou chamar de "estilo campus"26, normalmente associada com "edifícios verdes").

[4] O fato da sede da fundação do ex-presidente Bill Clinton ter escolhido o sistema LEED para a sua certificação pode ser considerado um indicativo de notoriedade no seu país.

[5] A certificação de um empreendimento comercial no México ilustra o caso da influência norteamericana nos padrões de edifícios comerciais de escritório em outros países (ex. Centro Internacional de Negócios).

[6] A certificação de empreendimentos na Índia com elevados níveis de certificação (2 projetos Gold e 1 Platinum) indica o grau de inserção do sistema daquele país, mesmo em um contexto ambiental e cultural bastante diferente do caso americano.

[7] É comum observar empresas que, aparentemente, tem interesse em valorizar sua imagem institucional escolhendo o LEED para certificar suas sedes corporativas nos EUA. Isso acontece também com órgãos públicos nos diversos níveis de governo (ex. Genzyme Center, Inland Empire Utilities Agency e IBM Tivoli Systems).

De modo geral observa-se a significativa relação entre a certificação e a imagem institucional desejada por cada empreendimento, seja ele público ou privado.

\subsection{BANCO DE DADOS DE PROJETOS}

Com a intenção de traçar um panorama do perfil dos projetos certificados pelo LEED-NC ao longo de 6 anos (de 2000 até 2005) foram reunidos e tabulados os dados a respeito de quais pontos foram alcançados por cada um dos 263 projetos constantes da lista pública do USGBC (2006).

Com esse banco de dados tabulado foi possível traçar um histórico do perfil de certificação e a descoberta dos créditos mais alcançados e menos alcançados pelos projetos ao longo desse período, traçando-se assim um mapa da certificação do LEED.

\footnotetext{
${ }^{26} 0$ "Estilo Campus" é uma convenção informal de mercado para designar empreendimentos comerciais corporativos com extensas áreas verdes em conglomerados de baixa altura — similares aos campi de universidades — usualmente associados a empresas de tecnologia e alto desempenho ambiental. Na cidade de São Paulo é possível identificar empreendimentos similares.
} 


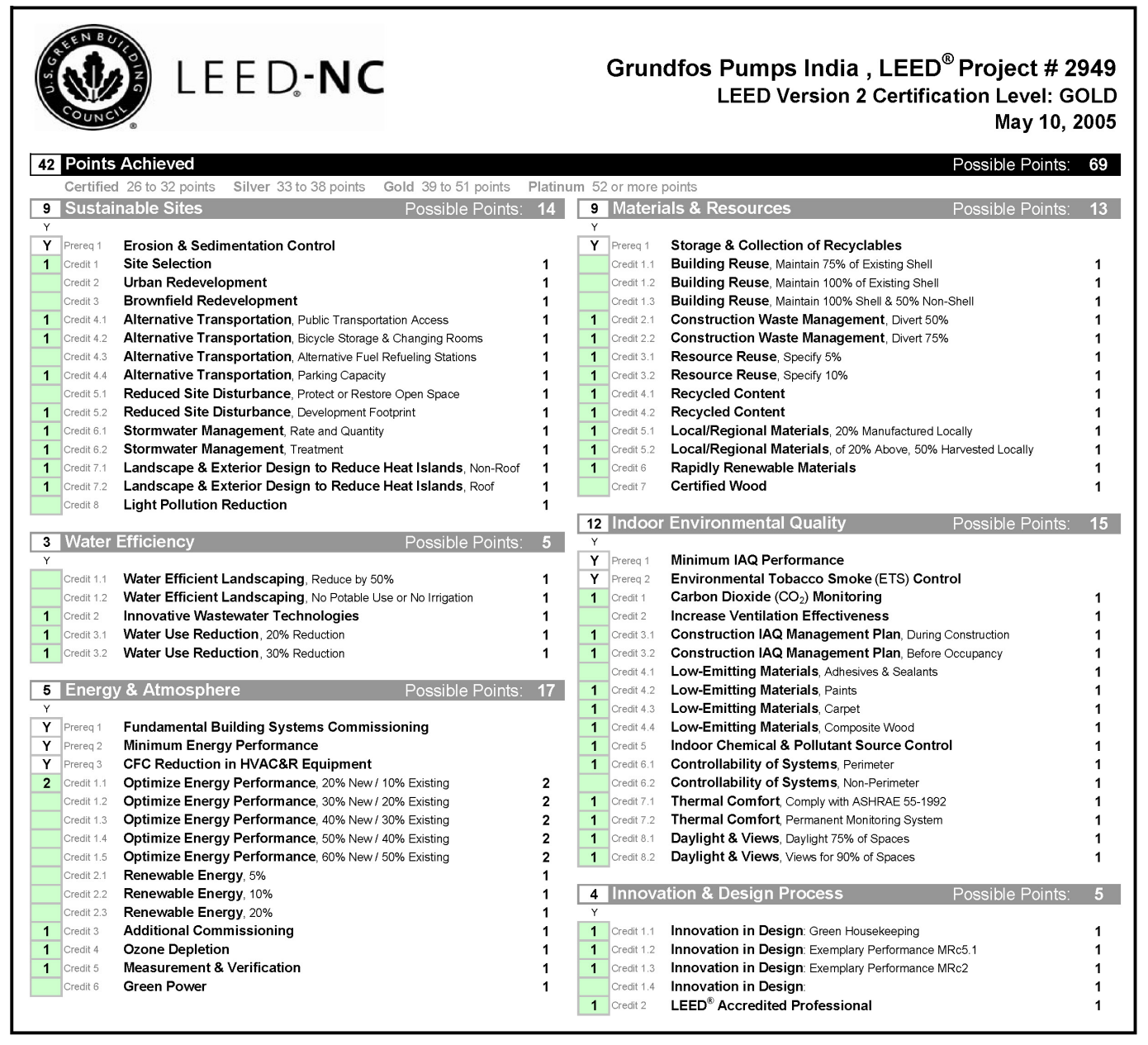




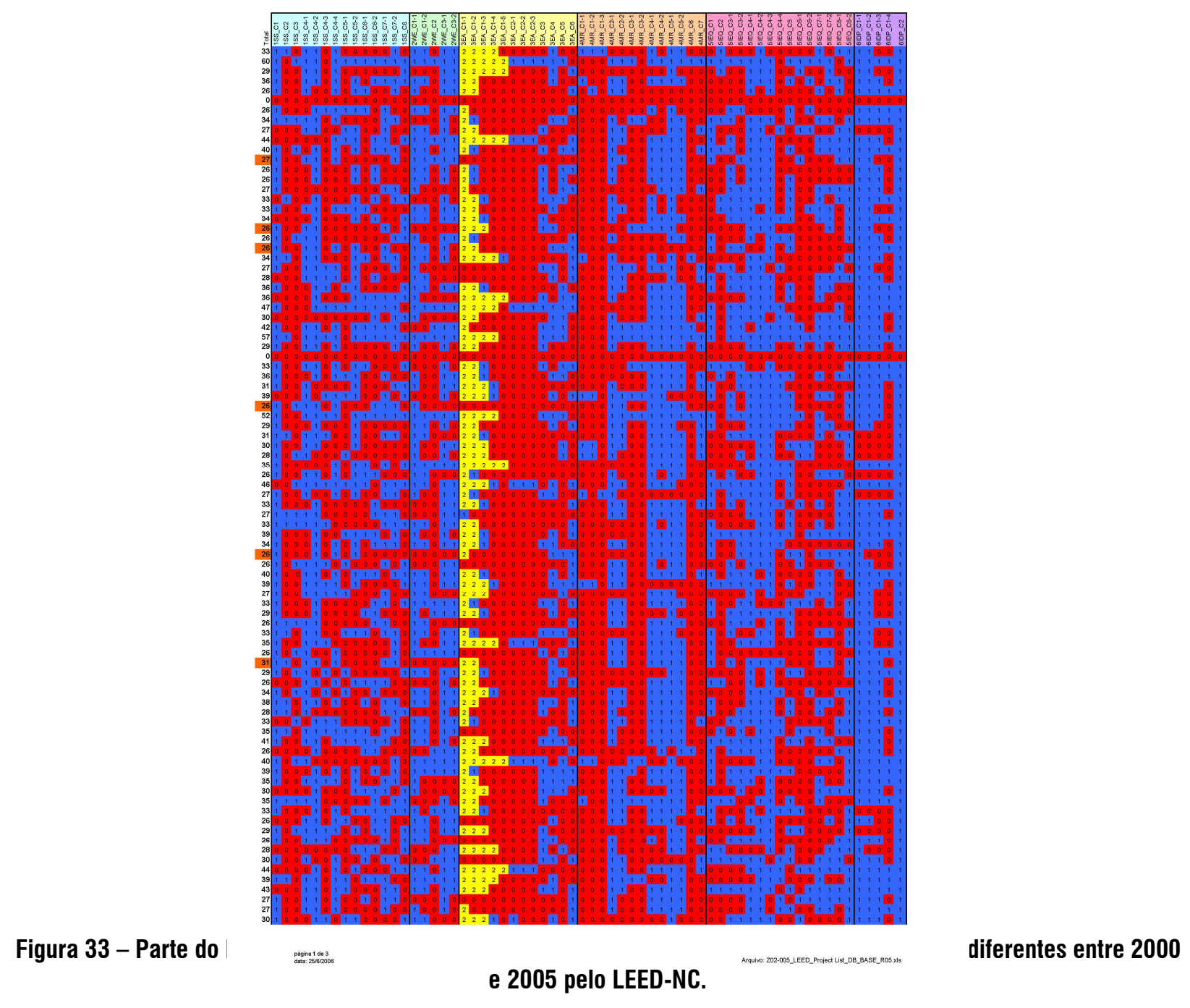

Avaliando-se a progressão do número de projetos certificados pelo sistema, observa-se um aumento expressivo de mais de 28 vezes nos últimos 5 anos, indo de 4 projetos no ano de 2001 para 114 projetos em 2005. 


\section{Quantidade de Projetos por Ano}

\section{$\square$ Projetos/Ano}

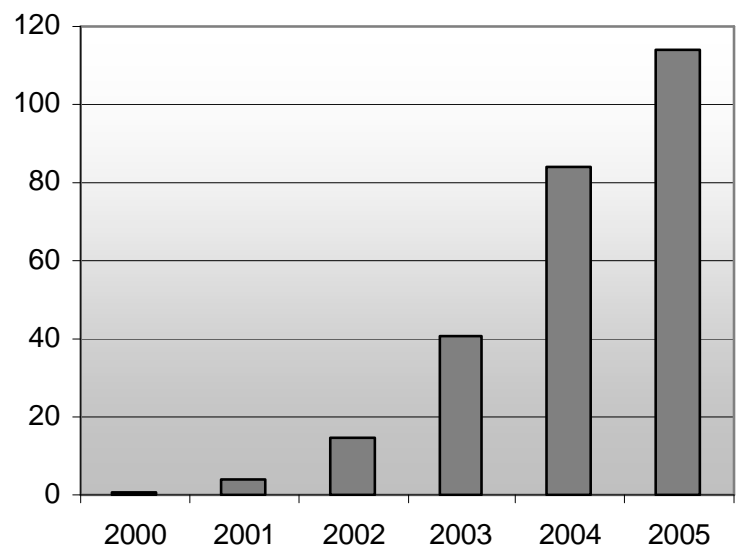

Gráfico 12 - Quantidade de Projetos certificados por Ano.

Acompanhando a evolução da nota máxima e da média das notas alcançadas pelos projetos, observa-se que a nota máxima apresenta uma razão de crescimento razoavelmente constante, enquanto a média das notas fica estacionada na faixa de 33 pontos.

Nota Média + Nota Máx. por Ano

\section{Nota Máx. $\square$ Nota Média}

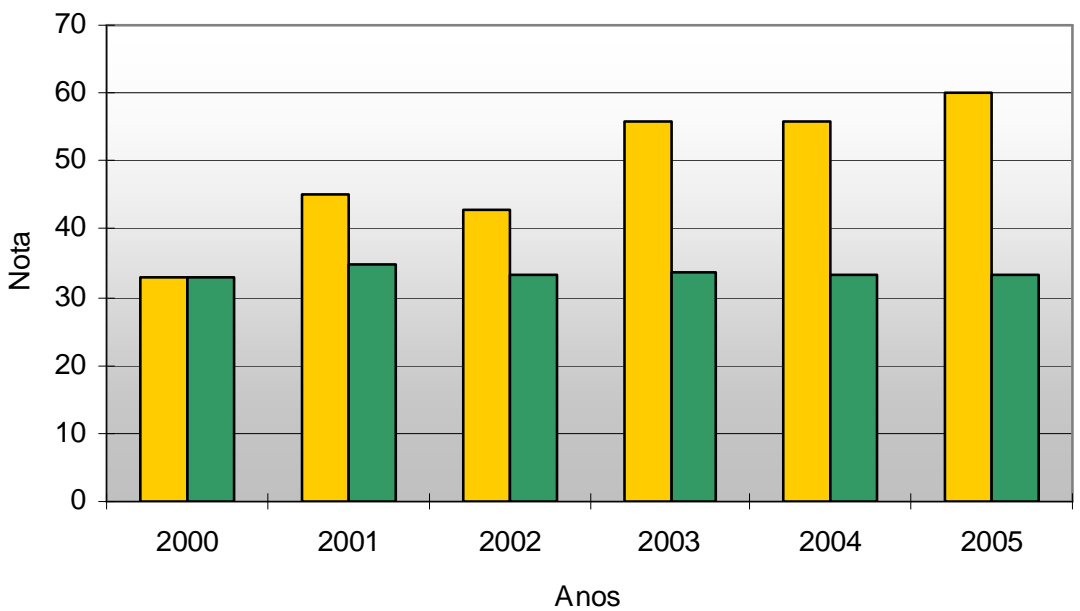

Gráfico 13 - Notas Médias e Notas Máximas dos projetos certificados por Ano.

O aumento nas notas máximas dos projetos é esperado até pelo movimento natural de mercado de competição acirrada entre os poucos projetos de altíssimo desempenho. Esses 
empreendimentos focam o máximo de créditos possível como diferencial estratégico, mas representam iniciativas pontuais de vanguarda pouco representativas do mercado como um todo.

O aspecto que desperta interesse é o fato de que, em mais de 5 anos de experiência com o mesmo sistema de avaliação, o LEED-NC, a média de pontos por projeto se manteve a mesma. Esse fato indica que, a princípio, o sistema pode não estar cumprindo sua premissa inicial de incentivar a transferência de tecnologias e práticas mais sustentáveis dos projetos de vanguarda — os famosos "LEEDers" — para o restante da massa de mercado. Aparentemente a maioria dos projetos está estagnada na média observada, curiosamente na categoria mais baixa: CERTIFIED. Associando isso com o fato já observado de que as atualizações do sistema são em grande parte facilitadoras tem-se um quadro preocupante em relação à consistência do sistema com um todo.

Considerando-se todo o universo observado, a relação entre os números de projetos certificados em cada categoria reflete de maneira equivalente o número de pontos necessários para alcançá-lo e a média de suas notas. Isso é consistente com a proposta do sistema.

\section{Número de Projetos por Categoria}

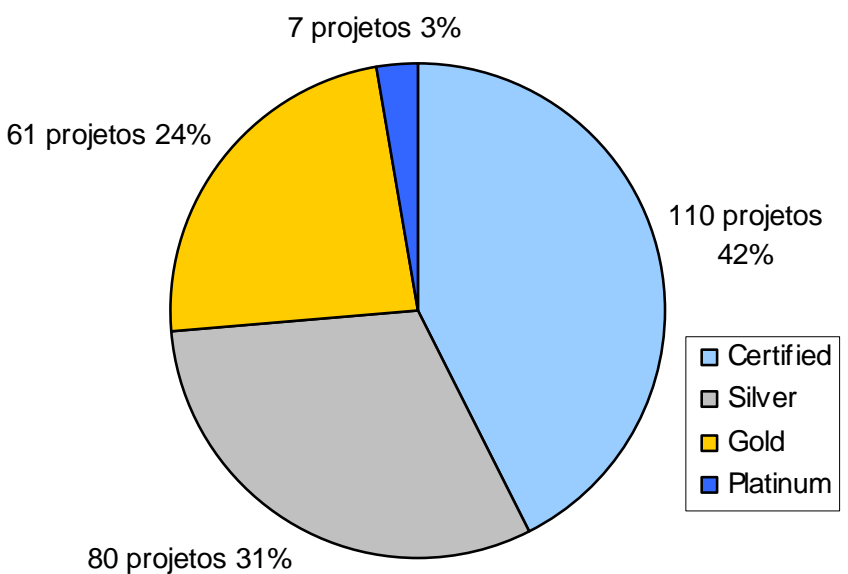

Gráfico 14 - Números de Projetos por Categoria.

A divisão de projetos em categorias mostra, como é de se esperar, uma ordem decrescente de projetos conforme aumentam o número de exigências, sendo que o primeiro nível de certificação

(Certified) representa quase metade de todos os projetos certificados. 
Média das Notas por Categoria

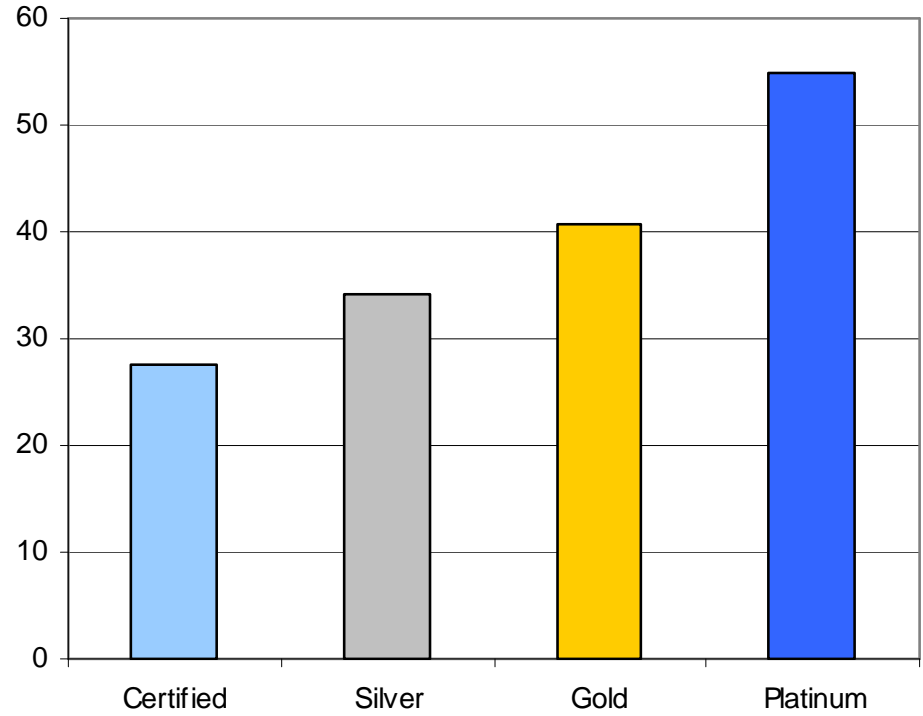

Gráfico 15 - Média das Notas dos projetos por Categoria.

Ao se analisar a evolução histórica do número de projetos certificados, nota-se uma inversão de hierarquia entre os anos de 2003 e 2004, quando a ordem se equilibrou, como era de se prever. Acreditase que essa inversão se deveu apenas à significativa ampliação do universo de dados em 2004 (aumento de mais de 100\% no número de projetos por ano em comparação com o ano anterior). Nota-se ainda uma discreta estabilização no número de projetos certificados na categoria mais alta (Platinum).

Número de Projetos por Categoria

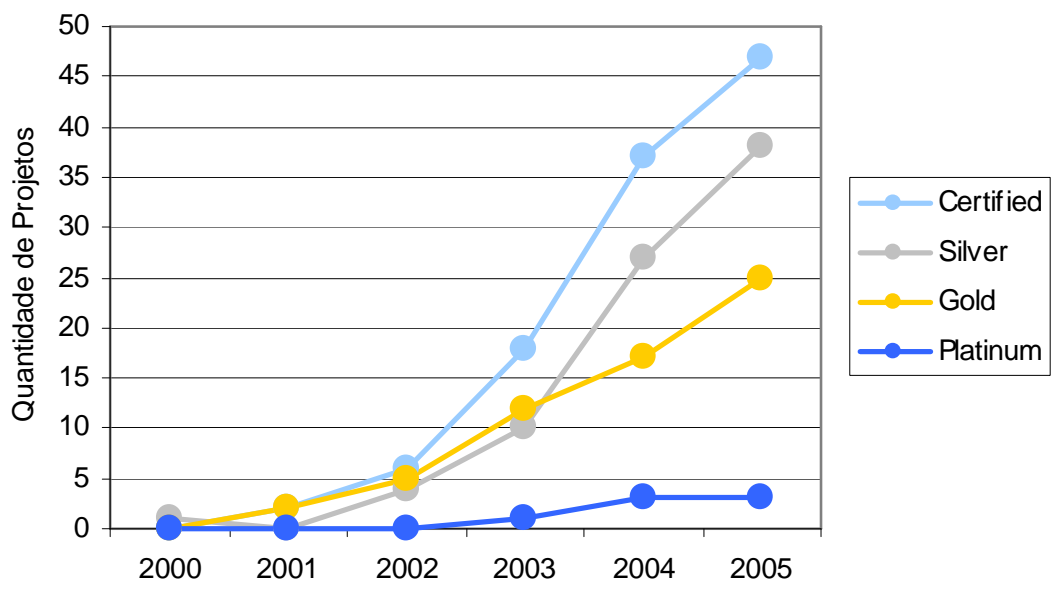

Gráfico 16 - Números de Projetos por Categoria. 
$\mathrm{Na}$ média de créditos alcançados em cada item, divididos pelas 4 categorias de certificação, é possível identificar os itens alcançados e os itens rejeitados nas certificações. Notadamente o item 1-3 no tema Materials \& Resources ${ }^{27}$ não foi alcançado pela maioria dos projetos observados nas 4 categorias. Esse fato indica a dificuldade no aproveitamento do estoque construído em empreendimentos novos.

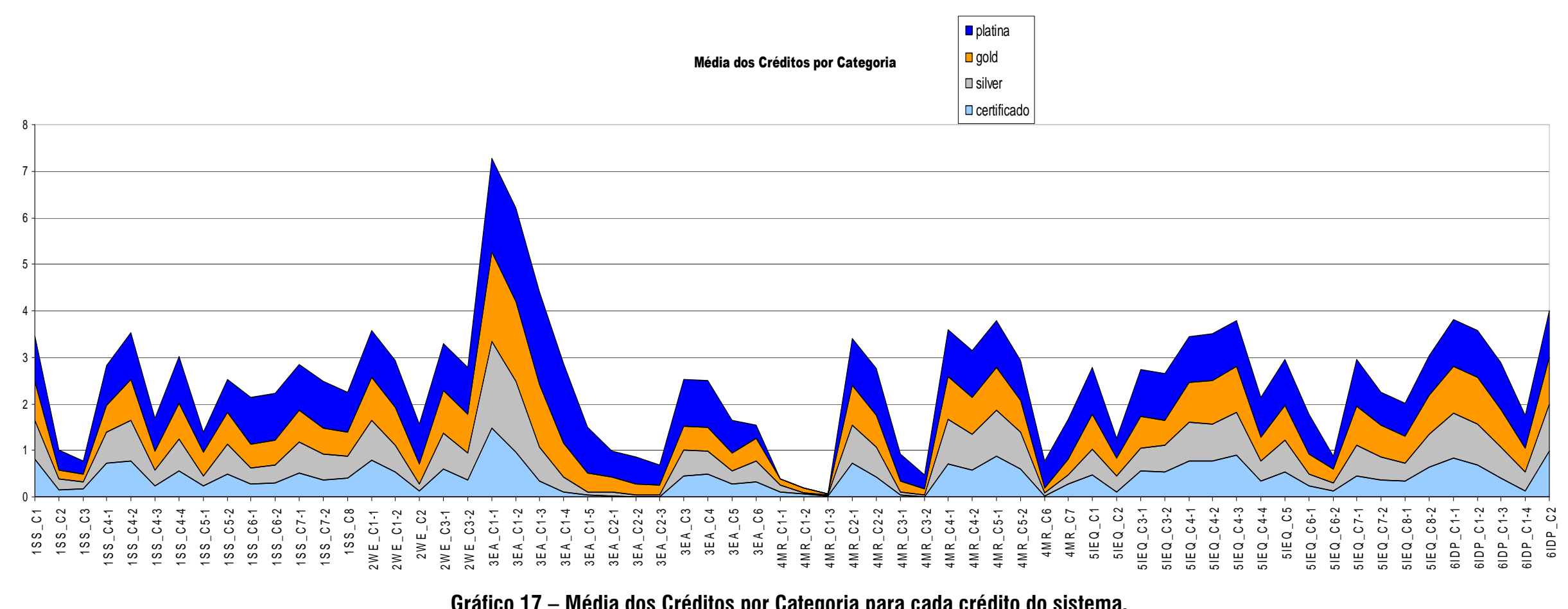

${ }^{27}$ Item relacionado com o aproveitamento da massa construída cujo requisito é aproveitar 100\% da estrutura e envoltória do edifício 
Número de Créditos por item em todo o Universo

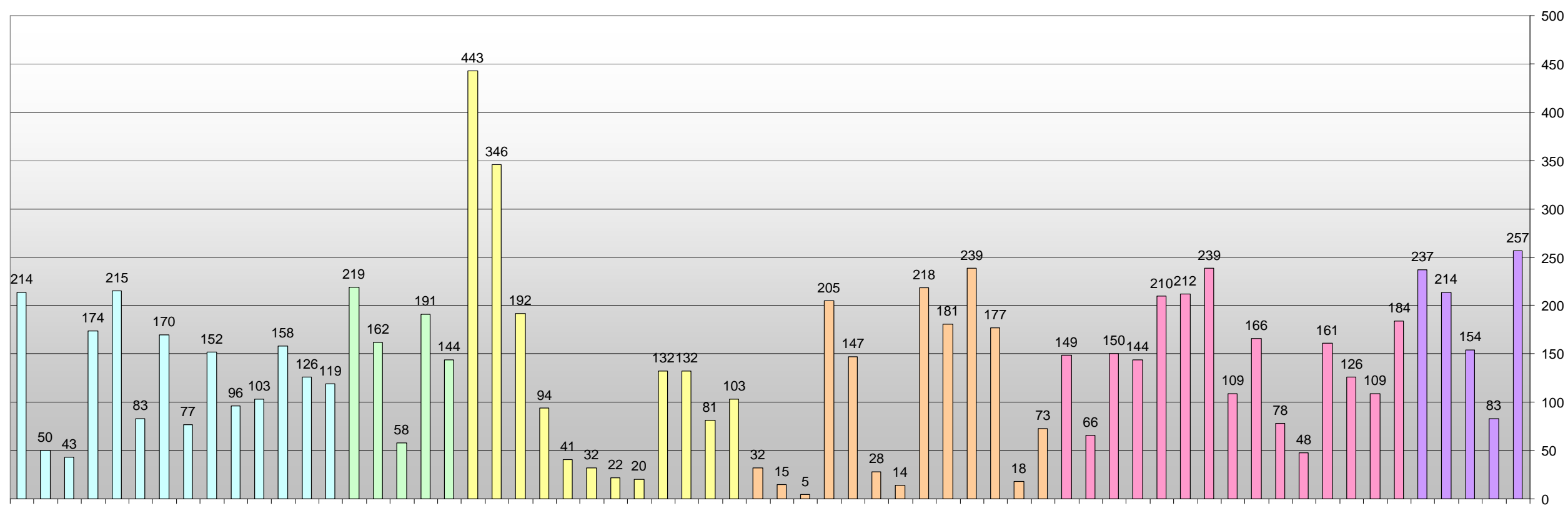

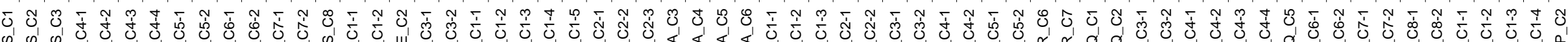
$\begin{array}{llll} & \\ 0 & \end{array}$

Gráfico 18 - Número de pontos alcançados pelos projetos em cada crédito do sistema.

${ }^{28}$ Os picos dos créditos de energia 3EA_1-1, 3EA_1-2 e 3EA_1-3 se devem ao fato de que é possível para cada projeto conseguir mais de um ponto nesse crédito em comparação com os outros créditos que só oferecem um ponto apenas. 


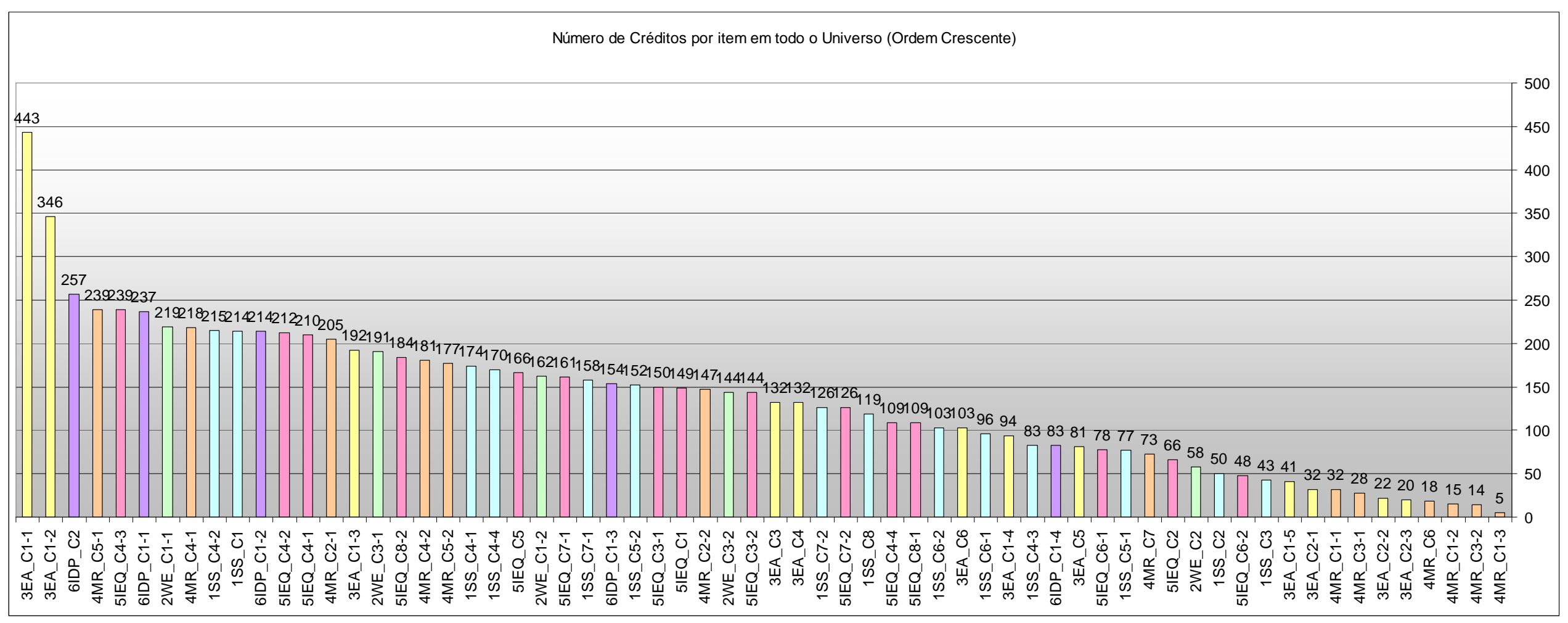

Gráfico 19 - Número de pontos alcançados pelos projetos em cada crédito do sistema, em ordem decrescente. 
Destacam-se de antemão os seguintes aspectos:

[1] Alta presença dos itens relacionados à qualidade do ar (Indoor Environmental Quality — IAQ, 5. ${ }^{\circ}$ tema a ser avaliado), um dos aspectos que chamam mais atenção do mercado americano pela tendência dos ambientes fechados em climas frios de serem menos salubres;

[2] Os itens relacionados com a disponibilidade de materiais de construção com baixa emissão de VOCs, fabricados localmente ou com conteúdo reciclado, têm grande destaque indicando a adaptação dos fornecedores desses materiais a novas exigências de mercado relacionadas ao desempenho ambiental;

[3] Destaque, como era de se esperar, dos itens relacionados ao uso racional da água; e

[4] Contra o senso comum, observa-se grande destaque dos créditos de inovação (último tema de análise - número 6).

Pelo que se observa no banco de dados a maior parte dos projetos que conseguem pontos por inovação não são, como se esperaria, os que tem notas altas (como o nível Platinum e Gold), e sim, em grande parte são projetos com notas mais baixas (Certified e Silver). Como esse tema de créditos usualmente é buscado quando o projeto esgotou as possibilidades de atender outros itens avaliados pelo sistema o seu destaque parece indicar que estão sendo usados como alternativa a outros quesitos básicos já avaliados pelo LEED.

No banco de dados foi possível identificar 7 projetos ( 1 em 2003, 3 em 2004 e outros 3 em 2005) que foram certificados com a nota mais baixa possível (26 pontos - Certified) que no entanto, conseguiram todos os 4 pontos de inovação. Dentre os mesmos projetos um em particular cumpriu apenas um único crédito em uma das questões mais estratégicas da sustentabilidade: uso racional da água. O único crédito que esse projeto em particular cumpriu nesse tema foi a redução de $20 \%$ no uso da água — considerada uma exigência conservadora e quase obrigatória para qualquer empreendimento que almeje algum status de alto desempenho ambiental.

Observando-se a média das notas nos diversos itens, plotadas da maneira a seguir, é possível traçar um "mapa" de créditos entre os projetos certificados com a categoria CERTIFIED até a categoria mais alta PLATINUM. Nesse gráfico estão plotados os itens avaliados no eixo $\mathrm{X}$ e as médias das 4 categorias de notas (CERTIFIED, SILVER, GOLD e PLATINUM) no eixo Y. As cores frias indicam créditos com médias baixas e as cores quentes indicam créditos com médias altas. Dessa forma, por exemplo, as linhas azuis que atravessam as diversas categorias (direção vertical) indicam créditos mais descartados, pouco escolhidos. Enquanto as linhas verde-claro indicam créditos alcançados, muito escolhidos pelos projetos avaliados em todas as categorias, do Certified até o Platinum. 


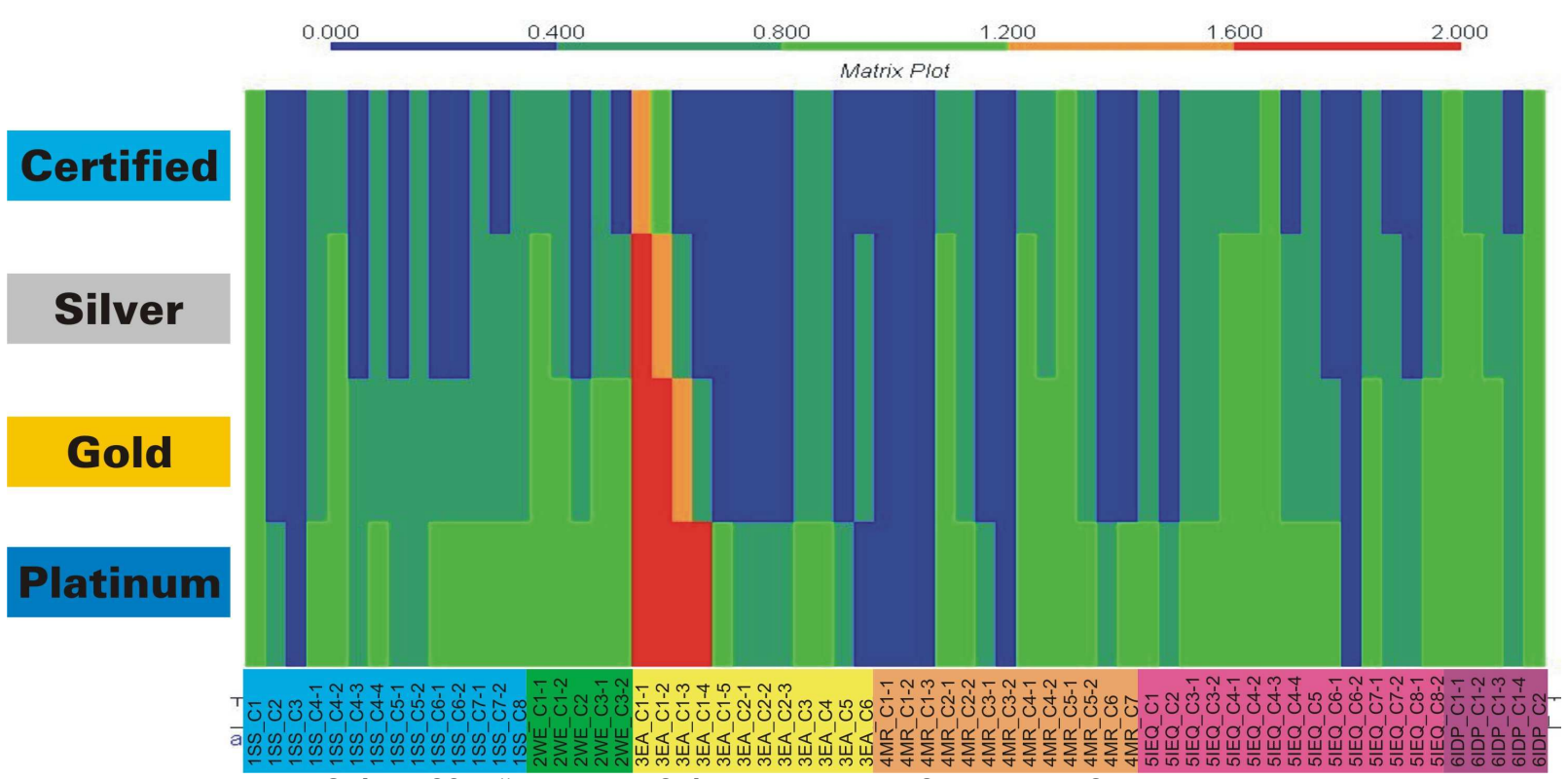

Gráfico 20 - "MAPA" de Créditos do LEED-NC para cada Categoria.

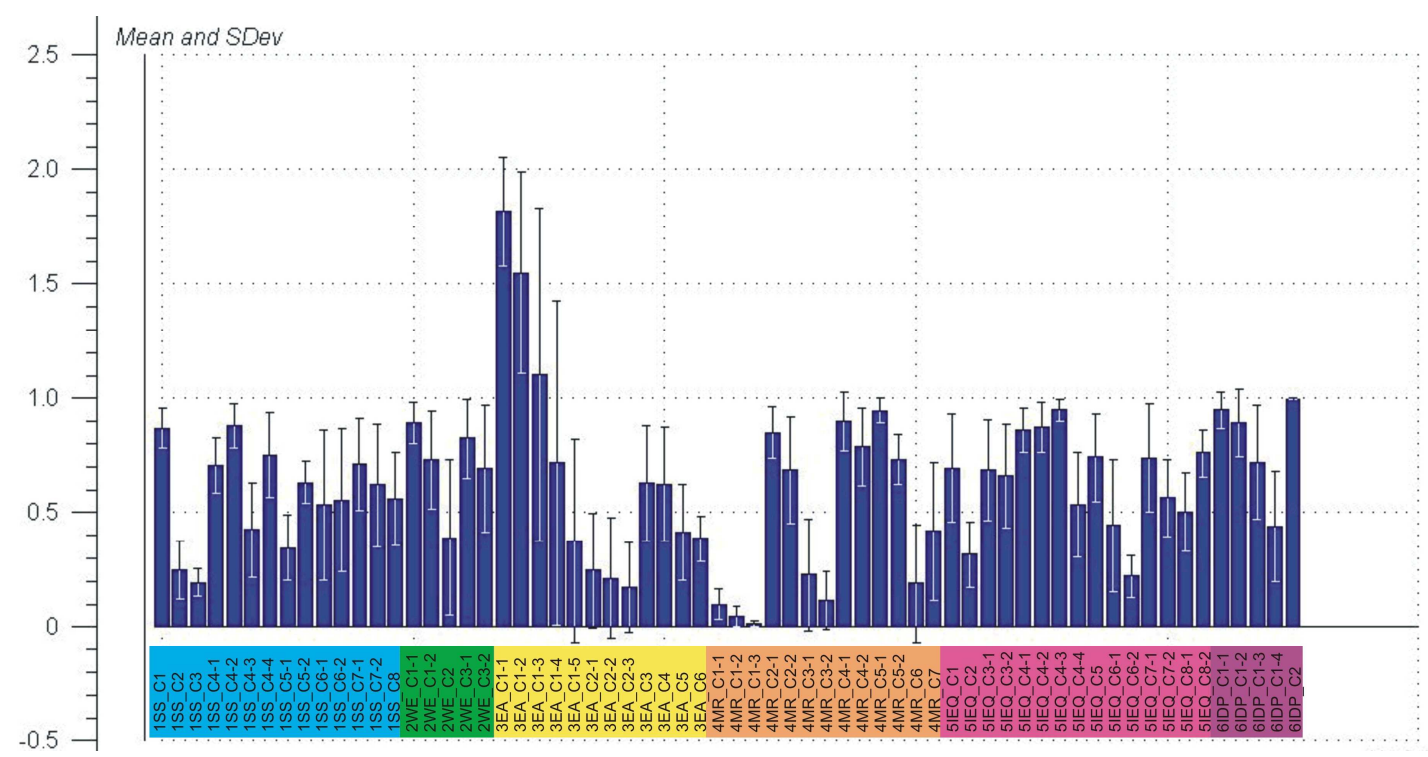

Gráfico 21 - Média com desvio padrão dos créditos para todo 0 universo da amostra.

Observando-se a escolha dos temas MAIS alcançados e MENOS alcançados nas certificações, observa-se um certo nível de equilíbrio entre os mais alcançados e uma discrepância entre os mais rejeitados, notadamente o papel do tema Materials \& Resources que, apesar de aparecer entre os mais alcançados, destaca-se como um dos temas mais rejeitados entre os 6 existentes. Sendo que os créditos menos alcançados desse tema são aqueles relacionados com: [1] o reuso da massa construída, [2] reuso de materiais e [3] uso de materiais rapidamente renováveis. 
Os temas mais escolhidos nos 16 itens mais conseguidos ( $25 \%$ dos 64 itens)

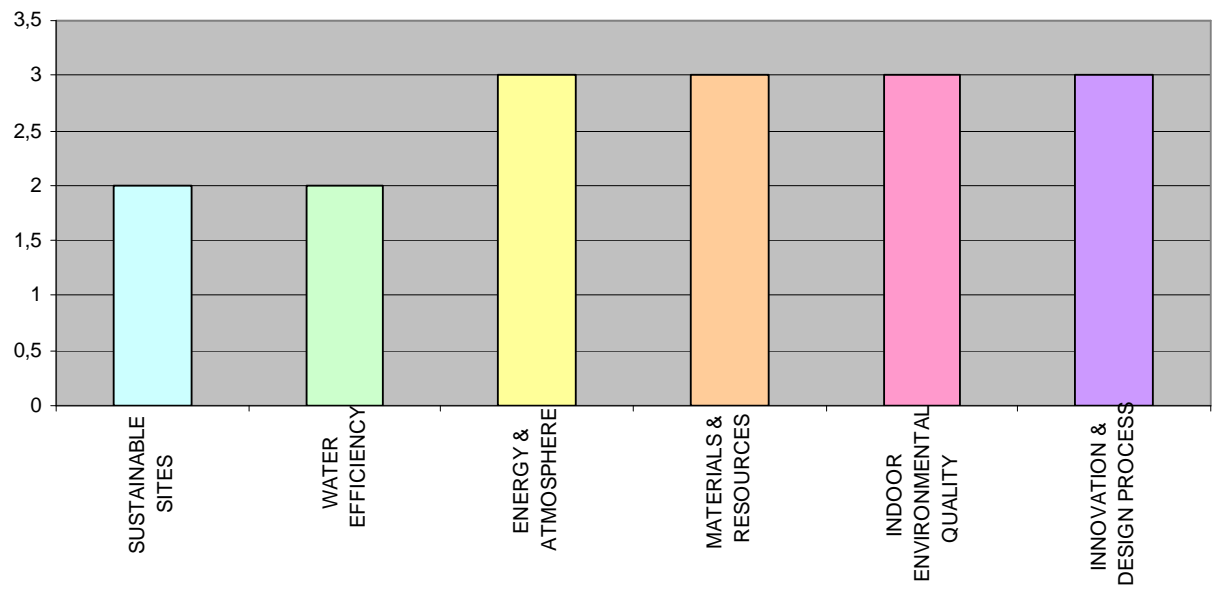

Gráfico 22 - 0s temas presentes nos 16 itens MAIS conseguidos (25\% mais altos).

Os temas mais escolhidos nos 32 itens mais conseguidos ( $50 \%$ dos 64 Itens)

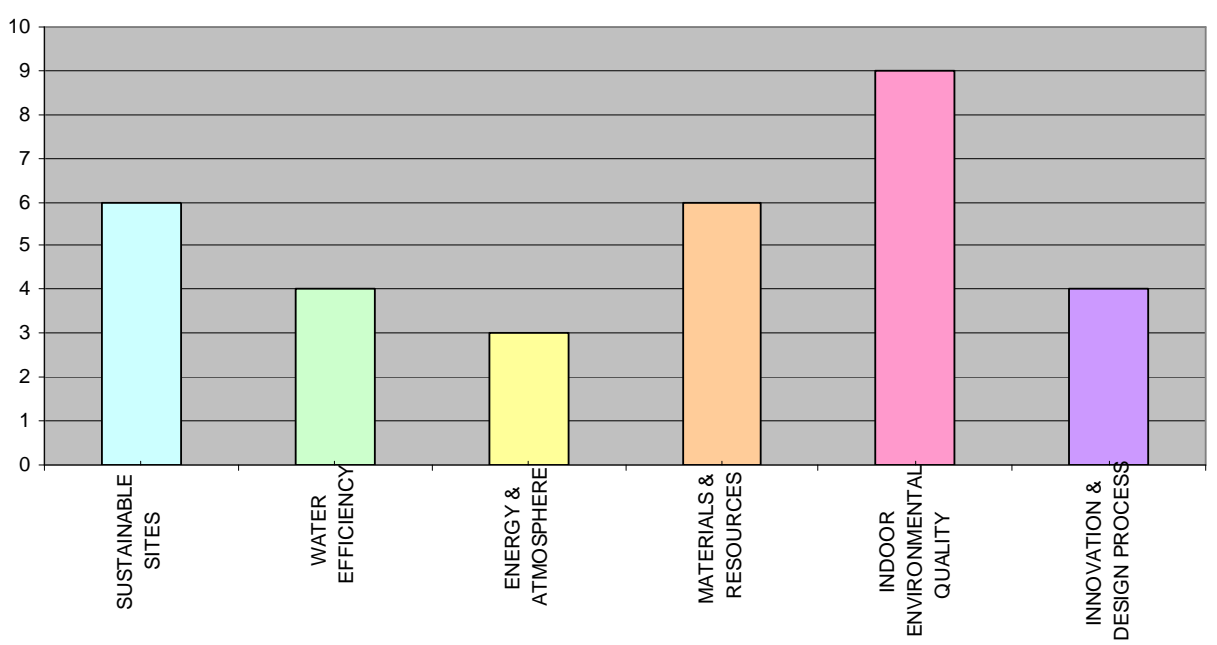

Gráfico 23 - 0s temas presentes nos 32 itens MAIS conseguidos ( $50 \%$ mais altos). 
Os temas mais escolhidos nos 16 itens MENOS conseguidos (25\% dos 64 Itens)

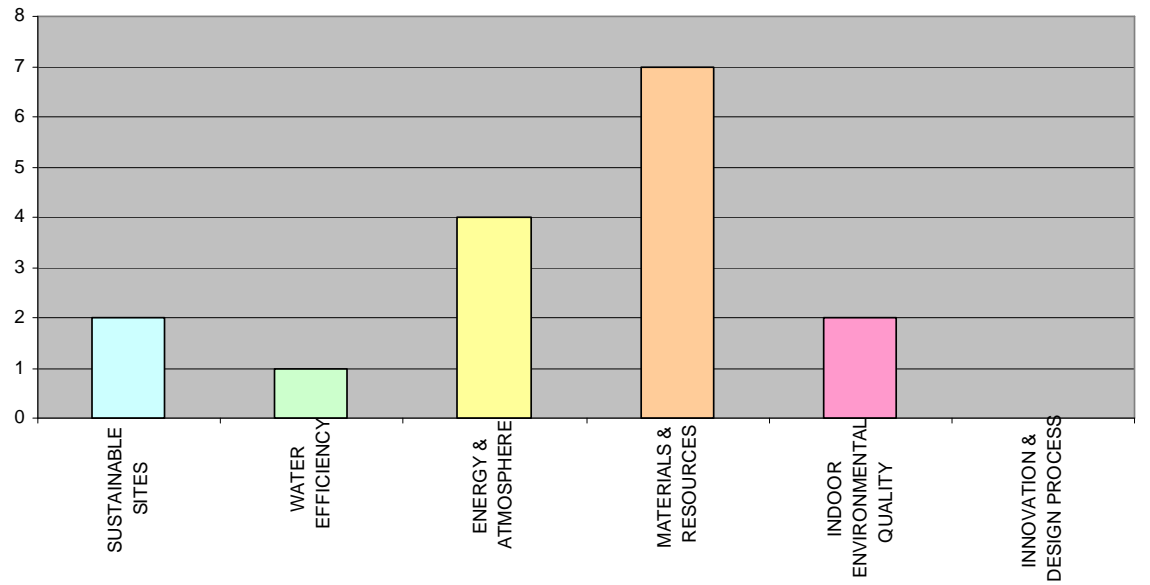

Gráfico 24 - 0s temas mais presentes nos 16 itens MENOS conseguidos (25\% mais baixos).

Quando se analisa a relação entre os itens MAIS alcançados com o tipo de benefício que esses itens oferecem para o empreendimento observa-se, como era de se esperar, uma hierarquia de graduação equivalente à facilidade de se medir esses mesmos benefícios (JOHNSON, 2000), ou seja, quanto mais fácil é para o empreendimento identificar a vantagem para ele mais privilegiado é o item.

No entanto um fato chama a atenção. Contra o senso comum de que essa hierarquia deveria se inverter entre os créditos MENOS alcançados, observa-se que, com uma pequena variação, ela se mantém. Ao que parece os motivos para não escolher alguns itens não parece ter relação com as vantagens, mas sim com as desvantagens dos mesmos. Nesses itens, questões como viabilidade econômica e técnica são mais determinantes do que as potenciais vantagens dos mesmos.

\section{Créditos MAIS Privilegiados}

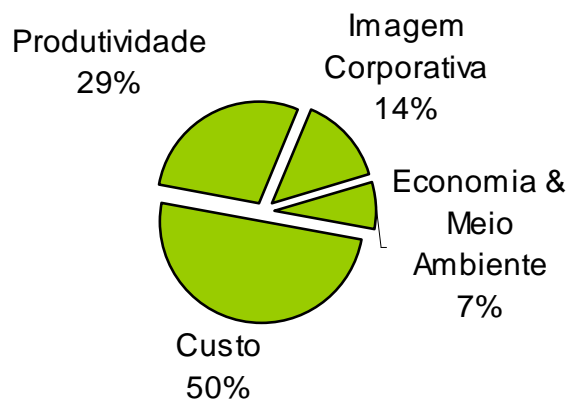

Gráfico 25 - Número de Créditos X Camada de Benefício dos 16 itens MAIS conseguidos. 


\section{Créditos MENOS Privilegiados}

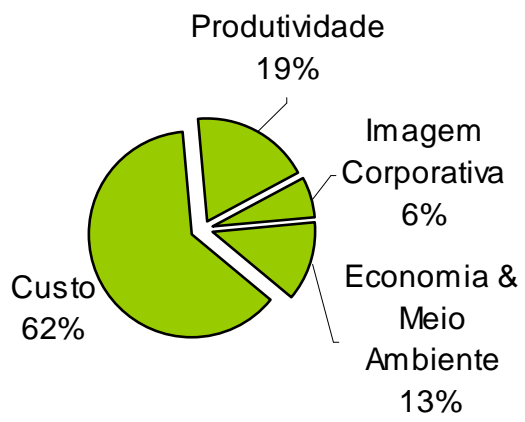

\section{Gráfico 26 - Número de Créditos X Camada de Benefício dos 16 itens MENOS conseguidos.}

Ainda com base no banco de dados foi possível observar:

[1] Apesar do sistema LEED permitir que um projeto seja certificado mesmo "zerando" um tema (ou seja, não conseguindo nenhum crédito além dos pré-requisitos) observou-se de fato que isso aconteceu com apenas $5 \%$ dos projetos avaliados.

[2] Observando-se os temas e créditos mais alcançados pelos projetos, percebe-se o significativo papel dos fornecedores de materiais de construção com bom desempenho ambiental. No total, metade dos créditos relacionados com a escolha de materiais de alto desempenho ambiental estão entre os mais alcançados. Nos EUA, instituições setoriais representando diversos tipos de materiais, tais como carpetes, tintas e madeira já se organizaram no sentido de cobrar das indústrias o atendimento às normas mínimas de desempenho.

[3] Entre os créditos mais alcançados do LEED ${ }^{\mathrm{TM}}$, observa-se o destaque aos créditos que apresentam grande potencial de economia de energia, água e, consequentemente, dinheiro.

[4] Notadamente, os créditos diretamente relacionados com o papel dos clientes/empreendedores — a escolha do terreno e o reaproveitamento de edifícios existentes — destacam-se entre os créditos mais rejeitados, representando 5 dos 16 créditos menos alcançados.

[5] Aparentemente os créditos relacionados com o incentivo às energias alternativas apresentam ainda um grande desafio para os projetos, já que apresentam 4 dos 16 créditos mais rejeitados. 


\subsection{QUADRO GERAL COMENTADO}

Com base nos resultados dos itens mais e menos alcançados do banco de dados, foi possível produzir um quadro com todos os itens de avaliação do sistema LEED-NC (aqui na sua versão 2.2), onde são relacionados:

[1] O Código do item de avaliação;

[2] O Nome do Item;

[3] O Objetivo/Intenção do item;

[4] Aspectos mais significativos do Desafio que esse item representa para ser alcançado no Brasil e

[5] Comentários sobre os itens Mais Alcançados e Itens Menos Alcançados.

A seguir é reproduzido o quando geral do sistema LEED com os comentários: 


\begin{tabular}{|c|c|c|c|c|}
\hline Código & $\begin{array}{l}\text { NC } 2.2 \text { Nome do } \\
\text { Item }\end{array}$ & NC 2.2 Objetivo/Intenção & Desafio & \begin{tabular}{|lccc} 
Itens & Mais & Alcançados & e \\
ltens Menos Alcançados & &
\end{tabular} \\
\hline \multicolumn{5}{|c|}{ Sustainable Sites } \\
\hline 1SS_Prereq_1 & $\begin{array}{l}\text { Construction } \\
\text { Activity } \\
\text { Pollution } \\
\text { Prevention } \\
\text { Required }\end{array}$ & \begin{tabular}{|l} 
Reduce pollution from \\
construction activities by \\
controlling soil erosion, \\
waterway sedimentation \\
and airborne dust \\
generation.
\end{tabular} & $\begin{array}{l}\text { Apesar do licenciamento ambiental de alguns } \\
\text { empreendimentos no Brasil exigir cuidados nesse tema isso } \\
\text { ainda pode ser considerado distante da realidade nacional não } \\
\text { tanto por aspectos de custo mas mais por falta de cultura em } \\
\text { ações desse gênero. }\end{array}$ & \\
\hline 1SS_C1 & Site Selection & $\begin{array}{l}\text { Avoid development of } \\
\text { inappropriate sites and } \\
\text { reduce the environmental } \\
\text { impact from the location of } \\
\text { a building on a site. }\end{array}$ & $\begin{array}{l}\text { Exigências contribuem para diminuir a pressão da urbanização } \\
\text { em áreas agrícolas ou reservas biológicas em contraposição ao } \\
\text { modelo presente no país de urbanização de baixa densidade } \\
\text { em áreas periféricas promovendo a constante ampliação do } \\
\text { perímetro urbano. }\end{array}$ & $\begin{array}{l}\text { Explicações possíveis: [1] as exigências } \\
\text { são pouco restritivas (as áreas restritas já } \\
\text { tendem naturalmente a repelir } \\
\text { empreendimentos). }\end{array}$ \\
\hline 1SS_C2 & $\begin{array}{l}\text { Development } \\
\text { Density \& } \\
\text { Community } \\
\text { Connectivity }\end{array}$ & $\begin{array}{l}\text { Channel development to } \\
\text { urban areas with existing } \\
\text { infrastructure, rotect } \\
\text { greenfields and preserve } \\
\text { habitat and natural } \\
\text { resources. }\end{array}$ & $\begin{array}{l}\text { Apesar de não representar nenhum desafio técnico específico } \\
\text { esse crédito encontra grande resistência nas análises de } \\
\text { viabilidade econômica alinhadas ao modelo presente no país } \\
\text { de urbanização de baixa densidade em áreas periféricas } \\
\text { promovendo a constante a constante ampliação do perímetro } \\
\text { urbano. }\end{array}$ & $\begin{array}{l}\text { Explicações possíveis: }[1] \text { são } \\
\text { significativamenteronerosas } \\
\text { economicamente (principalmente pelo alto } \\
\text { valor de terrenos densos inseridos no } \\
\text { tecido urbano). }\end{array}$ \\
\hline 1SS_C3 & $\begin{array}{l}\text { Brownfield } \\
\text { Redevelopment }\end{array}$ & $\begin{array}{|lr|}\text { Rehabilitate damaged sites } \\
\text { where development is } \\
\text { complicated } \\
\text { environmental by } \\
\text { contamination, reducing } \\
\text { pressure on undeveloped } \\
\text { land. }\end{array}$ & $\begin{array}{l}\text { A urbanização de áreas contaminadas se apresenta como um } \\
\text { desafio de grande ordem no país pelo alto custo das medidas } \\
\text { de reparação e pela constante disponibilidade de áreas de } \\
\text { baixo custo conseguidas com constantes ampliações do } \\
\text { perímetro urbano das cidades }{ }^{29} \text {. }\end{array}$ & $\begin{array}{l}\text { Explicações possíveis: [1] são } \\
\text { significativamente onerosas } \\
\text { economicamente (principalmente pelo alto } \\
\text { custo das ações de recuperação e pela } \\
\text { grande extensão de intervenção na } \\
\text { maioria dos casos). }\end{array}$ \\
\hline
\end{tabular}

${ }^{29}$ No entanto, em entrevista com Artur BASTOS (BASTOS, 2006) — diretor de empresa de consultoria ambiental de São José do Rio Preto-SP — ele esclareceu que em casos muito específicos como em terrenos de postos de gasolina em áreas urbanas é possível encontrar situações em que alternativas relativamente baratas (entre $R \$ 15$ mil e $R \$ 20$ mil) como 0 bombeamento de água, injeção de nutrientes e ar ou a fitoremediação podem garantir o aproveitamento da área para empreendimentos imobiliários. 


\begin{tabular}{|c|c|c|c|c|}
\hline 1SS_C4-1 & $\begin{array}{l}\text { Alternative } \\
\text { Transportation, } \\
\text { Public } \\
\text { Transportation } \\
\text { Access }\end{array}$ & $\begin{array}{l}\text { Reduce pollution and land } \\
\text { development impacts from } \\
\text { automobile use. }\end{array}$ & $\begin{array}{l}\text { O incentivo ao uso de transporte coletivo tem sintonia com os } \\
\text { problemas de mobilidade urbana no país mas a disponibilidade } \\
\text { e qualidade desse serviço público pode ser considerada } \\
\text { deficiente na maioria das cidades brasileiras. }\end{array}$ & \\
\hline 1SS_C4-2 & $\begin{array}{l}\text { Alternative } \\
\text { Transportation, } \\
\text { Bicycle Storage } \\
\text { \& Changing } \\
\text { Rooms }\end{array}$ & $\begin{array}{l}\text { Reduce pollution and land } \\
\text { development impacts from } \\
\text { automobile use. }\end{array}$ & $\begin{array}{l}\text { O incentivo ao uso de bicicletas é de simples implantação na } \\
\text { perspectiva do empreendimento mas enfrenta desafios para } \\
\text { ser efetivamente utilizado: falta de espaços de circulação } \\
\text { específico para bicicletas (tais como ciclovias), falta de } \\
\text { segurança pública e grandes distâncias relacionadas à baixa } \\
\text { densidade das cidades. }\end{array}$ & $\begin{array}{l}\text { Explicações possíveis: [1] tem impacto } \\
\text { físico e financeiro pequenos para } \\
\text { empreendimentos de grande e médio } \\
\text { porte; [2] as soluções podem ser usadas } \\
\text { como diferencial de mercado como uma } \\
\text { facilidade do empreendimento relacionada } \\
\text { diretamente à qualidade de vida dos } \\
\text { usuários. }\end{array}$ \\
\hline 1SS_C4-3 & $\begin{array}{l}\text { Alternative } \\
\text { Transportation, } \\
\text { Low Emitting \& } \\
\text { Fuel Efficient } \\
\text { Vehicles }\end{array}$ & $\begin{array}{l}\text { Reduce pollution and land } \\
\text { development impacts from } \\
\text { automobile use. }\end{array}$ & $\begin{array}{l}\text { O incentivo ao uso de combustíveis alternativos pode ser de } \\
\text { fácil implantação caso o álcool seja considerado como } \\
\text { combustível alternativo. O uso de "carpools" e "vanpools" no } \\
\text { país ainda é pouco conhecido e disseminado fora dos usos } \\
\text { típicos em grandes empresas com frota própria. }\end{array}$ & \\
\hline 1SS_C4-4 & $\begin{array}{l}\text { Alternative } \\
\text { Transportation, } \\
\text { Parking } \\
\text { Capacity }\end{array}$ & $\begin{array}{l}\text { Reduce pollution and land } \\
\text { development impacts from } \\
\text { single occupancy vehicle } \\
\text { use. }\end{array}$ & $\begin{array}{l}\text { A exigência relacionada com a diminuição das vagas de } \\
\text { estacionamento é de simples implantação e tem grande } \\
\text { sintonia em potencial com interesses econômicos em diminuir a } \\
\text { demanda por área construída. Novamente, o uso de "carpools" } \\
\text { e "vanpools" no país ainda é pouco conhecido e disseminado } \\
\text { fora dos usos típicos em grandes empresas com frota própria. }\end{array}$ & \\
\hline 1SS_C5-1 & $\begin{array}{l}\text { Site } \\
\text { Development, } \\
\text { Protect or } \\
\text { Restore Habitat }\end{array}$ & $\begin{array}{l}\text { Conserve existing } \text { natural } \\
\text { areas and } \text { restore } \\
\text { damaged areas to provide } \\
\text { habitat and promote } \\
\text { biodiversity. }\end{array}$ & $\begin{array}{l}\text { Conservar áreas naturais ou ampliar as áreas } \\
\text { verdes/permeáveis de um empreendimento tem fácil } \\
\text { implantação técnica mas apresenta um grande desafio devido } \\
\text { ao aproveitamento econômico da área total do } \\
\text { empreendimento. }\end{array}$ & \\
\hline 1SS_C5-2 & $\begin{array}{l}\text { Site } \\
\text { Development, } \\
\text { Maximize Open } \\
\text { Space }\end{array}$ & $\begin{array}{l}\text { Provide a high ratio of } \\
\text { open space } \\
\text { development footprint } \\
\text { promote biodiversity. }\end{array}$ & Idem & \\
\hline
\end{tabular}




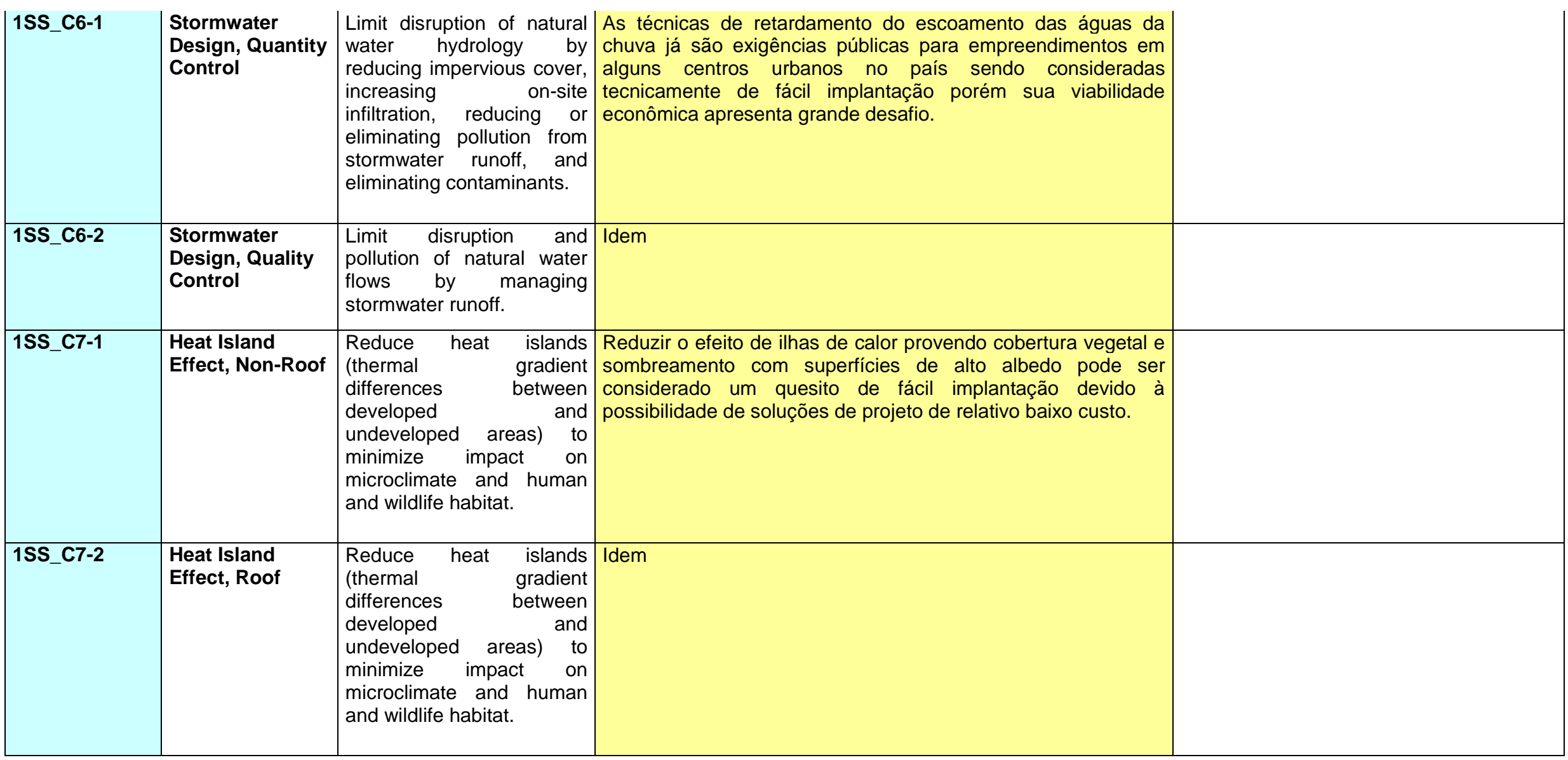




\begin{tabular}{|l|l|l|l|} 
1SS_C8 & $\begin{array}{l}\text { Light Pollution } \\
\text { Reduction }\end{array}$ & $\begin{array}{l}\text { Minimize light trespass } \\
\text { from the building and site, } \\
\text { reduce sky-glow towinuição da poluição luminosa pode ser considerada um } \\
\text { increase night sky access, } \\
\text { improve nighttime visibility } \\
\text { through glare reduction, } \\
\text { and reduce development } \\
\text { impact on nocturnal } \\
\text { environments. }\end{array}$ & $\mid$ \\
\hline
\end{tabular}

\footnotetext{
${ }^{30}$ ROZENDO (2006) desta o fato de que esse item pode representar um desafio no Brasil devido à falta de experiência nacional em atender os quesitos de desempenho exigidos.
} 


\begin{tabular}{|c|c|c|c|c|}
\hline Código & $\begin{array}{l}\text { NC } 2.2 \text { Nome do } \\
\text { Item }\end{array}$ & NC 2.2 Objetivo/Intenção & Desafio & \begin{tabular}{|l} 
Itens $\quad$ Mais $\quad$ Alcançados \\
Itens Menos Alcançados
\end{tabular} \\
\hline \multicolumn{5}{|c|}{ Water Efficiency } \\
\hline 2WE_C1-1 & $\begin{array}{l}\text { Water Efficient } \\
\text { Landscaping, } \\
\text { Reduce by } 50 \%\end{array}$ & $\begin{array}{l}\text { Limit or eliminate the use } \\
\text { of potable water, or other } \\
\text { natural surface or } \\
\text { subsurface } \\
\text { resources available on or } \\
\text { near the project site, for } \\
\text { landscape irrigation. }\end{array}$ & $\begin{array}{l}\text { A diminuição ou mesmo a completa eliminação do uso de água } \\
\text { potável para irrigação de paisagismo pode ser considerada um } \\
\text { quesito de fácil implantação devido à possibilidade de soluções } \\
\text { de projeto de relativo baixo custo. }\end{array}$ & $\begin{array}{l}\text { As soluções possíveis para o item: [1] } \\
\text { tendem a ter baixo impacto físico e } \\
\text { econômico no empreendimento; [2] tem } \\
\text { potencial para economizar dinheiro e [3] } \\
\text { são interessantes como instrumento } \\
\text { mercadológico diferencial. }\end{array}$ \\
\hline 2WE_C1-2 & $\begin{array}{l}\text { Water Efficient } \\
\text { Landscaping, No } \\
\text { Potable Use or } \\
\text { No Irrigation }\end{array}$ & $\begin{array}{|lr|}\text { Eliminate the use of } \\
\text { potable water, or other } \\
\text { natural surface or } \\
\text { subsurface } \quad \text { water } \\
\text { resources available on or } \\
\text { near the project site, for } \\
\text { landscape irrigation. }\end{array}$ & $\begin{array}{l}\text { A diminuição ou mesmo a completa eliminação do uso de água } \\
\text { potável para irrigação de paisagismo pode ser considerada um } \\
\text { quesito de fácil implantação devido à possibilidade de soluções } \\
\text { de projeto de relativo baixo custo }^{31} \text {. }\end{array}$ & \\
\hline 2WE_C2 & $\begin{array}{l}\text { Innovative } \\
\text { Wastewater } \\
\text { Technologies }\end{array}$ & $\begin{array}{l}\text { Reduce generation of } \\
\text { wastewater and potable } \\
\text { water demand, while } \\
\text { increasing the local aquifer } \\
\text { recharge. }\end{array}$ & $\begin{array}{l}\text { A redução da geração de esgoto e demanda por água potável } \\
\text { pode representa um desafio de grande ordem pelo custo e falta } \\
\text { de cultura nacional em iniciativas desse gênero }\end{array}$ & $\begin{array}{l}\text { Explicações possíveis: [1] são } \\
\text { significativamente onerosas } \\
\text { economicamente (tanto na opção de } \\
\text { economia de água como na possibilidade } \\
\text { de tratamento de esgoto no local). }\end{array}$ \\
\hline 2WE_C3-1 & $\begin{array}{l}\text { Water Use } \\
\text { Reduction, 20\% } \\
\text { Reduction }\end{array}$ & $\begin{array}{l}\text { Maximize water efficiency } \\
\text { within buildings to reduce } \\
\text { the burden on municipal } \\
\text { water supply and } \\
\text { wastewater systems. }\end{array}$ & $\begin{array}{l}\text { A redução da geração de esgoto e demanda por água potável } \\
\text { pode ser considerado de fácil implantação pelo fato de } \\
\text { potencialmente ser alcançadas com um relativo pequeno } \\
\text { acréscimo no orçamento para dispositivos de alta eficiência. }\end{array}$ & $\begin{array}{l}\text { As soluções possíveis para o item: [1] } \\
\text { tendem a ter baixo impacto físico e } \\
\text { impacto econômico absorvível no } \\
\text { empreendimento; [2] tem potencial para } \\
\text { economizar dinheiro e [3] são } \\
\text { interessantes comor instrumento } \\
\text { mercadológico diferencial. }\end{array}$ \\
\hline
\end{tabular}

${ }^{31}$ Para o clima brasileiro na maioria do território nacional uma preparação adequada do solo antes da execução do projeto paisagístico pode garantir a sobrevida da vegetação sem sistema de irrigação espećifico na maioria dos casos (BASTOS, 2006).

${ }^{32}$ No entanto, sistemas compactos de tratamento de água de lavatórios e chuveiros (“água cinza”) podem ser feitos de maneira compacta e a preços acessíveis para empreendimentos de pequeno e médio porte. 
2WE_C3-2

Water Use

Reduction, $30 \%$

Reduction

Maximize water efficiency A redução da geração de esgoto e demanda por água potável

within buildings to reduce em uma porcentagem ainda maior representa um desafio caso

the burden on municipal seja necessário o uso de técnicas ainda não usuais no país

water supply

wastewater systems. 


\begin{tabular}{|c|c|c|c|c|}
\hline Código & $\begin{array}{l}\text { NC } 2.2 \text { Nome do } \\
\text { Item }\end{array}$ & NC 2.2 Objetivo/Intenção & Desafio & $\begin{array}{l}\text { Itens Mais Alcançados } \\
\text { ltens Menos Alcançados }\end{array}$ \\
\hline \multicolumn{5}{|c|}{ Energy \& Atmosphere } \\
\hline 3EA_Prereq_1 & $\begin{array}{l}\text { Fundamental } \\
\text { Commissioning } \\
\text { of the Building } \\
\text { Energy Systems } \\
\text { Required }\end{array}$ & $\begin{array}{l}\text { Verify that the building's } \\
\text { energy related systems are } \\
\text { installed, calibrated and } \\
\text { perform according to the } \\
\text { owner's project } \\
\text { requirements, basis of } \\
\text { design, and construction } \\
\text { documents. }\end{array}$ & $\begin{array}{l}\text { Apesar da falta de cultura nacional relacionada com o } \\
\text { "comissionamento" para a análise do projeto e funcionamento } \\
\text { de um empreendimento esse item pode ser considerado um } \\
\text { desafio técnico de baixa ordem mas com custo elevado no } \\
\text { momento }{ }^{33} \text {. }\end{array}$ & \\
\hline 3EA_Prereq_2 & $\begin{array}{l}\text { Minimum Energy } \\
\text { Performance } \\
\text { Required }\end{array}$ & $\begin{array}{l}\text { Establish the minimum } \\
\text { level of energy efficiency } \\
\text { for the proposed building } \\
\text { and systems. }\end{array}$ & $\begin{array}{l}\text { Devido ao fato do item estar atrelado ao desempenho definido } \\
\text { em norma norte-americana e o país carecer de referências } \\
\text { oficiais nesse tema, a definição do nível mínimo de eficiência } \\
\text { pode apresentar um grande desafio devido à potencial } \\
\text { indefinição. }\end{array}$ & \\
\hline 3EA_Prereq_3 & $\begin{array}{l}\text { Fundamental } \\
\text { Refrigerant } \\
\text { Management } \\
\text { Required }\end{array}$ & Reduce ozone depletion. & $\begin{array}{l}\text { Devido à prévia adaptação dos fornecedores nacionais e } \\
\text { internacionais quanto à emissão de CFC para a atmosfera esse } \\
\text { item pode ser considerado de fácil implantação já que } \\
\text { representa uma posição próxima ao "establishment". }\end{array}$ & \\
\hline
\end{tabular}

${ }^{33}$ ROZENDO (2006) chama a atenção de que “isso (Comissionamento) não existe no Brasil” e pode ser considerado um item de custo significativo. 


\begin{tabular}{|c|c|c|c|c|}
\hline 3EA_C1 & $\begin{array}{l}\text { Optimize Energy } \\
\text { Performance }\end{array}$ & $\begin{array}{l}\text { Achieve increasing levels } \\
\text { of energy performance } \\
\text { above the baseline in the } \\
\text { prerequisite standard to } \\
\text { reduce environmental and } \\
\text { economic impacts } \\
\text { associated with excessive } \\
\text { energy use. }\end{array}$ & $\begin{array}{l}\text { Considerando que o nível mínimo de desempenho tenha sido } \\
\text { definido e corresponda à algo próximo do mínimo nacional uma } \\
\text { eficiência próxima de } 10 \% \text { para edifícos novos pode ser } \\
\text { considerada como médio desafio já que episódios como o risco } \\
\text { de "apagão" elétrico em } 2001 \text { incentivaram a disseminação de } \\
\text { práticas de alta eficiência energética, no entanto, qualquer } \\
\text { acréscimo a esse valor tem potencial de representar um } \\
\text { desafio de grande ordem }{ }^{34} \text {. }\end{array}$ & $\begin{array}{l}\text { As soluções possíveis para o item: [1] } \\
\text { podem ser alcançadas com interferências } \\
\text { físicas que valorizam o espaço útil (como } \\
\text { boa iluminação natural); [2] tem impacto } \\
\text { econômico amortizado pela valorização } \\
\text { direta do imóvel; [3] tem potencial para } \\
\text { economizar dinheiro e [4] são } \\
\text { interessantes como instrumento } \\
\text { mercadológico diferencial. No as } \\
\text { percentagens de economia mais altas } \\
\text { figuram entre os créditos menos } \\
\text { alcançados. }\end{array}$ \\
\hline 3EA_C2 & $\begin{array}{l}\text { On-Site } \\
\text { Renewable } \\
\text { Energy }\end{array}$ & $\begin{array}{l}\text { Encourage and recognize } \\
\text { increasing levels of on-site } \\
\text { renewable energy self- } \\
\text { supply in order to reduce } \\
\text { environmental and } \\
\text { economic impacts } \\
\text { associated with fossil fuel } \\
\text { energy use. }\end{array}$ & $\begin{array}{l}\text { O uso de sistemas de baixo custo para aquecimento solar pode } \\
\text { facilmente representar uma economia de até } 30 \% \text { de energia } \\
\text { elétrica em algumas tipologias como residências e hotéis, no } \\
\text { entanto, caso não seja possível considerar essa prática o uso } \\
\text { de outras fontes de energia renováveis dentro da área de } \\
\text { intervenção se apresenta como um desafio de grande } \\
\text { magnitude devido ao alto custo, demanda por áreas e } \\
\text { demanda técnica relacionada com a instalação e manutenção } \\
\text { dos sistemas (sendo que mesmo sistemas de baixa } \\
\text { manutenção como células fotovoltaicas tem custo elevado } \\
\text { devido à ausência de equivalentes nacionais para seus } \\
\text { insumos). }\end{array}$ & \begin{tabular}{|lrr} 
Explicações possíveis: & [1] são \\
significativamente & onerosas \\
economicamente. &
\end{tabular} \\
\hline 3EA_C3 & $\begin{array}{l}\text { Enhanced } \\
\text { Commissioning }\end{array}$ & $\begin{array}{l}\text { Begin the commissioning } \\
\text { process early during the } \\
\text { design process and } \\
\text { execute additional activities } \\
\text { after systems performance } \\
\text { verification is completed. }\end{array}$ & $\begin{array}{l}\text { Apesar da falta de cultura nacional relacionada com o } \\
\text { "comissionamento" para a análise do projeto e funcionamento } \\
\text { de um empreendimento essa técnica pode ser considerada } \\
\text { tecnicamente e economicamente de fácil implantação. }\end{array}$ & \\
\hline 3EA_C4 & $\begin{array}{l}\text { Enhanced } \\
\text { Refrigerant } \\
\text { Management }\end{array}$ & $\begin{array}{l}\text { Reduce ozone depletion } \\
\text { and support } \\
\text { compliance with the } \\
\text { Montreal Protocol while } \\
\text { minimizing } \\
\text { contributions to global }\end{array}$ & $\begin{array}{l}\text { Devido à prévia adaptação dos fornecedores nacionais e } \\
\text { internacionais quanto à emissão de CFC para a atmosfera esse } \\
\text { item pode ser considerado um requisito de baixo desafio } \\
\text { técnico mas com significativo desafio econômico já que os } \\
\text { equipamentos sem HCFCs e Halons são, em sua maioria, } \\
\text { importados. }\end{array}$ & \\
\hline
\end{tabular}

${ }^{34}$ ROMERO (2006) esclarece que a otimização do consumo de energia em edifícios no Brasil, tipicamente, edifícios de escritório nos grandes centros, podem com relativo baixo esforço alcançar eficiências de 10\% além do padrão estabelecido na ASHRAE citada, no entanto, percentuais maiores ainda representam desafios. 


\begin{tabular}{|c|c|c|c|c|}
\hline & & warming. & & \\
\hline 3EA_C5 & $\begin{array}{l}\text { Measurement \& } \\
\text { Verification }\end{array}$ & $\begin{array}{l}\text { Provide for the ongoing } \\
\text { accountability of building } \\
\text { energy consumption over } \\
\text { time. }\end{array}$ & $\begin{array}{l}\text { Sistemas prediais de medição e monitoramento ainda se } \\
\text { encontram em fase prematura de transferência de tecnologia } \\
\text { migrando de empreendimentos de alto custo para os de médio } \\
\text { custo (sendo que usualmente se concentram nas tipologias de } \\
\text { edifícios de escritório, hotéis e grandes centro comerciais, } \\
\text { tipicamente de alto custo). }\end{array}$ & \\
\hline 3EA_C6 & Green Power & $\begin{array}{l}\text { Encourage the } \\
\text { development and use of } \\
\text { grid-source, renewable } \\
\text { energy technologies on a } \\
\text { net zero pollution basis. }\end{array}$ & $\begin{array}{l}\text { Caso fontes renováveis de energia como a biomassa de cana } \\
\text { sejam consideradas "Green Power" esse item tem um } \\
\text { significativo potencial de aplicabilidade no país apesar de } \\
\text { aparentemente representar um desafio de grande ordem }{ }^{35} \text {. }\end{array}$ & \\
\hline
\end{tabular}

\footnotetext{
${ }^{35}$ Segundo ROZENDO (2006) não existem projetos de energia certificados no Brasil pela instituição responsável.
} 


\begin{tabular}{|c|c|c|c|c|}
\hline Código & $\begin{array}{l}\text { NC } 2.2 \text { Nome do } \\
\text { Item }\end{array}$ & NC 2.2 Objetivo/Intenção & Desafio & \begin{tabular}{|lcc} 
Itens & Mais $\quad$ Alcançados \\
ltens Menos Alcançadlos
\end{tabular} \\
\hline \multicolumn{5}{|c|}{ Materials \& Resources } \\
\hline 4MR_Prereq_1 & $\begin{array}{l}\text { Storage \& } \\
\text { Collection of } \\
\text { Recyclables } \\
\text { Required }\end{array}$ & $\begin{array}{l}\text { Facilitate the reduction of } \\
\text { waste generated by } \\
\text { building occupants that is } \\
\text { hauled to and disposed of } \\
\text { in landfills. }\end{array}$ & $\begin{array}{l}\text { O Pré-requisito de uma área dentro do empreendimento } \\
\text { voltada para a função de reciclagem pode ser considerada de } \\
\text { fácil implementação devido à inexistência de demandas } \\
\text { técnicas específicas e ao fato de empreendimentos já estarem } \\
\text { em vias de transformar isso em padrão. O fato do Brasil ser um } \\
\text { dos maiores recicladores de materiais como vidro e latas de } \\
\text { alumínio tem um impacto positivo nesse fato. }\end{array}$ & \\
\hline 4MR_C1-1 & $\begin{array}{l}\text { Building Reuse, } \\
\text { Maintain } 75 \% \text { of } \\
\text { Existing Walls, } \\
\text { Floors \& Roof }\end{array}$ & $\begin{array}{l}\text { Extend the life cycle of } \\
\text { existing building stock, } \\
\text { conserve resources, retain } \\
\text { cultural resources, reduce } \\
\text { waste and reduce } \\
\text { environmental impacts of } \\
\text { new buildings as they } \\
\text { relate to materials } \\
\text { manufacturing rand } \\
\text { transport. }\end{array}$ & $\begin{array}{l}\text { As exigências relacionadas com o aproveitamento da massa } \\
\text { construída tem um impacto positivo na diminuição da demanda } \\
\text { por energia e recursos naturais mas apresenta sérias restrições } \\
\text { quanto ao seu potencial por ser viável apenas em casos } \\
\text { específicos de empreendimentos em áreas ocupadas. } \\
\text { Aparentemente o espaço } 3 \text { créditos reservado pelo Sistema } \\
\text { para o aproveitamento do estoque construído parece ser uma } \\
\text { alternativa aos créditos voltados à exigências de áreas verdes } \\
\text { e permeáveis, tão difíceis de serem alcançados em projetos de } \\
\text { reforma. }\end{array}$ & $\begin{array}{l}\text { Explicações possíveis: }[1] \text { são } \\
\text { significativamente } \\
\text { economicamente e/ou [2] representam um } \\
\text { desafio técnico de grande dimensão } \\
\text { (principalmente pela necessidade } \\
\text { constante de adequação da massa } \\
\text { edificada às novas demandas } \\
\text { tecnológicas de trabalho, segurança e } \\
\text { conforto). }\end{array}$ \\
\hline 4MR_C1-2 & $\begin{array}{l}\text { Building Reuse, } \\
\text { Maintain } 95 \% \text { of } \\
\text { Existing Walls, } \\
\text { Floors \& Roof }\end{array}$ & $\begin{array}{l}\text { Extend the life cycle of } \\
\text { existing building stock, } \\
\text { conserve resources, retain } \\
\text { cultural resources, reduce } \\
\text { waste and reduce } \\
\text { environmental impacts of } \\
\text { new buildings as they } \\
\text { relate to } \text { materials } \\
\text { manufacturing } \\
\text { transport. }\end{array}$ & Idem & $\begin{array}{l}\text { Explicações possíveis: }[1] \text { são } \\
\text { significativamente } \\
\text { economicamente e/ou [2] representam um } \\
\text { desafio técnico de grande dimensão } \\
\text { (principalmente pela necessidade } \\
\text { constante de adequação da massa } \\
\text { edificada às novas demandas } \\
\text { tecnológicas de trabalho, segurança e } \\
\text { conforto). }\end{array}$ \\
\hline
\end{tabular}




\begin{tabular}{|c|c|c|c|c|}
\hline 4MR_C1-3 & $\begin{array}{l}\text { Building Reuse, } \\
\text { Maintain } 50 \% \text { of } \\
\text { Interior Non- } \\
\text { Structural } \\
\text { Elements }\end{array}$ & \begin{tabular}{|l} 
Extend the life cycle of \\
existing building stock, \\
conserve resources, retain \\
cultural resources, reduce \\
waste and reduce \\
environmental impacts of \\
new buildings as they \\
relate to $\quad$ materials \\
manufacturing r and \\
transport.
\end{tabular} & Idem & $\begin{array}{l}\text { Explicações possíveis: }[1] \text { são } \\
\text { significativamente } \\
\text { economicamente e/ou [2] representam um } \\
\text { desafio técnico de grande dimensão } \\
\text { (principalmente pela necessidade } \\
\text { constante de adequação da massa } \\
\text { edificada às novas demandas } \\
\text { tecnológicas de trabalho, segurança e } \\
\text { conforto). }\end{array}$ \\
\hline 4MR_C2-1 & $\begin{array}{l}\text { Construction } \\
\text { Waste } \\
\text { Management, } \\
\text { Divert } 50 \% \text { from } \\
\text { Disposal }\end{array}$ & \begin{tabular}{llr|} 
Divert & \multicolumn{2}{c|}{ construction, } \\
demolition and land- \\
clearing debris from \\
disposal in landfills and \\
incinerators. \\
recyclable Redirect \\
resources back to the \\
manufacturing process. \\
Redirect reusable materials \\
to appropriate sites.
\end{tabular} & $\begin{array}{l}\text { Redirecionar metade de todo o entulho gerado na construção } \\
\text { para a reciclagem representa um grande desafio tanto } \\
\text { econômico como técnico quando não existe demanda por tais } \\
\text { materiais, prestadores de serviços especializados em } \\
\text { reciclagem ou mesmo o mínimo de fiscalização para evitar sua } \\
\text { destinação indevida. Em casos particulares como cidades que } \\
\text { já dispõe de um sistema de gerenciamento de resíduos da } \\
\text { construção civil, como já exigem as resoluções do CONAMA - } \\
\text { notadamente a resolução } 307 / 2002 \text { - o reaproveitamento desse } \\
\text { material se torna não só possível como na realidade } \\
\text { obrigatório. }\end{array}$ & $\begin{array}{l}\text { Explicações possíveis: [1] tem grande } \\
\text { afinidade com metas de desempenho } \\
\text { existentes de construtoras [2] podem ter } \\
\text { seu impacto financeiro amortizado pela } \\
\text { economia e [3] tem pouca interferência } \\
\text { física no objeto acabado e } \\
\text { consequentemente no conceito comercial } \\
\text { do empreendimento. }\end{array}$ \\
\hline 4MR_C2-2 & $\begin{array}{l}\text { Construction } \\
\text { Waste } \\
\text { Management, } \\
\text { Divert } 75 \% \text { from } \\
\text { Disposal }\end{array}$ & $\begin{array}{l}\text { Divert construction and } \\
\text { demolition debris from } \\
\text { disposal in landfills and } \\
\text { incinerators. Redirect } \\
\text { recyclable recovered } \\
\text { resources back to the } \\
\text { manufacturing process. } \\
\text { Redirect reusable materials } \\
\text { to appropriate sites. }\end{array}$ & $\begin{array}{l}\text { Redirecionar } 75 \% \text { de todo o entulho gerado na construção para } \\
\text { a reciclagem representa um grande desafio tanto econômico } \\
\text { como técnico quando não existe demanda por tais materiais, } \\
\text { prestadores de serviços especializados em reciclagem ou } \\
\text { mesmo o mínimo de fiscalização para evitar sua destinação } \\
\text { indevida. Em casos particulares como cidades que já dispõe de } \\
\text { um sistema de gerenciamento de resíduos da construção civil, } \\
\text { como já exigem as resoluções do CONAMA - notadamente a } \\
\text { resolução } 307 / 2002 \text { - o reaproveitamento desse material se } \\
\text { torna não só possível como na realidade obrigatório. }\end{array}$ & \\
\hline
\end{tabular}




\begin{tabular}{|c|c|c|c|c|}
\hline 4MR_C3-1 & $\begin{array}{l}\text { Materials Reuse, } \\
5 \%\end{array}$ & $\begin{array}{l}\text { Reuse building materials } \\
\text { and products in order to } \\
\text { reduce demand for virgin } \\
\text { materials and to reduce } \\
\text { waste, thereby reducing } \\
\text { impacts associated with } \\
\text { the extraction and } \\
\text { processing of virgin } \\
\text { resources. }\end{array}$ & $\begin{array}{l}\text { O Reuso de materiais em empreendimentos novos representa } \\
\text { mais uma mudança de mentalidade relacionada com a } \\
\text { viabilização do produto imobiliário que propriamente um desafio } \\
\text { técnico, no entanto, a exigência de } 5 \% \text { de materiais reusados } \\
\text { em custo total de materiais representa um desafio pelo fato de } \\
\text { que, usualmente, os materiais reaproveitados mais facilmente } \\
\text { incorporáveis ao projeto terem baixo custo. }\end{array}$ & $\begin{array}{l}\text { Explicações possíveis: [1] representam } \\
\text { um desafio de coordenação entre projeto } \\
\text { e construção (para os casos de } \\
\text { aproveitamento de materiais da própria } \\
\text { construção) e/ou [2] estão diretamente } \\
\text { relacionados à disponibilidade de } \\
\text { produtos reaproveitados ou serviços de } \\
\text { fornecedores específicos. }\end{array}$ \\
\hline 4MR_C3-2 & $\begin{array}{l}\text { Materials Reuse, } \\
10 \%\end{array}$ & $\begin{array}{l}\text { Reuse building materials } \\
\text { and products in order to } \\
\text { reduce demand for virgin } \\
\text { materials and to reduce } \\
\text { waste, thereby reducing } \\
\text { impacts associated with } \\
\text { the extraction and } \\
\text { processing of virgin } \\
\text { resources. }\end{array}$ & $\begin{array}{l}\text { O Reuso de materiais em empreendimentos novos representa } \\
\text { mais uma mudança de mentalidade relacionada com a } \\
\text { viabilização do produto imobiliário que propriamente um desafio } \\
\text { técnico, no entanto, a exigência de } 10 \% \text { de materiais reusados } \\
\text { em custo total de materiais representa um desafio pelo fato de } \\
\text { que, usualmente, os materiais reaproveitados mais facilmente } \\
\text { incorporáveis ao projeto terem baixo custo. }\end{array}$ & $\begin{array}{l}\text { Explicações possíveis: [1] representam } \\
\text { um desafio de coordenação entre projeto } \\
\text { e construção (para os casos de } \\
\text { aproveitamento de materiais da própria } \\
\text { construção) e/ou [2] estão diretamente } \\
\text { relacionados à disponibilidade de } \\
\text { produtos reaproveitados ou serviços de } \\
\text { fornecedores específicos. }\end{array}$ \\
\hline 4MR_C4-1 & $\begin{array}{l}\text { Recycled } \\
\text { Content, } 10 \% \\
\text { (post-consumer } \\
+1 / 2 \text { pre- } \\
\text { consumer) }\end{array}$ & $\begin{array}{l}\text { Increase demand for } \\
\text { building products that } \\
\text { incorporate recycled } \\
\text { content materials, thereby } \\
\text { reducing impacts resulting } \\
\text { from extraction and } \\
\text { processing of virgin } \\
\text { materials. }\end{array}$ & $\begin{array}{l}\text { Tal qual o reuso de materiais, a exigência de uma porcentagem } \\
\text { do valor total dos materiais do projeto ser alcançado com } \\
\text { materiais com conteúdo reciclado apresenta tanto o desafio do } \\
\text { usual baixo valor desses materiais, como também a existência } \\
\text { de fornecedores no país ou região com opções viáveis de } \\
\text { produtos. Além disso, a relação com uma porcentagem fixa do } \\
\text { valor total dos materiais de construção faz com que alterações } \\
\text { de projeto durante a construção coloquem constantemente em } \\
\text { risco a viabilidade deste crédito. }\end{array}$ & $\begin{array}{l}\text { O sucesso nesse item está diretamente } \\
\text { relacionado com a disponibilidade e } \\
\text { variedade de materiais de construção que } \\
\text { atendam a exigência de conteúdo } \\
\text { reciclado. Pelo fato de ser um dos itens } \\
\text { mais alcançados é de se esperar que no } \\
\text { mercado americano (avaliado pelo BD) } \\
\text { existam condições mínimas viáveis em } \\
\text { ambos aspectos: disponibilidade e } \\
\text { variedade. }\end{array}$ \\
\hline
\end{tabular}




\begin{tabular}{|c|c|c|c|c|}
\hline 4MR_C4-2 & $\begin{array}{l}\text { Recycled } \\
\text { Content, } 20 \% \\
\text { (post-consumer } \\
+1 / 2 \text { pre- } \\
\text { consumer) }\end{array}$ & $\begin{array}{l}\text { Increase demand for } \\
\text { building products that } \\
\text { incorporate recycled } \\
\text { content materials, thereby } \\
\text { reducing the impacts } \\
\text { resulting from extraction } \\
\text { and processing of virgin } \\
\text { materials. }\end{array}$ & $\begin{array}{l}\text { Tal qual o reuso de materiais, a exigência de uma porcentagem } \\
\text { do valor total dos materiais do projeto ser alcançado com } \\
\text { materiais com conteúdo reciclado apresenta tanto o desafio do } \\
\text { usual baixo valor desses materiais, como também a existência } \\
\text { de fornecedores no país ou região com opções viáveis de } \\
\text { produtos. Além disso, a relação com uma porcentagem fixa do } \\
\text { valor total dos materiais de construção faz com que alterações } \\
\text { de projeto durante a construção coloquem constantemente em } \\
\text { risco a viabilidade deste crédito. }\end{array}$ & \\
\hline 4MR_C5-1 & $\begin{array}{l}\text { Regional } \\
\text { Materials, 10\% } \\
\text { Extracted, } \\
\text { Processed \& } \\
\text { Manufactured } \\
\text { Regionally }\end{array}$ & $\begin{array}{l}\text { Increase demand for } \\
\text { building materials and } \\
\text { products that are extracted } \\
\text { and manufactured within } \\
\text { the region, thereby } \\
\text { supporting the use of } \\
\text { indigenous resources and } \\
\text { reducing the environmental } \\
\text { impacts resulting from } \\
\text { transportation. }\end{array}$ & $\begin{array}{l}\text { Devido a concentração dos fabricantes de materiais de } \\
\text { construção nos arredores do eixo Rio-São Paulo e ao longo da } \\
\text { região sul do país a restrição de aprox. } 800 \mathrm{~km} \text { para se } \\
\text { conseguir } 20 \% \text { de todo o material de construção usado no } \\
\text { empreendimento não representa um desafio de grande porte } \\
\text { para essa região. No entanto, como exemplo, vale notar que a } \\
\text { cidade do Rio de Janeiro está a mais de } 800 \mathrm{~km} \text { do pólo } \\
\text { produtor de revestimentos cerâmicos do estado de Santa } \\
\text { Catarina (Criciúma e Tubarão). }\end{array}$ & $\begin{array}{l}\text { Tal qual o item referente ao conteúdo } \\
\text { reciclado. Esse crédito também está } \\
\text { diretamente relacionado com a } \\
\text { disponibilidade e variedade de materiais } \\
\text { de construção que atendam a exigência } \\
\text { do raio de aprox. } 800 \mathrm{Km} \text {. Sendo } \\
\text { igualmente razoável concluir que existem } \\
\text { nas regiões da maioria dos projetos tanto } \\
\text { disponibilidade como variedade de } \\
\text { materiais de construção. }\end{array}$ \\
\hline 4MR_C5-2 & $\begin{array}{l}\text { Regional } \\
\text { Materials, 20\% } \\
\text { Extracted, } \\
\text { Processed \& } \\
\text { Manufactured } \\
\text { Regionally }\end{array}$ & $\begin{array}{l}\text { Increase demand for } \\
\text { building materials and } \\
\text { products that are extracted } \\
\text { and manufactured within } \\
\text { the region, thereby } \\
\text { supporting the use of } \\
\text { indigenous resources and } \\
\text { reducing the environmental } \\
\text { impacts resulting from } \\
\text { transportation. }\end{array}$ & $\begin{array}{l}\text { Devido a concentração dos fabricantes de materiais de } \\
\text { construção nos arredores do eixo Rio-São Paulo e ao longo da } \\
\text { região sul do país a restrição de aprox. } 800 \mathrm{~km} \text { para se } \\
\text { conseguir } 20 \% \text { de todo o material de construção usado no } \\
\text { empreendimento não representa um desafio de grande porte } \\
\text { para essa região. No entanto, como exemplo, vale notar que a } \\
\text { cidade do Rio de Janeiro está a mais de } 800 \mathrm{~km} \text { do pólo } \\
\text { produtor de revestimentos cerâmicos do estado de Santa } \\
\text { Catarina (Criciúma e Tubarão). }\end{array}$ & \\
\hline
\end{tabular}




\begin{tabular}{|c|c|c|c|c|}
\hline 4MR_C6 & $\begin{array}{l}\text { Rapidly } \\
\text { Renewable } \\
\text { Materials }\end{array}$ & $\begin{array}{l}\text { Reduce the use and } \\
\text { depletion of finite raw } \\
\text { materials and long-cycle } \\
\text { renewable materials by } \\
\text { replacing them with rapidly } \\
\text { renewable materials. }\end{array}$ & $\begin{array}{l}\text { Enquanto nos EUA já existe uma rede estabelecida de } \\
\text { fornecedores de materiais rapidamente renováveis como pisos } \\
\text { de bambu e placas de sementes de girassol, esse mercado } \\
\text { pode ser considerado quase incipiente no país. }\end{array}$ & \begin{tabular}{|lrr} 
Explicações & possíveis: [1] estão \\
diretamente & relacionados à \\
disponibilidade & e competitividade \\
econômica de produtos rapidamente \\
renováveis ou serviços de fornecedores \\
específicos.
\end{tabular} \\
\hline 4MR_C7 & Certified Wood & $\begin{array}{l}\text { Encourage environmentally } \\
\text { responsible forest } \\
\text { management. }\end{array}$ & $\begin{array}{l}\text { A grande disponibilidade de madeiras não certificadas ou } \\
\text { mesmo ilegais no mercado nacional diminuindo o preço desse } \\
\text { material desestimula o investimento nessa área no entanto, a } \\
\text { disponibilidade de produtos como pisos, forros e estruturas } \\
\text { produzidas com madeira certificada no país mantém disponível } \\
\text { uma opção de mercado para esse item. }\end{array}$ & $\begin{array}{llr}\text { Explicações } & \text { possíveis: [1] } & \text { estão } \\
\text { diretamente } & \text { relacionados } & \text { à } \\
\text { disponibilidade } & \text { e competitividade } \\
\text { econômica de produtos de madeira } \\
\text { certificada ou serviços de fornecedores } \\
\text { específicos. }\end{array}$ \\
\hline
\end{tabular}




\begin{tabular}{|c|c|c|c|c|}
\hline Código & $\begin{array}{l}\text { NC } 2.2 \text { Nome do } \\
\text { Item }\end{array}$ & NC 2.2 Objetivo/Intenção & Desafio & \begin{tabular}{|l} 
Itens $\quad$ Mais $\quad$ Alcançados \\
Itens Menos Alcançados
\end{tabular} \\
\hline \multicolumn{5}{|c|}{ Indoor Environmental Quality } \\
\hline 5IEQ_Prereq_1 & \begin{tabular}{|l|} 
Minimum IAQ \\
Performance \\
Required
\end{tabular} & $\begin{array}{l}\text { Establish minimum indoor } \\
\text { air quality (IAQ) } \\
\text { performance to enhance } \\
\text { indoor air quality in } \\
\text { buildings, thus contributing } \\
\text { to the comfort and well- } \\
\text { being of the occupants. }\end{array}$ & $\begin{array}{l}\text { Para empreendimentos como grandes edifícios de escritório os } \\
\text { quais são projetados e construídos usando como referência } \\
\text { padrões internacionais de desempenho de sistemas de } \\
\text { instalação, atingir o nível mínimo de qualidade do ar interna } \\
\text { não representa um desafio de grande ordem. }\end{array}$ & \\
\hline 5IEQ_Prereq_2 & \begin{tabular}{|l|} 
Environmental \\
Tobacco Smoke \\
(ETS) Control \\
Required
\end{tabular} & $\begin{array}{l}\text { Minimize exposure of } \\
\text { building occupants, indoor } \\
\text { surfaces, and ventilation air } \\
\text { distribution systems to } \\
\text { Environmental Tobacco } \\
\text { Smoke (ETS). }\end{array}$ & $\begin{array}{l}\text { O pré-requisito relacionado com a prevenção à exposição à } \\
\text { fumaça de cigarros não representa desafio técnico ou mesmo } \\
\text { econômico por demandar poucos recursos para ser satisfeito. } \\
\text { Além de que muitas vezes já existem exigências legais tanto } \\
\text { municipais como estaduais proibindo e/ou desestimulando } \\
\text { fumar em ambientes fechados. }\end{array}$ & \\
\hline 5IEQ_C1 & $\begin{array}{l}\text { Outdoor Air } \\
\text { Delivery } \\
\text { Monitoring }\end{array}$ & $\begin{array}{l}\text { Provider capacity for } \\
\text { ventilation system } \\
\text { monitoring to help sustain } \\
\text { occupant comfort and well- } \\
\text { being. }\end{array}$ & $\begin{array}{l}\text { O custo inicial de instalação e manutenção de sistemas de } \\
\text { monitoramento automático restringe seu uso no momento à } \\
\text { grandes empreendimentos imobiliários (tipicamente edifícios de } \\
\text { escritório, hotéis e grandes centro comerciais). }\end{array}$ & \\
\hline 5IEQ_C2 & $\begin{array}{l}\text { Increased } \\
\text { Ventilation }\end{array}$ & $\begin{array}{l}\text { Provide additional outdoor } \\
\text { air ventilation to improve } \\
\text { indoor air quality for } \\
\text { improved occupant } \\
\text { comfort, well-being and } \\
\text { productivity. }\end{array}$ & $\begin{array}{l}\text { Considerando a possibilidade do uso tanto de ventilação } \\
\text { mecânica como de ventilação natural esse crédito pode } \\
\text { representar tanto um desafio técnico como econômico } \\
\text { significativo caso o projeto tiver grandes restrições quanto às } \\
\text { adaptações de otimização da ventilação já que esta quase que } \\
\text { obrigatoriamente modifica a pele, o padrão de ocupação dos } \\
\text { espaços e a área útil total. }\end{array}$ & $\begin{array}{l}\text { Explicações possíveis: [1] representam } \\
\text { interferencias físicas de grande extensão } \\
\text { o que compromete, quase que } \\
\text { obrigatoriamente, uma aproximação } \\
\text { convencional da questão. }\end{array}$ \\
\hline 5IEQ_C3-1 & $\begin{array}{l}\text { Construction } \\
\text { IAQ } \\
\text { Management } \\
\text { Plan, During } \\
\text { Construction }\end{array}$ & $\begin{array}{l}\text { Reduce indoor air quality } \\
\text { problems resulting from the } \\
\text { construction/renovation } \\
\text { process in order to help } \\
\text { sustain the comfort and } \\
\text { well-being of construction } \\
\text { workers and building } \\
\text { occupants. }\end{array}$ & $\begin{array}{l}\text { Apesar do gerenciamento da Qualidade do Ar Interno durante a } \\
\text { construção não ser prática corrente no país, a possibilidade de } \\
\text { se alcançar o nível de exigência com soluções de } \\
\text { gerenciamento relativamente simples representa um desafio de } \\
\text { baixa ordem. }\end{array}$ & \\
\hline
\end{tabular}




\begin{tabular}{|c|c|c|c|c|}
\hline 5IEQ_C3-2 & $\begin{array}{l}\text { Construction } \\
\text { IAQ } \\
\text { Management } \\
\text { Plan, Before } \\
\text { Occupancy }\end{array}$ & $\begin{array}{l}\text { Reduce indoor air quality } \\
\text { problems resulting from the } \\
\text { construction/renovation } \\
\text { process in order to help } \\
\text { sustain the comfort and } \\
\text { well-being of construction } \\
\text { workers and building } \\
\text { occupants. }\end{array}$ & $\begin{array}{l}\text { Apesar do gerenciamento da Qualidade do Ar Interno durante a } \\
\text { construção não ser prática corrente no país, a possibilidade de } \\
\text { se alcançar o nível de exigência com soluções de } \\
\text { gerenciamento relativamente simples representa um desafio de } \\
\text { baixa ordem. }\end{array}$ & \\
\hline 5IEQ_C4-1 & $\begin{array}{l}\text { Low-Emitting } \\
\text { Materials, } \\
\text { Adhesives \& } \\
\text { Sealants }\end{array}$ & $\begin{array}{l}\text { Reduce the quantity of } \\
\text { indoor air contaminants } \\
\text { that are odorous, irritating } \\
\text { and/or harmful to the } \\
\text { comfort and well-being of } \\
\text { installers and occupants. } \\
\end{array}$ & $\begin{array}{l}\text { Esse crédito representa um desafio relacionado com a } \\
\text { disponibilidade de materiais de construção. Enquanto que nos } \\
\text { EUA as associações de fabricantes já se organizaram para } \\
\text { restringir ou, em alguns casos, banir o uso de Compostos } \\
\text { Orgânicos Voláteis nos processos de fabricação no Brasil esse } \\
\text { tipo de iniciativa ainda não se estabeleceu no mercado. }\end{array}$ & $\begin{array}{l}\text { A iniciativa das associações de } \\
\text { fabricantes americanas em adaptar seus } \\
\text { produtos a restrição na emissão de COVs } \\
\text { facilita a conquista desse item por parte } \\
\text { dos empreendimentos. }\end{array}$ \\
\hline 5IEQ_C4-2 & $\begin{array}{l}\text { Low-Emitting } \\
\text { Materials, Paints } \\
\text { \& Coatings }\end{array}$ & $\begin{array}{l}\text { Reduce the quantity of } \\
\text { indoor air contaminants } \\
\text { that are odorous, irritating } \\
\text { and/or harmful to the } \\
\text { comfort and well-being of } \\
\text { installers and occupants. }\end{array}$ & $\begin{array}{l}\text { Esse crédito representa um desafio relacionado com a } \\
\text { disponibilidade de materiais de construção. Enquanto que nos } \\
\text { EUA as associações de fabricantes já se organizaram para } \\
\text { restringir ou, em alguns casos, banir o uso de Compostos } \\
\text { Orgânicos Voláteis nos processos de fabricação, no Brasil esse } \\
\text { tipo de iniciativa ainda não se estabeleceu no mercado. }\end{array}$ & $\begin{array}{l}\text { A iniciativa das associações de } \\
\text { fabricantes americanas em adaptar seus } \\
\text { produtos a restrição na emissão de COVs } \\
\text { facilita a conquista desse item por parte } \\
\text { dos empreendimentos. }\end{array}$ \\
\hline 5IEQ_C4-3 & $\begin{array}{l}\text { Low-Emitting } \\
\text { Materials, Carpet } \\
\text { Systems }\end{array}$ & $\begin{array}{l}\text { Reduce the quantity of } \\
\text { indoor air contaminants } \\
\text { that are odorous, irritating } \\
\text { and/or harmful to the } \\
\text { comfort and well-being of } \\
\text { installers and occupants. } \\
\end{array}$ & $\begin{array}{l}\text { Esse crédito representa um desafio relacionado com a } \\
\text { disponibilidade de materiais de construção. Enquanto que nos } \\
\text { EUA as associações de fabricantes já se organizaram para } \\
\text { restringir ou, em alguns casos, banir o uso de Compostos } \\
\text { Orgânicos Voláteis nos processos de fabricação, no Brasil esse } \\
\text { tipo de iniciativa ainda não se estabeleceu no mercado. }\end{array}$ & $\begin{array}{l}\text { A iniciativa das associações de } \\
\text { fabricantes americanas em adaptar seus } \\
\text { produtos a restrição na emissão de } \\
\text { odores facilita a conquista desse item por } \\
\text { parte dos empreendimentos. }\end{array}$ \\
\hline 5IEQ_C4-4 & $\begin{array}{l}\text { Low-Emitting } \\
\text { Materials, } \\
\text { Composite } \\
\text { Wood \& } \\
\text { Agrifiber } \\
\text { Products } \\
\end{array}$ & $\begin{array}{l}\text { Reduce the quantity of } \\
\text { indoor air contaminants } \\
\text { that are odorous, irritating } \\
\text { and/or harmful to the } \\
\text { comfort and well-being of } \\
\text { installers and occupants. } \\
\end{array}$ & $\begin{array}{l}\text { Esse crédito representa um desafio relacionado com a } \\
\text { disponibilidade de materiais de construção. Enquanto que nos } \\
\text { EUA as associações de fabricantes já se organizaram para } \\
\text { restringir ou, em alguns casos, banir o uso de Compostos } \\
\text { Orgânicos Voláteis nos processos de fabricação, no Brasil esse } \\
\text { tipo de iniciativa ainda não se estabeleceu no mercado. }\end{array}$ & \\
\hline 5IEQ_C5 & $\begin{array}{l}\text { Indoor Chemical } \\
\text { \& Pollutant } \\
\text { Source Control }\end{array}$ & 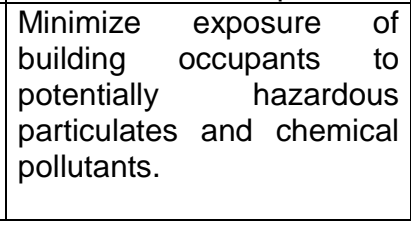 & $\begin{array}{l}\text { O relativo baixo nível de dificuldade das adaptações exigidas } \\
\text { nesse crédito já são, em parte, aplicados na atualidade em } \\
\text { empreendimentos de grande porte. Pode-se dizer que desenho } \\
\text { e zoneamento específico de áreas com fontes poluidoras nos } \\
\text { edifícios já toma parte das preocupações preliminares da } \\
\text { maioria dos projetos. }\end{array}$ & \\
\hline
\end{tabular}




\begin{tabular}{|c|c|c|c|c|}
\hline 5IEQ_C6-1 & $\begin{array}{l}\text { Controllability of } \\
\text { Systems, } \\
\text { Lighting }\end{array}$ & $\begin{array}{l}\text { Provide a high level of } \\
\text { lighting system control by } \\
\text { individual occupants or by } \\
\text { specific groups in multi- } \\
\text { occupant spaces (i.e. } \\
\text { classrooms or conference } \\
\text { areas) to promote the } \\
\text { productivity, comfort and } \\
\text { well-being of building } \\
\text { occupants. }\end{array}$ & $\begin{array}{l}\text { Seguindo a tendência por alta produtividade, adaptações de } \\
\text { projeto para proporcionar controle para uma janela e para o } \\
\text { nível de iluminação para cada } 18 \mathrm{~m}^{2} \text { (aprox.) representam um } \\
\text { nível de desafio baixo caso sejam previstas desde as fases } \\
\text { preliminares de projeto. }\end{array}$ & \\
\hline 5IEQ_C6-2 & $\begin{array}{l}\text { Controllability of } \\
\text { Systems, } \\
\text { Thermal Comfort }\end{array}$ & $\begin{array}{l}\text { Provide a high level of } \\
\text { thermal comfort system } \\
\text { control by individual } \\
\text { occupants or by specific } \\
\text { groups in multi-occupant } \\
\text { spaces (i.e. classrooms or } \\
\text { conference areas) to } \\
\text { promote the productivity, } \\
\text { comfort and well-being of } \\
\text { building occupants. }\end{array}$ & $\begin{array}{l}\text { Seguindo a tendência por alta produtividade, adaptações de } \\
\text { projeto para proporcionar o nível de controle exigido } \\
\text { representam um nível de desafio baixo caso sejam previstas } \\
\text { desde as fases preliminares de projeto. }\end{array}$ & $\begin{array}{l}\text { Explicações possíveis: }[1] \text { são } \\
\text { significativamente } \\
\text { economicamente pelo amerosas } \\
\text { generalizada de } \\
\text { equipamentosção } \\
\text { instalações, }\end{array}$ \\
\hline 5IEQ_C7-1 & $\begin{array}{l}\text { Thermal } \\
\text { Comfort, Design }\end{array}$ & $\begin{array}{l}\text { Provide a comfortable } \\
\text { thermal environment that } \\
\text { supports the productivity } \\
\text { and well-being of building } \\
\text { occupants. }\end{array}$ & $\begin{array}{l}\text { O nível de desempenho de conforto térmico tanto para edifícios } \\
\text { com condicionamento artificial como aqueles com ventilação } \\
\text { natural representa um desafio de grande ordem tanto devido a } \\
\text { cultura estabelecida de condicionamento artificial como } \\
\text { também pelo baixo nível de informação dos profissionais de } \\
\text { projeto no Brasil quanto ao know-how relacionado com } \\
\text { soluções de ventilação natural de alto desempenho. }\end{array}$ & \\
\hline 5IEQ_C7-2 & $\begin{array}{l}\text { Thermal } \\
\text { Comfort, } \\
\text { Verification }\end{array}$ & $\begin{array}{l}\text { Provide for the assessment } \\
\text { of building thermal comfort } \\
\text { over time. }\end{array}$ & $\begin{array}{l}\text { Apesar do monitoramente eletrônico já ser uma realidade para } \\
\text { grandes empreendimentos imobiliários essa tecnologia ainda } \\
\text { precisa de tempo e amadurecimento para migrar para } \\
\text { empreendimentos e médio e pequeno porte - mais } \\
\text { representativos do mercado nacional. }\end{array}$ & \\
\hline 5IEQ_C8-1 & $\begin{array}{l}\text { Daylight \& } \\
\text { Views, Daylight } \\
75 \% \text { of Spaces }\end{array}$ & $\begin{array}{l}\text { Provide for the building } \\
\text { occupants a connection } \\
\text { between indoor spaces } \\
\text { and the outdoors through } \\
\text { the introduction of daylight } \\
\text { and views into the regularly } \\
\text { occupied areas of the } \\
\text { building. }\end{array}$ & $\begin{array}{l}\text { As exigências desse crédito tem potencial para serem } \\
\text { consideradas relativamente fáceis de serem alcançadas caso } \\
\text { essa preocupação esteja presente desde as fases preliminares } \\
\text { de desenvolvimento do projeto, caso contrário se torna na } \\
\text { maioria das vezes inviável. }\end{array}$ & \\
\hline
\end{tabular}


5IEQ_C8-2 $\mid$ Daylight \&

Provide for the building As exigências desse crédito tem potencial para serem

Views, Views for occupants a connection consideradas relativamente fáceis de serem alcançadas caso

$90 \%$ of Spaces

between indoor spaces essa preocupação esteja presente desde as fases preliminares

and the outdoors through de desenvolvimento do projeto.

the introduction of daylight

and views into the regularly

occupied areas of the

building. 


\begin{tabular}{|c|c|c|c|c|}
\hline Código & $\begin{array}{l}\text { NC } 2.2 \text { Nome do } \\
\text { Item }\end{array}$ & NC 2.2 Objetivo/Intenção & Desafio & \begin{tabular}{|lcc} 
Itens & Mais $\quad$ Alcançados & e \\
ltens Menos Alcançados &
\end{tabular} \\
\hline \multicolumn{5}{|c|}{ Innovation \& Design Process } \\
\hline 6IDP_C1-1 & $\begin{array}{l}\text { Innovation in } \\
\text { Design }\end{array}$ & $\begin{array}{l}\text { To provide design teams } \\
\text { and projects the } \\
\text { opportunity to be awarded } \\
\text { points for exceptional } \\
\text { performance above the } \\
\text { requirements set by the } \\
\text { LEED-NC Green Building } \\
\text { Rating System and/or } \\
\text { innovative performance in } \\
\text { Green Building categories } \\
\text { not specifically addressed } \\
\text { by the LEED-NC Green } \\
\text { Building Rating System. }\end{array}$ & $\begin{array}{l}\text { Por exigir que os níveis de desempenho padrão estabelecidos } \\
\text { sejam superados de maneira significativa, os créditos por } \\
\text { inovação representam desafios de grande ordem. }\end{array}$ & $\begin{array}{l}\text { Privilegiar o item por desempenho } \\
\text { "excepcional" ou "inovador" mostra a } \\
\text { tendência dos empreendimentos por } \\
\text { buscarem caminhos alternativos (já } \\
\text { abordados ou não pelo LEED) para } \\
\text { conquistar mais pontos. }\end{array}$ \\
\hline 6IDP_C1-2 & $\begin{array}{l}\text { Innovation in } \\
\text { Design }\end{array}$ & Idem & Idem & $\begin{array}{l}\text { Privilegiar o item por desempenho } \\
\text { "excepcional" ou "inovador" mostra a } \\
\text { tendência dos empreendimentos por } \\
\text { buscarem caminhos alternativos (já } \\
\text { abordados ou não pelo LEED) para } \\
\text { conquistar mais pontos. }\end{array}$ \\
\hline 6IDP_C1-3 & $\begin{array}{l}\text { Innovation in } \\
\text { Design }\end{array}$ & Idem & Idem & \\
\hline 6IDP_C1-4 & $\begin{array}{l}\text { Innovation in } \\
\text { Design }\end{array}$ & Idem & Idem & \\
\hline 6IDP_C2 & $\begin{array}{l}\text { LEED } \\
\text { Accredited } \\
\text { Professional }\end{array}$ & $\begin{array}{l}\text { To support and encourage } \\
\text { the design integration } \\
\text { required by a LEED-NC } \\
\text { green building project and } \\
\text { to streamline the } \\
\text { application and certification } \\
\text { process. }\end{array}$ & $\begin{array}{l}\text { Devido ao inexpressivo número de profissionais certificados } \\
\text { pelo LEED no Brasil, esse credito representa um desafio } \\
\text { relacionado à disponibilidade prestadores de serviços. }\end{array}$ & $\begin{array}{l}\text { A disponibilidade de profissionais } \\
\text { credenciados pelo LEED nos grandes } \\
\text { centros dos EUA facilita a conquista } \\
\text { desse item. }\end{array}$ \\
\hline
\end{tabular}




\section{[CAPÍtulo 4] CONCLUSÕES}

Com base no que foi constatado ao longo deste trabalho, os resultados e as conclusões são apresentadas da seguinte maneira:

[1] Aspectos positivos do sistema LEED;

[2] Aspectos negativos do sistema LEED;

[3] Perspectivas do uso do LEED no Brasil;

[4] Lições aprendidas com a experiência LEED; e

[5] Insumos para uma proposta de sistema de avaliação da sustentabilidade do espaço construído no Brasil.

\subsection{LEED - ASPECTOS POSITIVOS}

Tendo em vista a inserção do LEED no país, este item relaciona os aspectos positivos mais significativos, segundo as demandas nacionais:

[1] Tem grande potencial para disseminar conceitos e boas práticas.

[2] Tem notoriedade no seu país de origem com alto potencial de influenciar o mercado nacional. 
[3] Valoriza o processo de projeto, já que para diminuir custos é necessário considerar as exigências do sistema desde as etapas mais anteriores do processo.

[4] Incentiva a disseminação de boas práticas, tais como as análises e simulações de desempenho energético, conforto térmico e luminoso, por exemplo.

[5] Tem um efeito educativo de disseminação de idéias e valores relacionados com o alto desempenho ambiental sobre os agentes da cadeia da indústria da construção (incluindo os clientes e usuários finais). No entanto, o mau uso desse potencial pode acarretar em um equivocado do mercado.

Em resumo, seu maior potencial são os aspectos relacionados à sua influência como sistema de avaliação, e não tanto com as qualidades intrínsecas de sua avaliação.

\subsection{LEED - ASPECTOS NEGATIVOS}

Tendo em vista a inserção do LEED no país, este item relaciona os aspectos com potencial negativo mais significativos, segundo as demandas nacionais.

[1] Pelo fato de permitir a certificação de projetos com conceitos convencionais e apenas algumas preocupações ambientais, o sistema definitivamente não garante boa arquitetura;

[2] Apesar do sistema apresentar como uma das suas vantagens estratégicas as comparações diretas entre projetos proporcionadas pela classificação obtida com o sistema, estas podem mascarar inconsistências;

[3] O sistema pode mascarar o real impacto de um empreendimento, por questões relacionadas ao seu tamanho, contexto urbano e especificidades do projeto 36 ;

[4] A aplicação de normas estrangeiras como referências em alguns créditos do sistema pode mascarar inconsistências (sendo muito exigentes ou pouco exigentes em questões pouco importantes ou muito importantes, respectivamente);

[5] Devido ao fato de focar somente a porção mais elevada do mercado da construção, o sistema contribui pouco para diminuir a desigualdade entre os extremos desse mercado, sendo que essa questão se torna mais aguda no Brasil onde essa desigualdade toma dimensões desproporcionais (temos o mais alto nível de desempenho em projetos e construção tentando conviver com padrões inaceitáveis de qualidade social, econômica e ambiental) ${ }^{37}$; e, também,

\footnotetext{
${ }^{36}$ Projetos de grande porte, sem atender créditos de avaliação estratégicos no local ou região onde se encontram podem ser certificados com notas maiores que outros com condições claramente mais favoráveis.

${ }^{37}$ É possível considerar que 0 sistema não se dispõe a avaliar condições no contexto de países como 0 Brasil e por tal motivo não devesse ser "cobrado" por aspectos como esse, o objeto da crítica em aspectos como não é o sistema em si mais, na realidade, 0 uso que fazemos dele no país.
} 
[6] Devido ao mesmo fato, tem um impacto direto pouco significativo na sustentabilidade do espaço construído do país, considerando-se a fatia do mercado que ele pode atingir, comparada ao total do que é construído.

Em resumo, seus potenciais negativos são relacionados mais ao conceito da avaliação do que aos níveis de desempenho de seus quesitos.

\subsection{PERSPECTIVAS DO USO DO LEED NO BRASIL}

Quando são observados os exemplos brasileiros de inserção do sistema LEED duas questões principais chamam a atenção: o uso de um corpo normativo totalmente estrangeiro em um grande número de itens avaliados e o conceito de avaliação voltado para as questões ambientais típicas do seu país de origem.

Quanto a questão normativa é legítimo discutir a respeito das minúcias dos efeitos da aplicação das normas estrangeiras no Brasil, mas isso não representa o cerne da questão. Mesmo com resultados menos consistentes é de se esperar que o próprio movimento de se valorizar a aplicação de uma norma de desempenho (como energia e conforto, por exemplo) no país por si só tenha um efeito positivo, qualquer que seja a norma. A discussão mais séria é a respeito do conceito de sustentabilidade que está sendo avaliado, aplicado e disseminado no país. Essa é a resposta que somos chamados a responder como sociedade.

Será que um rótulo que diz que um empreendimento no Brasil é sustentável sem comprovar [1] preocupação com direitos sociais, [2] educação básica de trabalhadores, [3] educação ambiental, [4] respeito à cultura nacional, [5] uso racional da água, [6] formalidade do mercado e, principalmente, [7] nivelamento mínimo e diminuição da desigualdade dos padrões de qualidade do mercado nacional da construção; pode ser considerado um rótulo aceitável para a nossa realidade? Com base neste trabalho é possível dizer que não. Analisando seu potencial de impactos positivos e negativos é possível dizer que a aplicação do sistema ainda pode ser benéfica, mas a conclusão é de que esse benefício está longe de ser considerado suficientemente abrangente para atender as demandas locais. Como uma primeira tentativa, o sistema pode resultar em um saldo potencial positivo no Brasil até que se possa criar, divulgar, aplicar, revisar e disseminar o uso de um sistema nacional de avaliação de sustentabilidade que atenda às demandas locais.

Pensado para focar os problemas de seu país de origem (emissão de carbono, qualidade do ar interno, proteção ao habitat natural, etc.), o LEED não responde bem às demandas nacionais, assim como também pode não responder às demandas de outros países em desenvolvimento. Rotular um empreendimento no Brasil como sustentável devido à uma certificação do LEED americano pode mascarar uma triste constatação: isso não representa nenhuma garantia de que esse empreendimento é sustentável para a realidade nacional. Até mesmo pela ausência de normas nacionais para vários quesitos e conseqüente adoção de normas americanas para a avaliação, a certificação do LEED poderia sim dizer que 
se este empreendimento brasileiro estivesse dentro dos EUA ele, provavelmente, teria um elevado desempenho ambiental em comparação com o resto do mercado americano.

A análise do sistema permite constatar que, mesmo nos cenários mais otimistas de sua disseminação no país, seu foco nas exceções do mercado tem pouco potencial de trazer melhorias significativas na sustentabilidade da indústria da construção nacional. Isso fica ainda mais patente quando considera-se que:

- No Brasil, algo próximo de $70 \%$ das construções nos grandes centros é irregular;

- Aproximadamente 7 em cada 10 sacos de cimento (SNIC, 2005) usados na construção são vendidos em lojas para pequenos empreiteiros e autoconstrutores; e

- Segundo o IBGE, em 2003, no setor da construção, havia 170.803 empresas informais contra 118.993 empresas formais no Brasil (FGV, 2005b).

\subsection{LIÇÕES APRENDIDAS}

O panorama geral mostra que, apesar das diversas indicações de inconsistências, o LEED pode ser considerado um sistema de avaliação de grande potencial pelo fato de ter alcançado uma posição próxima dos objetivos finais que ele se propôs a alcançar. Essa é uma das questões centrais a respeito das lições que se pode aprender com essa experiência. Qualquer que seja a conclusão de um juízo de valores sobre o sistema, ele ainda se mantém como uma das referências mais influentes ao nosso alcance.

O LEED começou com um degrau alto de exigências que poucos nos EUA poderiam alcançar. No entanto, salvo as revisões de algumas normas específicas, ele vem, até o momento e de modo geral, gradativamente estabilizando ou diminuindo suas exigências. Ao que parece nem mesmo os $25 \%$ de líderes do mercado não conseguem subir esse degrau de excelência. Quando consta-se o uso do sistema no Brasil entende-se o quanto isso é preocupante. No Brasil, com uma indústria da construção civil pautada pela desigualdade em todos os aspectos, a questão estratégica não é avançar no desenvolvimento de poucas iniciativas de vanguarda de alto padrão, e sim tentar nivelar em um patamar minimamente aceitável a grande massa de projetos e construções de padrão inaceitável. Nessa questão estratégica parece mais sensato começar com o atendimento às exigências básicas elementares e focar as energias nos meios que incentivem a evolução contínua e consistente do processo de projeto e da indústria da construção civil. Se isso for alcançado, esse eventual modelo brasileiro já nasceria tão ou mais consistente do que o modelo instituído pelo sistema LEED no seu país de origem.

Observando o comportamento histórico do LEED-NC (o "carro chefe" da família de sistemas) é possível descobrir que ele privilegia uma relação próxima com as demandas de mercado de empreendimentos de vanguarda com grandes interesses de valorização de sua imagem institucional. Isso não é essencialmente bom ou ruim. É um partido. O LEED é uma marca. Para o USGBC (2004) o LEED como marca é o segundo maior patrimônio da instituição, somente atrás de seus profissionais. Ainda 
segundo a instituição, a política de administração do LEED ${ }^{\mathrm{TM}}$, tanto nos EUA como internacionalmente, é feita como a administração de uma marca de produto.

Uma forma interessante de olhar para a questão é considerar que o LEED não é um sistema de avaliação da sustentabilidade ambiental com um forte viés mercadológico. Ele, na realidade, é uma ferramenta mercadológica com forte viés ambiental. Entendendo-o dessa forma é possível aproveitar seu potencial positivo de maneira mais segura e madura.

Observando novamente o trajeto do LEED como iniciativa percebe-se que o apoio institucional que ele teve foi mais determinante para seu sucesso nos EUA do que a qualidade ou consistência da sua avaliação em especial o apoio de órgãos do governo federal que tiveram um papel decisivo criando a demanda para que o volume de projetos não perdesse força ao longo do tempo. Faz sentido acreditar que um eventual sistema nacional que almeje uma posição análoga no Brasil necessita de suporte equivalente.

No caso americano, esse apoio colabora para sua "exportação" para outros mercados, mesmo sendo notada sua aparente inadequação para uso e adaptação em países em desenvolvimento. O caso de seu licenciamento para uso na Índia ilustra o caso.

Era de se esperar que, por conviver com problemas de distribuição de renda tão ou mais graves que os do Brasil, a Índia necessitasse de um sistema de avaliação de sustentabilidade com grande foco em questões sociais e econômicas — em sintonia com a Agenda Marrom — mas, no entanto, em sua abordagem de revisão do sistema LEED essa preocupação não é destacada, ou até mesmo, não é considerada. As adaptações propostas para o caso indiano demonstram a fragilidade do sistema LEED fora de seu país de origem, e sugerem o mesmo fato preocupante para o caso brasileiro: na Índia o sistema está sendo adaptado para uso sem considerar aspectos sociais estratégicos daquele contexto.

Apesar da diferença social no Brasil gerar incongruências tais como a presença de nichos de mercado na construção civil com padrões equiparáveis aos mais altos níveis internacionais, o país de fato é carente de qualidade, recursos e infra-estrutura em sua vasta extensão territorial e social. Tendo isso em mente, a possibilidade real de disseminação de um sistema de avaliação que não considera adequadamente a nossa realidade desperta atenção e demanda iniciativas para abordá-la com uma posição crítica e consistente.

\subsection{INSUMOS PARA UM SISTEMA DE AVALIAÇÃO DA SUSTENTABILIDADE DO ESPAÇO CONSTRUÍdO NO BRASIL: PROPOSTA DE PARTIDO}

A seguir, apresentam-se alguns insumos para uma futura e eventual proposta de partido para um sistema nacional de avaliação da sustentabilidade do espaço construído, a partir da experiência resultante deste trabalho. 


\subsubsection{CONTEXTO}

A partir da constatação do uso do sistema LEED no Brasil e de seu alto potencial de disseminação no mercado identifica-se a necessidade da elaboração de uma iniciativa local que responda de maneira consistente às demandas e particularidades nacionais.

\subsubsection{JUSTIFICATIVA}

Elementos que justificam a elaboração de uma proposta de sistema de avaliação nacional.

[1] O LEED foi pensado para um mercado com menor desigualdade de desempenho do que o brasileiro;

[2] O LEED foca as iniciativas de exceção — como sedes corporativas e institucionais que valorizam muito a imagem institucional;

[3] O nível de desempenho exigido pelo sistema pode ser considerado mais restritivo na realidade brasileira do que no seu mercado nativo;

[4] O foco da avaliação do LEED não considera aspectos da Agenda Marrom especialmente importantes para o Brasil;

[5] O Brasil apresenta uma grande desigualdade entre os padrões de desempenho das construções nacionais; e

[6] O potencial de disseminação do sistema LEED é uma referência importante na elaboração de uma proposta nacional.

\subsubsection{OBJETO}

Partido de perfil de exigências para um sistema de avaliação da sustentabilidade do espaço construído no Brasil.

\subsubsection{OBJETIVO}

O objetivo principal desse sistema seria focar o seu efeito positivo na questão mais estratégica para o contexto nacional:

A grande desigualdade e baixa média de sustentabilidade dos projetos e novas construções no Brasil.

Com vistas à otimização do efeito positivo do sistema ele teria seu uso focado nos grandes centros urbanos, à começar pelas maiores cidades da região Sul e Sudeste do país de modo a envolver a porção mais representativa da indústria da construção nacional e aproveitando o efeito multiplicador dos grandes centros. 


\subsubsection{MÉTODO}

O método do sistema de avaliação poderia ser resumido da seguinte maneira:

[1] Enxergar e se manter acessível para uma parcela maior do mercado, focando os nichos de sustentabilidade mais baixa usando uma perspectiva glocal ${ }^{38}$;

[2] Nivelar os nichos de sustentabilidade mais baixa com quesitos elementares focando a porção mais crítica do mercado;

[3] Garantir a disseminação e abrangência do uso do sistema com o apoio generalizado de instituições públicas e privadas relacionadas com o setor (Secretarias e Ministério do Meio Ambiente, Bancos Financiadores da Construção, Entidades Representantes de Classe, Fabricantes, Incorporadoras e Imobiliárias etc.); e

[4] A partir de um início acessível e abrangente nos nichos mais críticos do mercado promover pequenas revisões simples, contínuas e regulares.

Essas revisões teriam um maior potencial na melhoria da sustentabilidade do mercado da construção no país quanto maior fosse a parcela do mercado já inserida nesse sistema nos degraus anteriores mais baixos.

Em resumo o sistema primaria por ser: [1] Apoiado na participação dos agentes mais importantes, [2] Contínuo no seu melhoramento em pequenos degraus e [3] Simples e acessível para ser usado, no seu início, com o mínimo de informações, recursos e experiências.

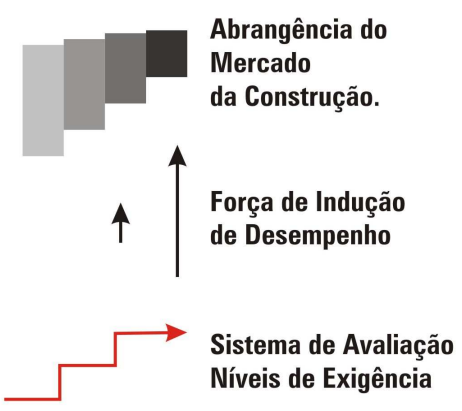

Figura 34 - Legenda para as ilustrações dos modelos a seguir.

\footnotetext{
${ }^{38}$ Expressão originária da língua inglesa que se refere à idéia de pensar globalmente (Global) e agir localmente (Local). Diz-se de uma abordagem GLOCAL aquela que considera aspectos globais (usualmente aspectos ambientais) mas age localmente, onde é possível agir diretamente.
} 


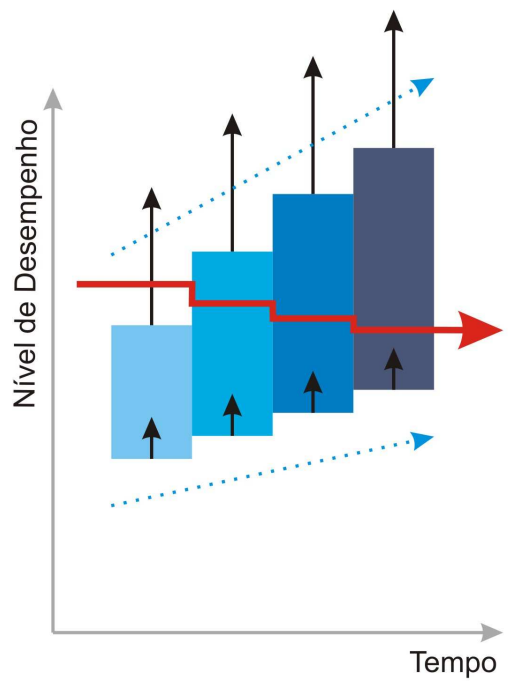

Figura 35 - Modelo de evolução do sistema LEED.

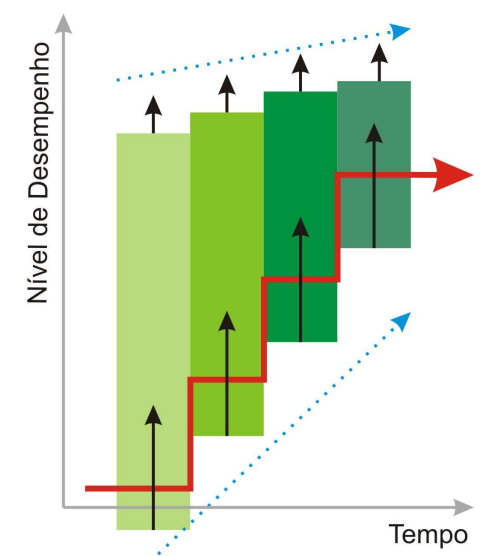

Figura 36 - Modelo proposto para um sistema nacional.

As avaliações simples orientadas ao baixo nível médio nacional de sustentabilidade dos serviços de projeto, construção, uso e desconstrução do espaço construído permitiriam reunir uma parcela mais significativa do mercado como um todo. Exigências iniciais simples causariam menor resistência do mercado. Poderia se chegar à conclusão de que os resultados no todo do mercado seriam mais significativos e eficientes caso as exigências pudessem ser alcançadas, na sua primeira fase, com soluções fáceis de serem viabilizadas e projetadas (mais próximas à média da realidade nacional). Soluções como, por exemplo, manter $50 \%$ de área permeável em terrenos urbanos e garantir aberturas para ventilação cruzada em todos os ambientes com ventilação natural e longa permanência.

Depois que o sistema tivesse conseguido abarcar uma parcela significativa do mercado seria mais fácil implementar as revisões contínuas e consistentes em pequenos degraus, aumentando significativamente e, em definitivo, o nível de sustentabilidade do mercado da construção no país ou, pelo menos, nos seu nichos mais importantes. 


\section{[CAPÍTUL0 5] REFERÊNCIAS BIBLIOGRÁFICAS}

ABNT - Associação Brasileira de Normas Técnicas. NBR ISO 14001:1996. Sistemas de gestão ambiental - Diretrizes gerais sobre princípios, sistemas e técnicas de apoio. Rio de Janeiro: 1996.

ANDRADE, Liza; ROMERO, Marta. Green Agenda X Brown Agenda: Such as a Dilemma in Developing Countries. In: PLEA2005 - THE 22ND CONFERENCE ON PASSIVE AND LOW ENERGY ARCHITECTURE. Beirut, Lebanon, 13-16 November 2005.

BALL, Jonathan. Can ISO 14000 and eco-labelling turn the construction industry green? In: ELSEVIER Building and Environment, 37: 2002. p. 421-428

BASTOS, Artur Eduardo Ribeiro. Entrevista em áudio. Entrevistador: T. Z. HERNANDES. São José do Rio Preto: 2006. Arquivo WAV. Entrevista concedida na empresa EKOARA Tecnologia Ambiental no dia 16 de Novembro de 2006.

BD\&C - BUILDING DESIGN \& CONSTRUCTION. White Paper on Sustainability. Oak Brook, IL: Building Design \& Construction, 2003.

BRE - Building Research Establishment. Quantifying the Business Benefits of Sustainable Buildings Summary of existing research findings (Extracts). Org. YATES, Alan. Centre for Sustainable Construction, BRE, 16 February 2001. 
BRUNTLAND, G. H. (editor). Our Common Future: The World Commission on Environment and Development. Oxford: Oxford University Press, 1987.

CAGBC - CANADA GREEN BUILDING COUNCIL. LEED Certified Projects. Página institucional. Disponível em: <http://www.cagbc.org/uploads/>. Acesso em: 24 de Novembro de 2006.

CESANO, Daniele. Market needs for promoting LEED Rating System and green building design. ARUP NY, office, Kinship Conservation Institute Program, Montana University: 2002.

CHADIRJI, Rifat. The Optimality of the Building Environment. In: PLEA2005 - THE 22ND CONFERENCE ON PASSIVE AND LOW ENERGY ARCHITECTURE. Beirut, Lebanon, 13-16 November 2005.

CIB / UNEP-IETC. The International Council for research and Innovation in Building and Construction / United Nations Environment Programme International Environmental Technology Centre. Agenda 21 for Sustainable Construction in Developing Countries - A discussion Document. Pretoria, South Africa: CSIR, 2002.

COOK, Jeffrey. Millennium Measures of Sustainability: Beyond Bioclimatic Architecture. In: Proceedings of PLEA 2001 Conference - The 18th International Conference on Passive and Low Energy Architecture - Renewable Energy for a Sustainable Development of Built Environment, November 7 to 9, 2001, Florianópolis, Brasil, p. 37-44.

DEGANI, Clarice Menezes; CARDOSO, Francisco Ferreira. A Sustentabilidade ao longo do ciclo de vida de edifícios: a importância da etapa de projeto arquitetônico. In: NUTAU 2002 Sustentabilidade, Arquitetura e Desenho Urbano. Núcleo de Pesquisa em Tecnologia da Arquitetura e Urbanismo da Faculdade de Arquitetura e Urbanismo da Universidade de São Paulo. São Paulo: 7 a 11 de outubro, 2002.

EDWARDS, Brian. Rough Guide to Sustainability. Londres: RIBA Enterprises Ltd., 2005. (2. ${ }^{a}$ Edição).

EDWARDS, S.; BENNETT, P. Construction Products and Life-cycle Thinking. Revista: Industry and Environment. UNEP, a publication of the United Nations Environment Programme, Volume 26 no. 2-3, April - September, 2003. 57-65p.

EVANS, J. M. Passive and Low Energy Architecture - Education for Change in South America. Proceedings: PLEA 2001 Conference - The 18th International Conference on Passive and Low Energy Architecture - Renewable Energy for a Sustainable Development of Built Environment, November 7 to 9, 2001, Florianopolis, Brasil.

FEDERAL TRADE COMMISSION (FTC). Guides For The Use Of Environmental Marketing Claims. 16 CFR PART 260. Washington, USA: FTC, 1998. 
FGV. A carga tributária do setor da construção. Relatório de Trabalho realizado para o SINDUSCON-SP. São Paulo: GVconsult, 2005a.

FGV. Construção Formal x Informal: produtividade e carga tributária. Relatório de Pesquisa realizada para o SINDUSCON-SP. São Paulo: GVconsult, 2005b.

FGV. Por dentro do déficit habitacional brasileiro Evoluções estimativas recentes. Estudo realizado para o SINDUSCON-SP. São Paulo: GVconsult, Setembro 2005c.

GLOBAL FOOTPRINT NETWORK. Global Footprint Network. 3270 Lakeshore Ave Oakland,CA 94610 USA. Página institucional com informações sobre pegadas ecológicas. Disponível em: <http://www.footprintnetwork.org> Acessado em: 21 de Agosto de 2006.

GONÇALVES, Joana Carla Soares ; DUARTE, D. H. S. CENPES II, o novo centro de pesquisas da Petrobrás, no Rio de Janeiro: uma atitude ambiental inovadora na arquitetura brasileira. In: ENCAC 2005 - VIII Encontro Nacional sobre Conforto no Ambiente Construído e ELACAC - IV Encontro Latino-Americano sobre Conforto no Ambiente Construído, 2005, Maceió. Conforto e Eficiência Energética nos Trópicos. Maceió : EDUFAL, 2005.

GONÇALVES, Joana Carla Soares. A sustentabilidade do edifício alto: uma geração de edifícios altos e sua inserção urbana. 2003. Tese (Doutorado em Arquitetura) - Faculdade de Arquitetura e Urbanismo, Departamento de Tecnologia da Arquitetura, Universidade de São Paulo, São Paulo.

GOWRI, Krishnan. Green Building Rating Systems: An Overview. In: ASHARE Journal: November, 2004.

GRUMMAN, D. ASHRAE Green Guide. Ed. 2003.

HAGAN, Susannah. Taking Shape: a new contract between architecture and nature. Oxford: ButterworthHeinemann, 2001.

JOHN, Vanderley. Construção Sustentável. Revista Téchne, edição 108, ano 14, março de 2006.

JOHNSON, Scott D. The Economic Case for "High Performance Buildings". In: ELSEVIER Corporate Environmental Strategy, 7: 2000. p. 350-361.

LAMBERTS, Roberto. Publicação Eletrônica [mensagem pessoal]. Mensagem recebida por <thiagohernandes@terra.com.br>em 27 de novembro de 2006.

LAMBERTS, Roberto; TRIANA, Andrea. Eficiência Energética em Edificações: a Lei da Eficiência. Apresentação de Trabalho. Universidade Federal de Santa Catarina, Departamento de Engenharia Civil, Laboratório de Eficiência Energética em Edificações (LabEEE). 2006.

LEED STERRING COMMITTEE. LEED Policy Manual. USGBC, Spring 2003. 
LEWIS, Malcom; HOWARD, Nigel. The Future of LEED. Revista: Environmental Design+Construction. Disponível em: <www.edcmag.com/CDA/Articles/Leed> . Acesso em: 3 de Maio de 2006.

MANSY, K.; WILLIAMS, J. Sustainable Architecture... Is It a New Style ...? In: PLEA2005 - THE 22ND CONFERENCE ON PASSIVE AND LOW ENERGY ARCHITECTURE. Beirut, Lebanon, 13-16 November 2005.

MINISTÉRIO DE MINAS E ENERGIA. BEN 2003 Balanço Energético Nacional 2003. Ministério de Minas e Energia, Secretaria de Energia. Brasil: 2003.

MÜLFARTH, Roberta C. Kronka. Arquitetura de Baixo Impacto Humano e Ambiental. 2002. Tese (Doutorado em Arquitetura) - Faculdade de Arquitetura e Urbanismo, Departamento de Tecnologia da Arquitetura, Universidade de São Paulo, São Paulo.

NATIONAL STRATEGIES FOR SUSTAINABLE DEVELOPMENT - NSSD. Sustainable Development: Concepts and Approaches. 2003. Disponível em: $<$ http://www.nssd.net/references/SustDev.htm>. Acesso em: 24 de abril de 2006.

NRDC - NATURAL RESOURCES DEFENCE COUNCIL. Mission Statement. Página Institucional. Disponível em: <http://www.nrdc.org/>. Acesso em: 11 de maio de 2006.

OLGYAY, Victor; HERDT, Julee. The application of ecosystems services criteria for green building assessment. In: ELSEVIER Solar Energy, 77: 2004.

ORNSTEIN, Sheila W. Publicação Eletrônica [mensagem pessoal]. Mensagem recebida por <thiagohernandes@terra.com.br>em 26denovembro de 2006.

RAMETSTEINER, Ewald; SIMULA, Markku. Forest Certification - an instrument to promote sustainable forest management? In: ELSEVIER Journal of Environmental Management, 67: 2003. p.87-98.

RIBA (Royal Institute of British Architects). RIBA Environment Manifesto. London: 2000.

RILEY, David; PEXTON, Kim; DRILLING, Jennifer. Procurement of sustainable construction services in the United States: the constractor's role in green buildings. Revista: Industry and Environment. UNEP, a publication of the United Nations Environment Programme, Volume 26 no. 2-3, April - September, 2003. 66-69p.

ROGERS, Richard; GUMUCHDJIAN, Philip. Cidades para um pequeno planeta. Barcelona: Editorial Gustavo Gili, 2001.

ROMERO, Marcelo. Entrevista em Áudio. Entrevistador: T. Z. HERNANDES. São Paulo: 2006. Arquivo WAV. Entrevista concedida no Departamento de Tecnologia da Faculdade de Arquitetura e Urbanismo da Universidade de São Paulo no dia 17 de novembro de 2006. 
ROZENDO, Saulo. Entrevista em Áudio. Entrevistador: T. Z. HERNANDES. São Paulo: 2006. Arquivo WAV. Entrevista concedida no Departamento de Engenharia Civil da Escola Politécnica da Universidade de São Paulo no dia 17 de novembro de 2006.

SACHS, Ignacy, Estratégias de transição para o século XXI. In: "Para Pensar o Desenvolvimento Sustentável"; BURSZTYN, M.(Org.) et al., Ed. Brasiliense, 1994.

SILVA, V. G. Avaliação da Sustentabilidade de Edifícios de Escritórios Brasileiros: Diretrizes e Base Metodológica. 2003. Tese de Doutorado em Engenharia. Universidade de São Paulo, Escola Politécnica, Departamento de Engenharia de Construção Civil, São Paulo.

SNIC Sindicato Nacional da Indústria do Cimento. Relatório Anual 2005. São Paulo: 2006. Disponível em: http://snic.org.br/25set1024/index.html Acessado em: 14 de Novembro de 2006.

TRIANA, Maria Andrea; LAMBERTS, Roberto; RUTTKAY, Oscar e outros. Certificação LEED como Norteador do Processo de Projeto para um Edifício Comercial em Florianópolis, Brasil. Comunicação Técnica. In: XI Encontro Nacional de Tecnologia do Ambiente Construído - ENTAC 2006, 23 a 25 de agosto, Florianópolis, SC, Brasil.

UMUC (UNIVERSITY OF MARYLAND UNIVERSITY COLLEGE). UMUC and Marriott Partner to Win: America's First "Green" Hotel and Conference Center. Organizado por: MARTINO, Andrea. October 6, 2005. Disponível em: <http://www.umuc.edu/events/press/news222.html>. Acesso em: 05 de Maio de 2006.

UNEP United Nations Environment Programme.. Revista: Industry and Environment. UNEP, a publication of the United Nations Environment Programme, Volume 26 no. 2-3, April September, 2003.

UNITED NATIONS. Earth Summit Agenda 21. United Nations Conference on Environment and Development - UNCED. Rio de Janeiro. June 1992. (verse :10 em português: Agenda 21 - Conferencia das Nações Unidas sobre Meio Ambiente e Desenvolvimento, 1992 - Rio de Janeiro. Brasilia: Senado Federal, 1996.)

USGBC - UNITED STATES GREEN BUILDING COUNCIL. Green Building Fact Sheet: March 2006. Páginal Institucional. Disponível em: < http://www.usgbc.org/>. Acesso em: 11 de maio de 2006. (2006a)

USGBC - UNITED STATES GREEN BUILDING COUNCIL. LEED Policy Manual. LEED Steering Committee. Summer 2004.

USGBC - UNITED STATES GREEN BUILDING COUNCIL. LEED-NC Info Sheet. Página Institucional. Disponível em: <http://www.usgbc.org/>. Acesso em: 11 de maio de 2006. (2006b) 
USGBC - UNITED STATES GREEN BUILDING COUNCIL. Página institucional. Disponível em: <http:/ /www.usgbc.org>. Acesso em: 23 de Novembro de 2006 (2006c).

USGBC - UNITED STATES GREEN BUILDING COUNCIL. USGBC News. Página institucional. Disponível em: <http:/ /www.usgbc.org>. Acesso em: 23 de Novembro de 2006 (2006c).

USGBC - UNITED STATES GREEN BUILDING COUNCIL. Why build Green? Página institucional. Disponível em: <http://www.usgbc.org>. Acesso em: 26 de Abril de 2006 (2006d).

VITTORINO, Fulvio. Entrevista em Áudio. Entrevistador: T. Z. HERNANDES. São Paulo: 2006. Arquivo WAV. Entrevista concedida no Laboratório de Conforto Ambiental do Instituto de Pesquisas Tecnológicas (IPT) no dia 17 de novembro de 2006.

WALLBAUM, H.; BUERKIN, C. Concepts and instruments for a sustainable construction sector. UNEP, a publication of the United Nations Environment Programme, Volume 26 no. 23, April - September, 2003.

WGBC - WORLD GREEN BUILDING COUNCIL. U.N. Environment Program Launches green Building Iniciative. Página institucional. Disponível em: <http:// www.worldgbc.org> Acesso em: 06 de Maio de 2006. (2006a)

WGBC - WORLD GREEN BUILDING COUNCIL. Emerging Green Building Councils. Página institucional. Disponível em: <http:// www.worldgbc.org>. Acesso em: 06 de Maio de 2006. (2006b)

WGBC - WORLD GREEN BUILDING COUNCIL. LEED-India Summary of Suggestions. Apresentação da Confederation of Indian Industry. Página Institucional. Disponível em: <http:/ /www.worldgbc.org>. Acesso em: 12 de maio de 2006. (2006c)

WILLIAMS, Kath. Beyond Borders. Revista: Environmental Design+Construction. Disponível em: $<$ http://www.edcmag.com/CDA/Articles/Leed>. Acesso em: 3 de Maio de 2006.

YUDELSON, Jerry. Is LEED Broken? Revista: Environmental Design+Construction. Disponível em: <http://www.edcmag.com/CDA/Articles/Leed>. Acesso em: 3 de maio de 2006.

ZHU, Yingxin; LIN, Borong. Sustainable Housing and Urban Construction in China. In: ELSEVIER Energy and Buildings 36: 2004. 